
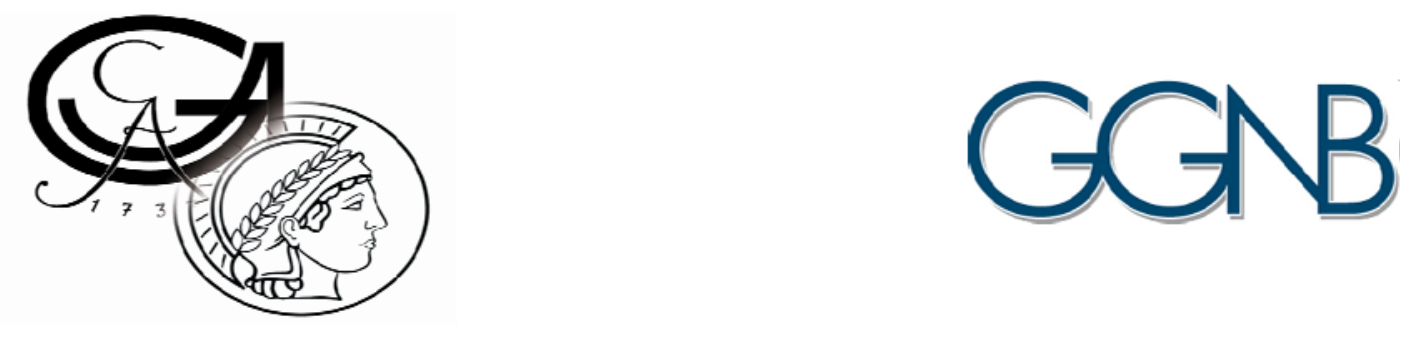

\title{
Transport Mechanisms of the Vesicular Glutamate Transporter 1
}

\author{
Dissertation \\ for the award of the degree \\ "Doctor rerum naturalium" (Dr. rer. nat) \\ Division of Mathematics and Natural Sciences \\ of the Georg-August-Universität Göttingen
}

\author{
Submitted by \\ Julia Preobraschenski
}

from Nowokusnezk, Russia

Göttingen, 2012 


\section{Committee members:}

\section{Prof. Dr. Reinhard Jahn (1. reviewer)}

Department of Neurobiology, Max Planck Institute for Biophysical Chemistry, Göttingen

Prof. Dr. Claudia Steinem (2. reviewer)

Institute for Organic and Biomolecular Chemistry, Georg August University of Göttingen

\section{Prof. Dr. Marina Bennati}

Research Group for Electron Paramagnetic Resonance, Max Planck Institute for Biophysical Chemistry, Göttingen

Date of oral examination: 


\section{Declaration of Authorship}

Herewith I declare, that I prepared this work "Transport mechanisms of the Vesicular Glutamate Transporter 1" on my own and with no other sources and materials than quoted.

Göttingen, May 16, 2012 
Моим родителям 


\section{Contents}

\section{ABBREVIATIONS}

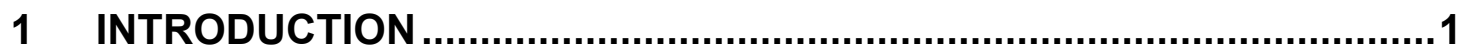

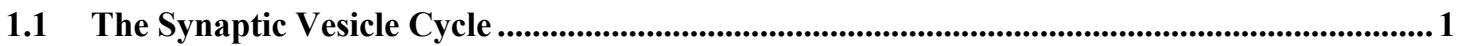

1.2 Synaptic Vesicle ..............................................................................................................................

$1.3 \quad$ Synaptic Strength and Plasticity ...................................................................................................

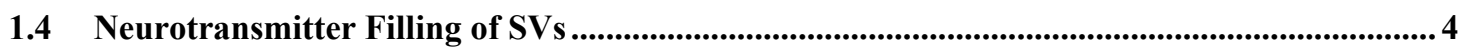

1.4.1 Electrochemical Gradient and Chloride Channels ................................................................ 4

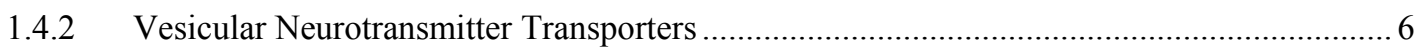

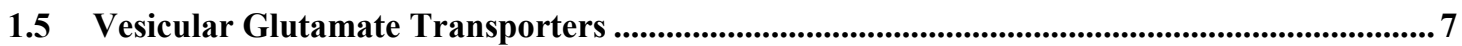

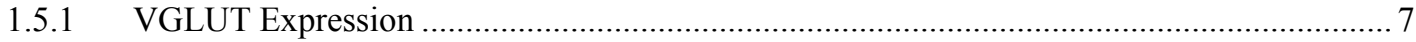

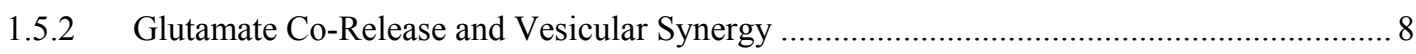

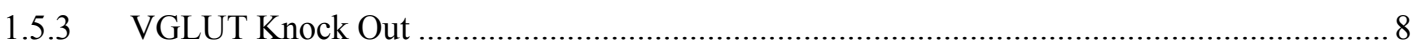

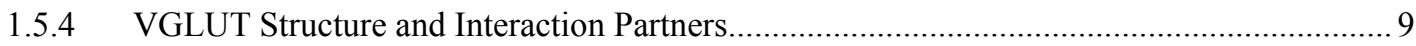

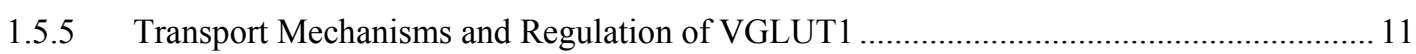

1.5.5.1 Allosteric Regulation of VGLUT1 and the Contribution of $\Delta \mathrm{pH}$ to Glutamate

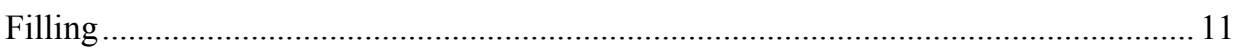

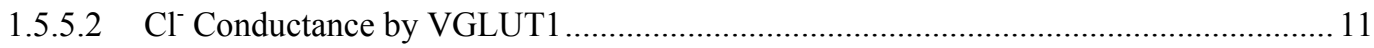

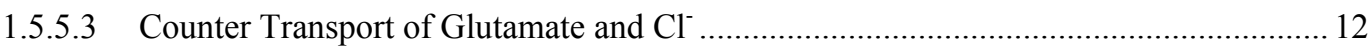

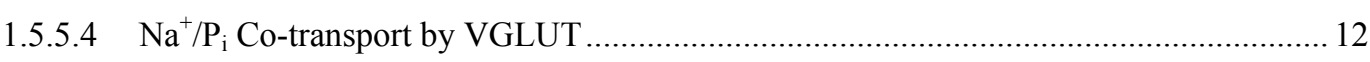

1.5.5.5 Enhancement of Glutamate Uptake Underlying a $\mathrm{H}^{+} / \mathrm{K}^{+}$Exchange Mechanism in

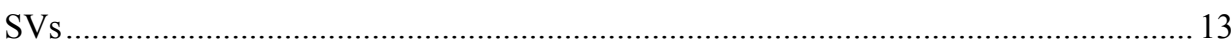

1.6 Motivation and Aim of the Study ……......................................................................................... 13

2 MATERIAL AND METHODS ............................................................ 15

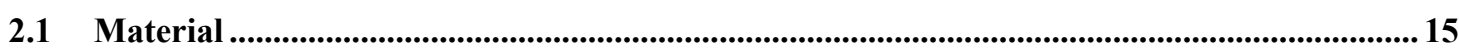

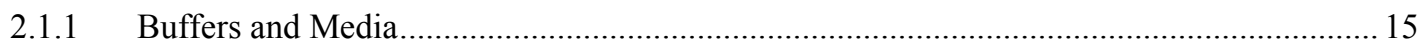

2.1.2 Mammalian and Insect Cell Lines and Bacterial Strains.................................................... 15 
2.2 Methods . 17

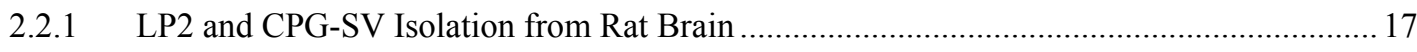

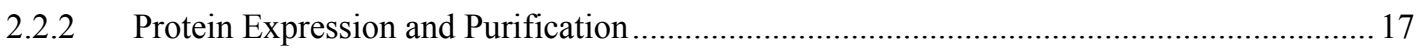

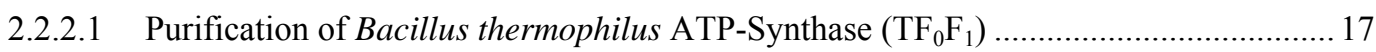

2.2.2.2 Cell-Free Expression of Rat VGLUT1 ................................................................. 18

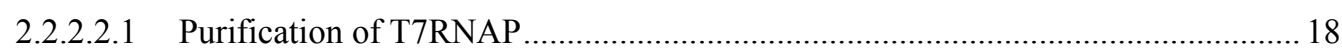

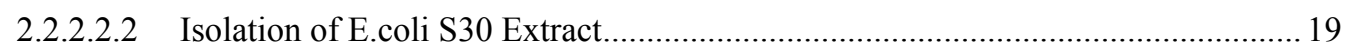

2.2.2.2.3 Cell-Free Reaction Setup for Rat VGLUT1 Expression ...................................... 20

2.2.2.3 Heterologous Expression and Purification of VGLUT1 in Insect Cells....................... 20

2.2.2.3.1 Expression of VGLUT1 in Insect Cells............................................................ 20

2.2.2.3.2 Detergent Screen for Solubilisation of VGLUT1 from Insect Cells..................... 20

2.2.2.3.3 Purification of SBP-tagged VGLUT1 from Insect Cells ..................................... 21

2.2.2.4 Heterologous Expression and Purification of VGLUT1 in HEK293 cells................... 21

2.2.3 Reconstitution of VGLUT1 and $\mathrm{TF}_{0} \mathrm{~F}_{1}$ into Liposomes ...............................................22

2.2.3.1 VGLUT/TF $\mathrm{TF}_{1}$ Liposomes from Soybean Lipids formed by the Co-Micellisation

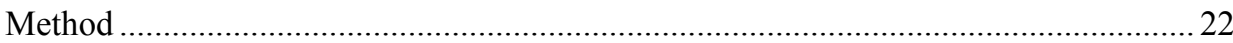

2.2.3.2 VGLUT1/TF $\mathrm{F}_{0} \mathrm{~F}_{1}$ Liposomes from Synthetic Lipids formed by the Step-by-Step

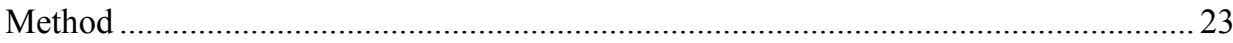

2.2.4 Liposome Co-flotation on a Density Gradient for Evaluation of Insertion Efficiency ........23

2.2.5 Proteolytic Digestion for Evaluation of VGLUT1 Orientation ........................................2 24

2.2.6 Vesicle Acidification Measurement with Acridine Orange ........................................... 24

2.2.7 Measurement of Membrane Potential Changes across Vesicular Membranes with

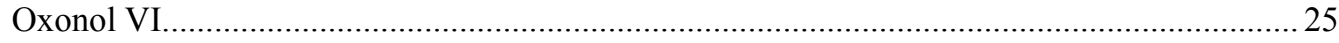

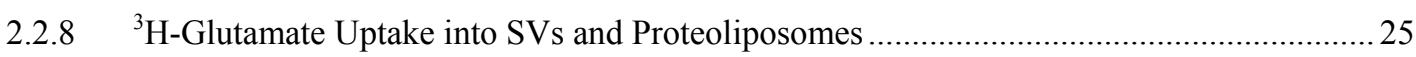

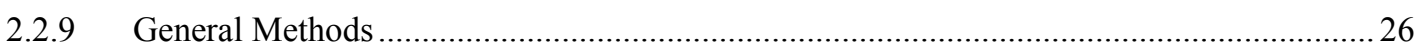

2.2.9.1 SDS-PAGE and Coomassie Blue Staining ........................................................ 26

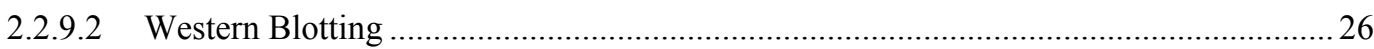

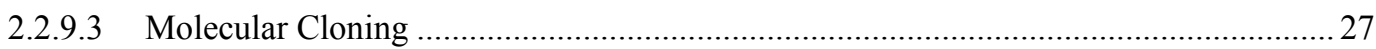

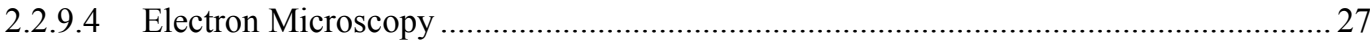

2.2.9.5 Size Distribution Analysis by FFF-MALLS ........................................................... 27

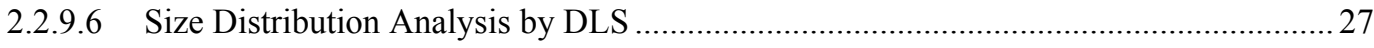

2.2.9.7 Fluorescence Dequenching for Lipid-Mixing Measurements ................................... 27

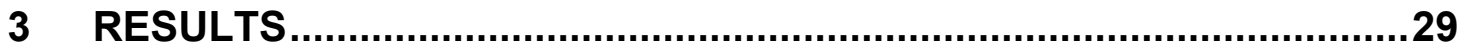

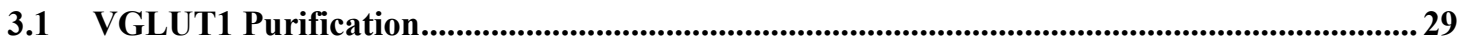




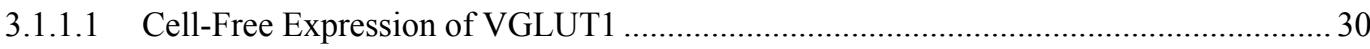

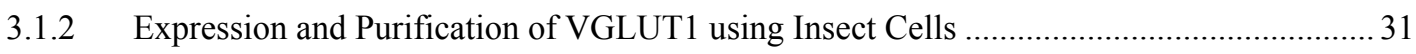

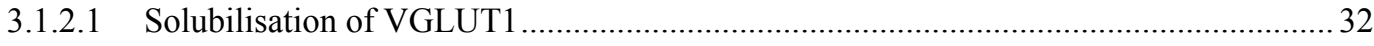

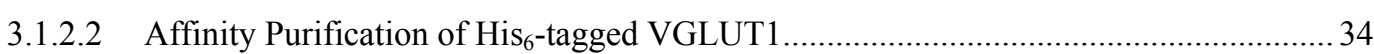

3.1.2.3 Affinity Purification of Streptavidin Binding Peptide (SBP)-tagged VGLUT1 ............ 35

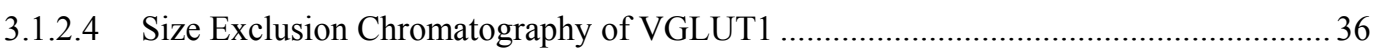

3.1.3 Expression and Purification of VGLUT1 using Mammalian Cells...................................... 36

3.2 Purification of Proton Pumps and Acidification ....................................................................37

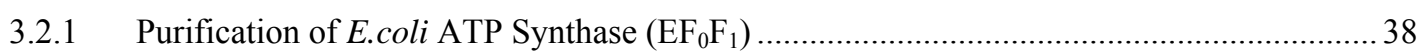

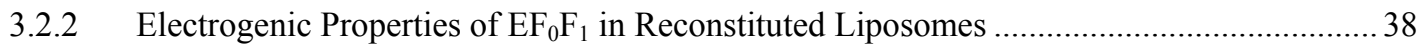

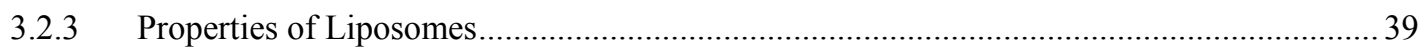

3.2.4 Purification of His-tagged $\mathrm{F}_{0} \mathrm{~F}_{1}\left(\mathrm{TF}_{0} \mathrm{~F}_{1}\right)$ from Bacillus thermophilus .............................. 41

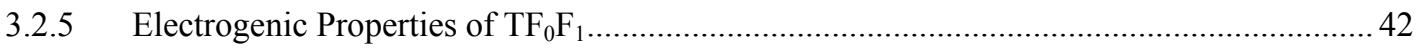

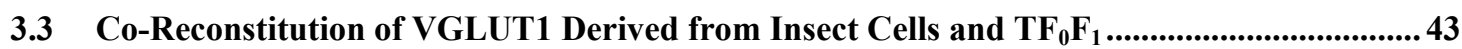

3.3.1 Co-Reconstitution of VGLUT1 and $\mathrm{TF}_{0} \mathrm{~F}_{1}$ by the Co-Micellisation Method with Lipids from Soybean Extract.

3.3.1.1 Incorporation of Proteins into Liposomes Generated by the Co-Micellisation

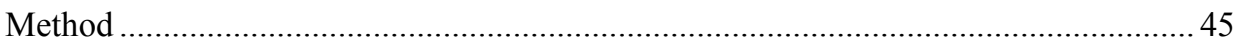

3.3.1.2 Orientation of Proteins in Liposomes Generated by the Co-Micellisation Method ....... 46

3.3.1.3 Size Distribution in Liposomes Generated by the Co-Micellisation Method................ 46

3.3.1.4 Glutamate Uptake as Control of Proper Orientation and Biological Activity of VGLUT1 in Liposomes Generated by the Co-Micellisation Method ........................... 47

3.3.2 Co-Reconstitution of VGLUT1 and $\mathrm{TF}_{0} \mathrm{~F}_{1}$ by the Direct Method with Synthetic Lipids ......... 48

3.3.2.1 Incorporation of Proteins into Liposomes Generated by the Direct Method................. 49

3.3.2.2 Orientation of VGLUT1 in Proteoliposomes Generated by the Direct Method............ 49

3.3.2.3 Size Distribution of Proteoliposomes Generated by the Direct Method ......................55

3.3.2.4 Glutamate Uptake as Control of Proper Insertion of VGLUT1 in Liposomes

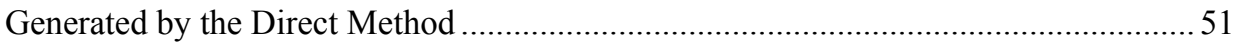

3.3.2.5 $\mathrm{Cl}^{-}$Conductance of VGLUT1/ $\mathrm{TF}_{0} \mathrm{~F}_{1}$ Proteoliposomes................................................... 51

3.3.2.6 Dependence of Glutamate Uptake on Luminal $\mathrm{Cl}^{-}$................................................. 52

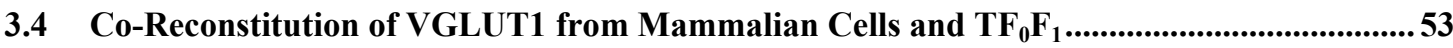

3.4.1 Co-reconstitution of VGLUT1 and $\mathrm{TF}_{0} \mathrm{~F}_{1}$ by the Direct Method with Synthetic Lipids..... 53

3.4.1.1 Characterisation of Liposomes Containing VGLUT1 Derived from Mammalian Cells and $\mathrm{TF}_{0} \mathrm{~F}_{1}$ Generated by the Direct Method. 
3.4.1.2 Glutamate Uptake in Liposomes Containing VGLUT1 Derived from Mammalian

Cells and TF0F1 as Control of VGLUT1 Activity

\subsection{Identification of a Putative $\mathrm{K}^{+} / \mathrm{H}^{+}$Exchanger Affecting the Bioenergetics of}

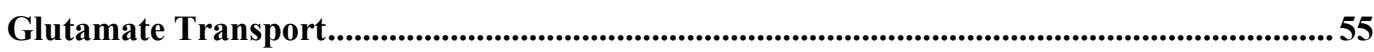

3.5.1 Changes in SV $\Delta$ pH Evoked by Monovalent Cations ....................................................... 55

3.5.2 Changes of SV $\Delta \Psi$ Evoked by Monovalent Cations...................................................... 57

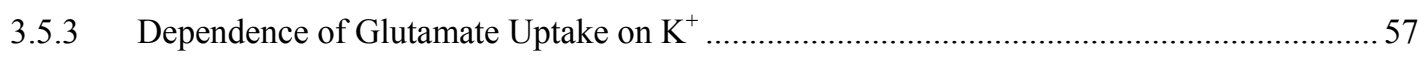

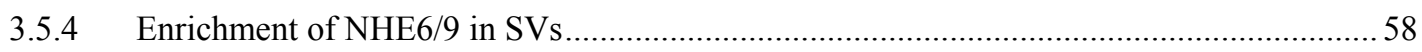

3.5.5 Changes of $\Delta \mathrm{pH}$ in Dense Core Vesicles Mediated by Monovalent Cations......................5 59

3.5.6 VGLUT1 Dependent Monovalent Cation Effect on $\Delta \mathrm{pH}$ in SVs ..................................6 60

3.5.7 VGLUT1 Dependent Monovalent Cation Effect on $\Delta \Psi$ in SVs ...................................6 61

3.6 Study of VGLUT Function using "Fused SVs" ...............................................................62

3.6.1 Co-Reconstitution of the Fusion $\Delta \mathrm{N}$ Complex and $\mathrm{TF}_{0} \mathrm{~F}_{1}$ by the Direct Method ..............6 63

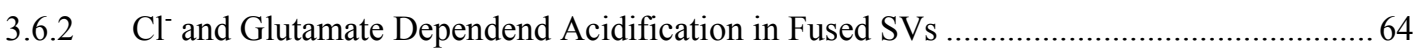

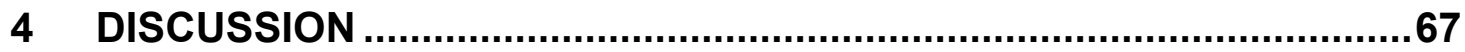

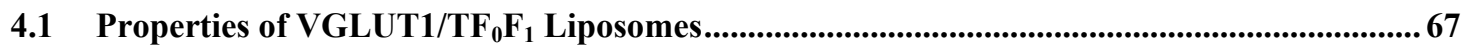

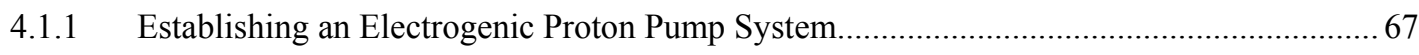

4.1.2 Expression and Purification of Differentially Tagged VGLUT1 and its Activity...............67

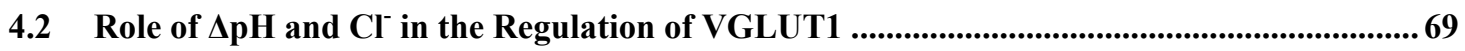

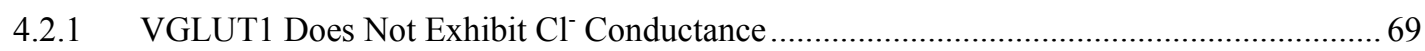

4.2.2 Role of Luminal $\mathrm{Cl}^{-}$in the Regulation of Glutamate Uptake ......................................... 70

4.3 Role of $\mathrm{K}^{+} / \mathrm{H}^{+}$Exchange in the Regulation of VGLUT1 .......................................................... 71

4.3.1 Investigation of the $\mathrm{K}^{+} / \mathrm{H}^{+}$Exchange Mode on SVs .................................................... 71

4.3.2 Indications for VGLUT1 Mediating $\mathrm{K}^{+} / \mathrm{H}^{+}$Exchange .................................................. 71

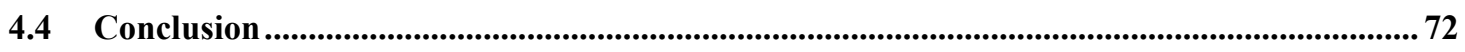

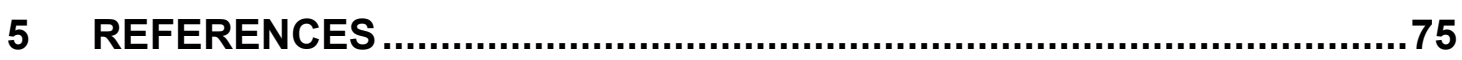




\section{Abbreviations}

$\begin{array}{ll}\text { ADP } & \text { Adenosin-diphosphat } \\ \text { ATP } & \text { Adenosin-triphosphat } \\ \text { Baf } & \text { BafilomycinA1 } \\ \beta \text {-CD } & \text { 2,6-di-O-methyl- } \beta \text {-cyclodextrin } \\ \text { ClC } & \text { intracellular chloride channel } \\ \text { DDM } & \text { n-dodecyl- } \beta \text {-D-maltopyranoside } \\ \text { DOPC } & \text { 1,2-dioleoyl-sn-glycero-3-phosphocholine } \\ \text { DOPS } & \text { 1,2-dioleoyl-sn-glycero-3-phospho-L-serine } \\ \text { DTT } & \text { dithiothreitol } \\ \Delta \text { pH } & \text { pH gradient } \\ \Delta \Psi & \text { membrane potential } \\ \Delta \mu H^{+} & \text {electrochemical gradient } \\ \text { FCCP } & p \text {-(trifluoromethoxy)phenylhydrazone } \\ \text { F }_{0} F_{1} & \text { ATP-synthase } \\ \text { GABA } & \gamma \text {-aminobutyric acid } \\ \text { Glut } & \text { glutamate } \\ \text { Gluc } & \text { gluconate } \\ \text { Nig } & \text { nigericin } \\ \text { OG } & \text { n- } \beta \text {-octylglucoside } \\ \text { SDS-PAGE } & \text { sodium dodecyl sulfate polyacrylamide gel electrophoresis } \\ \text { SV } & \text { synaptic vesicle } \\ \text { TFF } F_{1} & \text { Bacillus thermophilus ATP-synthase } \\ \text { VAchT } & \text { vesicular actylcholine transporter } \\ \text { Val } & \text { valinomycin } \\ \text { V-ATPase } & \text { vacuolar ATPase } \\ \text { vGAT } & \text { vesicular GABA transporter } \\ \text { vesicular glutamate transporter } \\ \text { vesicular inhibitory amino acid transporter } \\ \text { vesicular monoamine transporter }\end{array}$


Introduction

\section{Introduction}

\subsection{The Synaptic Vesicle Cycle}

The synapse is the communication site between two neurons. Neurotransmitters are the molecules passing on the signal and are stored in synaptic vesicles (SVs). An incoming action potential mediates calcium influx through calcium channels triggering fusion of SVs with the plasma membrane and releasing the neurotransmitters into the synaptic cleft, a process called exocytosis. The content of a single vesicle released is the elementary unit, or quantum, of synaptic transmission, first postulated by Katz [1]. Postsynaptic receptors are then activated by neurotransmitter binding allowing ion influx into the postsynaptic cell generating a new action potential.

$\mathrm{SV}$ exocytosis is confined to specific membrane compartments of the presynapse referred to as active zones and proceeds in three temporally and spatially distinct steps: docking, priming and fusion. In the docking step SVs are recruited into the active zone and positioned in close proximity to the plasma membrane [2]. Priming is the process by which vesicles become fusion competent as they wait for a $\mathrm{Ca}^{2+}$ triggering signal, defined as the ready releasable pool (RRP) of vesicles [3]. Synaptotagmin is a regulatory factor, which primes $\mathrm{SV}$ into a fusion-ready state and fuses upon a $\mathrm{Ca}^{2+}$ influx [4].

After exocytosis new SVs are endocytosed, recycled and refilled with neurotransmitter for another round of exocytosis. Sustained synaptic transmission is a highly synchronised interplay between repetitive exo- and endocytotic processes which are part of the synaptic vesicle cycle (fig. 1.1). 


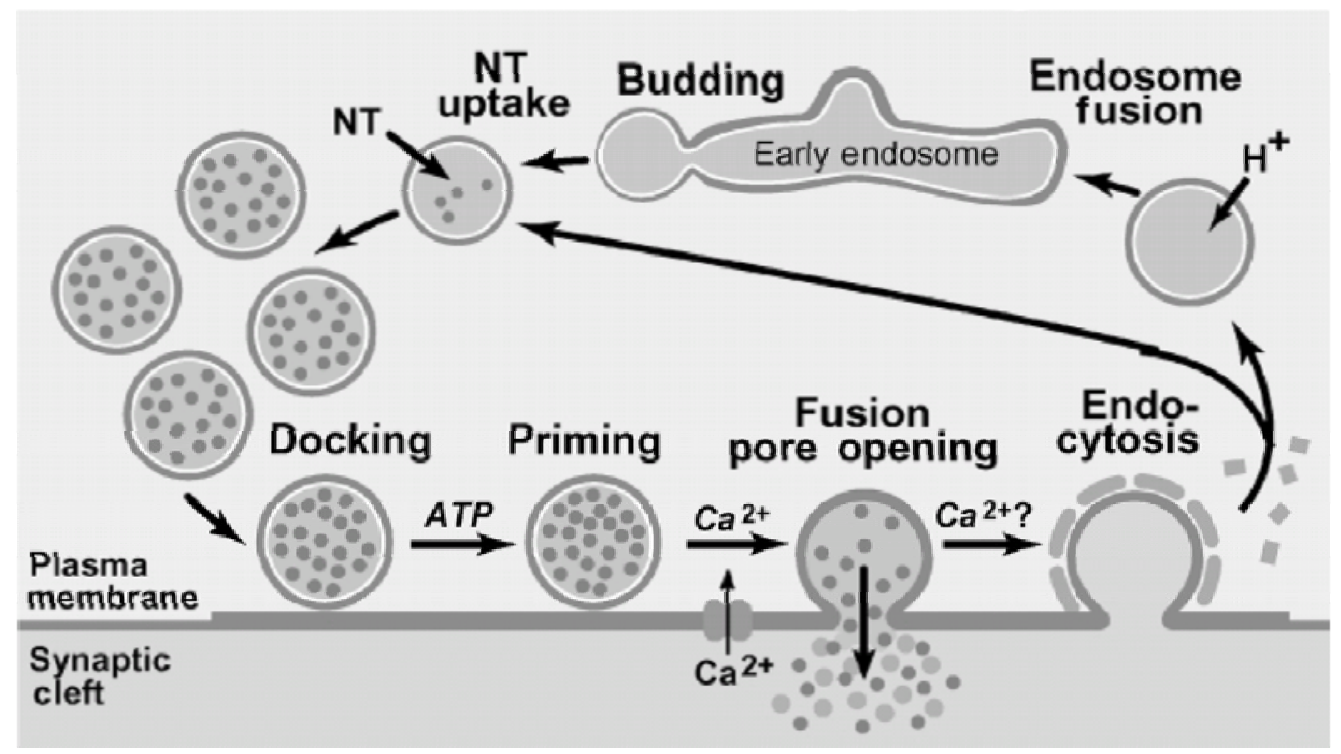

Figure 1.1 The synaptic vesicle cycle. Schematic delineation of key steps in presynaptic neurotransmitter release. After docking and priming SVs release their content upon fusion with the plasma membrane. After direct or early endosomal recycling, SVs are refilled with neurotransmitter and proceed to a next round of exocytosis. Scheme taken from [2].

\subsection{Synaptic Vesicle}

SVs are the key organelles of synaptic transmission. To understand the essence of neurotransmission a detailed comprehension of the vesicle architecture is required. SVs exhibit a homogenous size distribution with a diameter of about $40 \mathrm{~nm}$ and can be highly enriched by purification procedures including size exclusion chromatography [5] [6]. This makes them accessible for biochemical and proteomic studies.

In 2006, Takamori and co-workers succeeded on the quantification of an average SV including its protein and lipid composition by mass spectrometry analysis (fig. 1.2 ) [7]. The major phospholipid components of the membrane are phosphatidylcholine (PC), phosphatidylethanolamine (PE), phosphatidylserine (PS) and phosphatidylinositol (PI). In addition to phospholipids, cholesterol is highly predominant comprising about $40 \%$ of all lipids.

Many proteins were identified, including fusion relevant proteins and their interaction partners. Furthermore, SVs contain the vacuolar-type $\mathrm{H}^{+}$-ATPase (VATPase) which energises neurotransmitter filling in the lumen. In the presence of 


\section{Introduction}

cytosolic ATP it generates an electrochemical gradient $\left(\Delta \mu \mathrm{H}^{+}\right)$across the vesicle membrane that is required for the transport of neurotransmitters into the SV. With 1-2 copies per vesicle it is low in abundance.

Neurotransmitter translocation is mediated by vesicular neurotransmitter transporters. Their activity directly depends on the V-ATPase induced $\Delta \mu \mathrm{H}^{+}$, as they are secondary active transporters. The average copy number for the vesicular glutamate transporter (VGLUT) 1 and 2 was determined to be $\sim 9$ and $\sim 14$, respectively.

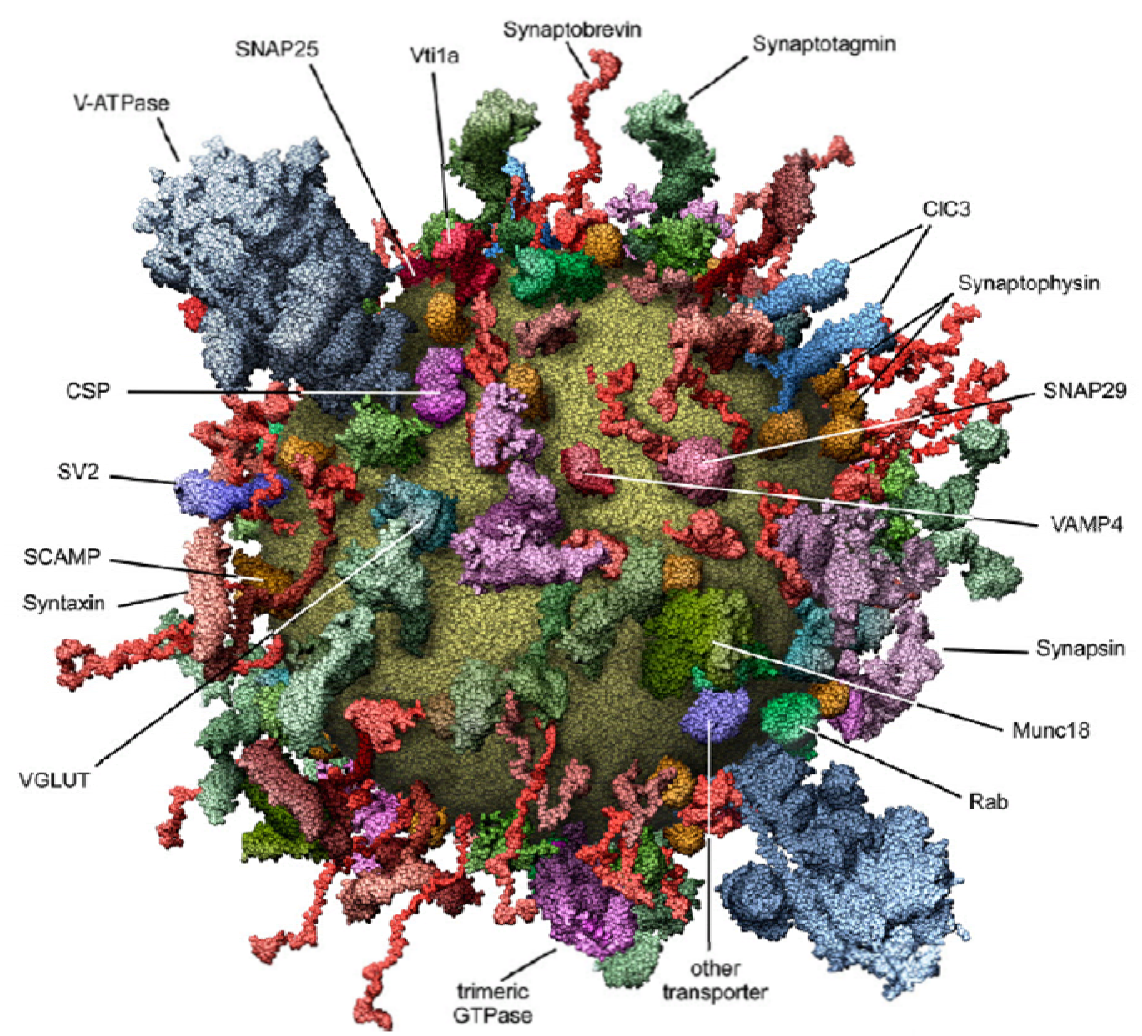

Figure 1.2 Molecular model of an average SV. The model is based on quantitative analysis of the protein and lipid contents. Protein structures were taken either from crystallographic studies (if available) or from computational modelling. The average height of the V-ATPase is $\sim 20 \mathrm{~nm}$ and the membrane diameter is $\sim 4 \mathrm{~nm}$. The concentration of neurotransmitters in a SV is estimated to 100-150 mM which would correspond to 1500 molecules. Taken from [7].

\subsection{Synaptic Strength and Plasticity}

Synaptic strength and plasticity are parameters which modulate essential processes in the brain, such as learning, memory and coordinative functions.

The changes in exocytotic release upon successive stimulation define synaptic plasticity. The extent of synaptic strength is, apart from changes in postsynaptic 
Introduction

receptor expression, dependent on the amount of neurotransmitter released upon stimulation. It is known that postsynaptic receptors in synapses are not always saturated upon a single exocytotic event, e.g. in the calyx of Held [8] and in hippocampal and cerebellar synapses [9] [10], directing the focus to SV quantal size as a crucial regulating factor of synaptic strength and plasticity. However, little is known about presynaptic regulation of quantal size.

Vesicular neurotransmitter transporters fill SVs with neurotransmitter molecules and are therefore critical for quantal size [11]. It was found that the level of VGLUT expression does indeed seem to influence quantal size [12] [13]. Furthermore, reduction of vesicular acetylcholine transporter (VAchT) expression in the neuromuscular junction reduces SV filling and affects the release of acetylcholine [14]. On the other hand, data from Drosophila suggest that a single VGLUT is sufficient to fill a SV with glutamate [15]. However, not much is known about the mechanisms by which vesicular neurotransmitter transporters regulate SV filling as they are scarcely accessible to standard electrophysiological approaches due to their intracellular localisation. Understanding the mechanisms of SV filling will provide clarification of fundamental questions regarding synaptic function.

\subsection{Neurotransmitter Filling of SVs}

\subsubsection{Electrochemical Gradient and Chloride Channels}

Neurotransmitter filling into SVs by neurotransmitter transporters is fueled by the V-ATPase generated $\Delta \mu \mathrm{H}^{+}$(section 1.3). V-ATPase is converting cytosolic ATP into ADP, $\mathrm{P}_{\mathrm{i}}$ and $\mathrm{H}^{+}$, which are then transported into the vesicle lumen. This gives rise to the $\Delta \mu \mathrm{H}^{+}$across the membrane, composed of the membrane potential $(\Delta \Psi)$ and the $\mathrm{pH}$ gradient $(\Delta \mathrm{pH})$ :

$$
\Delta \mu \mathrm{H}^{+}=\Delta \Psi+(2.3 R T / z F) \log \left(\left[\mathrm{H}^{+}\right]_{\text {in }} /\left[\mathrm{H}^{+}\right]_{\text {out }}\right)
$$

$R=$ gas constant,$T=$ temperature $[\mathrm{K}], z=$ ion valence, $F=$ Faraday constant. 
Introduction

Since the V-ATPase is electrogenic, it requires charge balance for $\mathrm{H}^{+} . \mathrm{Cl}^{-}$ functions as counter ion for $\mathrm{H}^{+}$charge balance. Consequently, the established $\Delta \mu \mathrm{H}^{+}$ critically depends on the external $\mathrm{Cl}^{-}$concentration. At lower $\mathrm{Cl}^{-}$concentrations, $\Delta \Psi$ is the major component of $\Delta \mu \mathrm{H}^{+}$due to a lack of counter ions. With increasing $\mathrm{Cl}^{-}$ concentration the $\mathrm{SV}$ can be acidified to a higher extent, with predominating $\Delta \mathrm{pH}$ (fig.1.3).

It is still under debate which molecule is mediating $\mathrm{Cl}^{-}$conductance on SVs [16]. $\mathrm{Cl}^{-}$ channels (ClCs) 3 and 7 are the prime candidates proposed to be involved in the bioenergetics of vesicular neurotransmitter filling [17]. It should be noted that related ClCs have been shown to function as $\mathrm{Cl}^{-} / \mathrm{H}^{+}$exchangers rather than $\mathrm{Cl}^{-}$channels [18] [19]. Apart from ClCs, vesicular neurotransmitter transporters are discussed as putative $\mathrm{Cl}^{-}$shunts [20] [21].

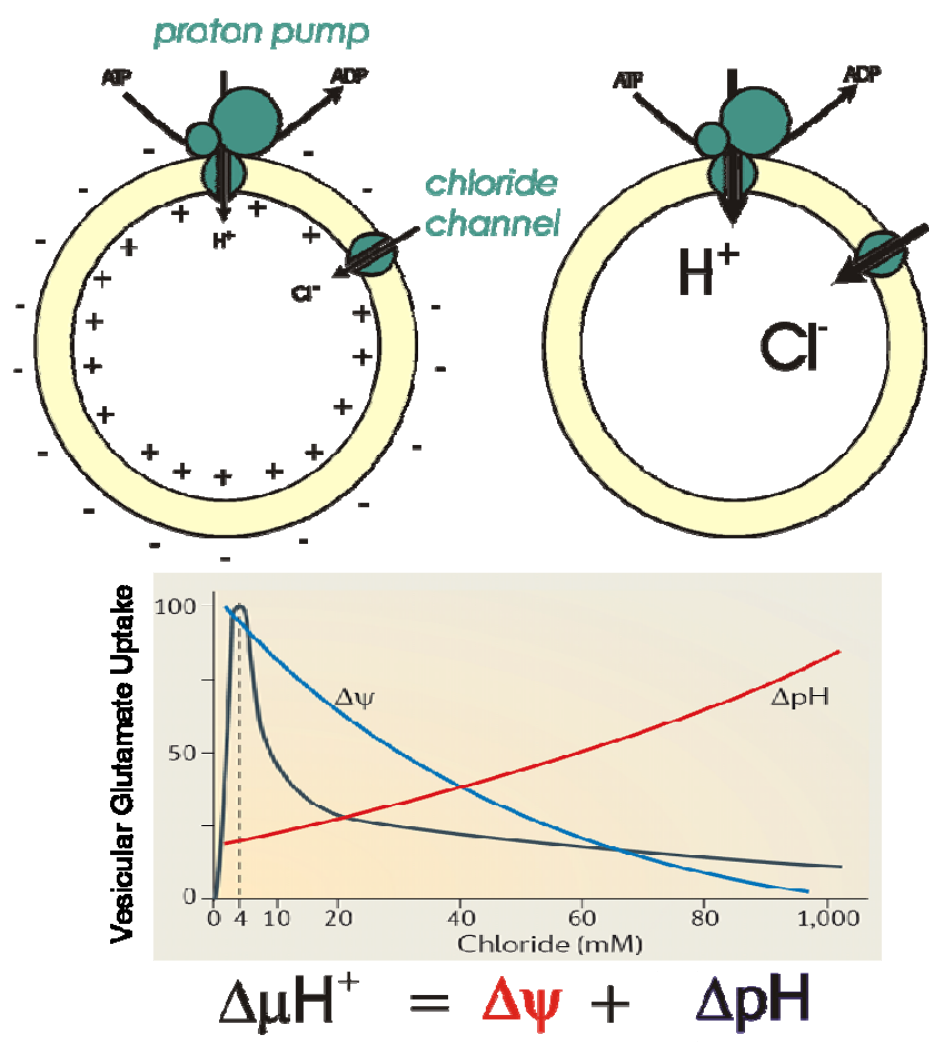

Figure 1.3 The electrochemical gradient formation across a semipermeable membrane. Interplay of $\Delta \mu \mathrm{H}^{+}$components $\Delta \Psi$ and $\Delta \mathrm{pH}$ as a function of the external chloride concentration.Picture taken from [22] and kindly provided by Reinhard Jahn. 
Introduction

\subsubsection{Vesicular Neurotransmitter Transporters}

Traditionally, neurons are classified depending on the neurotransmitter they release. The neurotransmitter transporters, which fill SVs with neurotransmitters by using $\Delta \mu \mathrm{H}^{+}$as an energy source, can be subdivided in three classes: VMATs/VAchT, VIAAT (or VGAT) and VGLUTs.

Monoamines such as dopamine, serotonine, noradrenaline and adrenaline are substrates of vesicular monoamine transporters (VMATs). There are two isoforms of VMATs with VMAT2 mainly expressed in the brain [23] [24] and VMAT1 in the periphery such as chromaffin cells of the adrenal gland [25] [26]. VMATs display high affinity towards their substrate in the submicromolar range [27] [24], which is necessary given the low cytosolic concentrations and toxicity of monoamines. The transport mechanism of VMATs has been extensively characterised. Two luminal protons are exchanged for one positively charged monoamine, therefore neurotransmitter transport mainly depends on the $\Delta \mathrm{pH}$ component of $\Delta \mu \mathrm{H}^{+}$[28].

VAchT is closely related to the VMATs but is responsible for acetylcholine transport [29] [30]. In contrast to VMATs it exhibits a $\mathrm{K}_{\mathrm{m}}$ of $\sim 1 \mathrm{mM}$ [31] suggestive of a higher cytosolic concentration of acetylcholine. Similarly to VMATs, it transports one acetylcholine for two protons [32].

The vesicular inhibitory amino acid transporter (VIAAT or VGAT), identified by two independent studies in 1997 [33] [34], exhibits low substrate affinity to $\gamma$ aminobutyric acid (GABA) in the $5 \mathrm{mM}$ range and a $\mathrm{K}_{\mathrm{m}}$ of $25 \mathrm{mM}$ for glycine. Transport is driven simultaneously by $\Delta \mathrm{pH}$ and $\Delta \Psi$. The proposed transport mechanism includes $\mathrm{H}^{+} / \mathrm{GABA}$ antiport. Juge and coworkers obtained biochemical evidence of a chloride conductance by VIAAT, by using an in vitro system [20] By contrast, Riazanski and colleagues performed electrophysiological and biochemical studies demonstrating an absolute requirement of the chloride channel $\mathrm{ClC} 3$ for vesicular GABA filling [35] [36]. How exactly GABA and glycine are accumulated in SVs remains contentious. 
Introduction

VGLUTs will be discussed in separate section, as they are the main focus of the present work. An overview of vesicular neurotransmitter transporters including ionic coupling and $\Delta \mu \mathrm{H}^{+}$contribution is depicted in figure 1.5.

\subsection{Vesicular Glutamate Transporters}

Three different vesicular glutamate transporters (VGLUTs) have been identified. VGLUT1 [37] [38], VGLUT2 [39-41] [42] and VGLUT3 [43] [44] [45] [46]. VGLUT1 and 2 were initially described as brain-specific or differentiation-associated $\mathrm{Na}^{+}-$ dependent inorganic phosphate transporters. These include BNPI [47] and DNPI [48], both located on the plasma membrane of synapses and work by transporting inorganic phosphate into the cytosol. Later on, they were discovered to translocate L-glutamate, the major excitatory neurotransmitter, into SVs with high specificity [37] [38].

VGLUT has a low substrate affinity of 2-4 mM. Unlike dopamine, the cytosolic concentration of glutamate is considerably high $(10 \mathrm{mM})$, thus high substrate affinity is not necessarily required. By contrast, plasma membrane glutamate transporters display a much higher affinity [49] as they have to rapidly clear the synaptic cleft from glutamate to reduce receptor activation time.

\subsubsection{VGLUT Expression}

VGLUTs exhibit mutually exclusive distribution patterns in the brain with very limited overlap. VGLUT1 is mainly expressed in the cerebral cortex and hippocampus and VGLUT2 in the thalamus and brain stem [22]. VGLUT1/2 expressing synapses define the glutamatergic phenotype of neurons. VGLUT1/2 expression in the brain is not only restricted to neurons, but is further detected in synaptic-like microvesicles (SLMVs) in astrocytes [50] which are capable of releasing glutamate [51].

Unlike the predominant two isoforms, VGLUT3 is expressed in neurons exhibiting cholinergic, serotonergic and gabaergic phenotypes [46] [45]. In cochlear inner hair cell synapses and in pain-sensing neurons of the dorsal root ganglion, VGLUT3 is the essential neurotransmitter transporter [52] [53]. 
Introduction

\subsubsection{Glutamate Co-Release and Vesicular Synergy}

Expression of VGLUT3 in non-glutamatergic neurons was surprising, as until then it was believed that neurons release only one type of transmitter (Dale's principle) and that VGLUTs are expressed in glutamatergic neurons only. Meanwhile, studies suggest that neurons are capable of releasing two neurotransmitters from the same release site, reviewed in [22] [54]. Dopaminergic neurons expressing VGLUT2 have been shown to co-release glutamate [55] [56] and gabaergic neuron cultures transfected with VGLUT3 were capable of releasing GABA and glutamate [57].

A synergistic effect by VGLUTs on monoamine, GABA and acetylcholine filling by alteration of $\Delta \mu \mathrm{H}^{+}$has also been proposed. VGLUTs can promote $\Delta \mathrm{pH}$ formation by translocating glutamate as a counter ion for $\mathrm{H}^{+}$. VGLUT3 knock out (ko) reduces acetylcholine release in striatum slices [58], whereas dopamine storage is enhanced by VGLUT2 in cultured midbrain neurons [56]. However, the consequences of co-release for vesicle filling, neurotransmission and synaptic plasticity are just starting to be understood.

\subsubsection{VGLUT Knock Out}

VGLUT1 ko mice did not display any distinctive features up to 2 weeks after birth. Thereafter, ko mice showed severe impairment in coordination, learning and memory, largely surviving several months after birth [59] [13]. Miniature excitatory postsynaptic current (mEPSC) amplitudes in VGLUT1 ko neurons were significantly smaller compared to wild type (wt) neuron amplitudes, implicating reduced glutamate filling into SVs [13]. VGLUT2 ko causes perinatal lethality [60] [61]. In heterozygous thalamic neurons, a reduction in postsynaptic response further affirmed VGLUTs being critically important for quantal size [60].

The inner hair cell are the sensory receptors of the auditory nerve pathway. As their synapses are glutamatergic, VGLUT3 ko mice are completely deaf [52]. 
Introduction

\subsubsection{VGLUT Structure and Interaction Partners}

Structurally, VGLUTs share $76 \%$ amino acid identity in humans, with highly homologous transmembranal domains and $\mathrm{N}$-and $\mathrm{C}$-terminal tails displaying very little homology. Hydropathy analysis predicts 12 transmembranal domains connected by loops. The $\mathrm{N}$ - and $\mathrm{C}$-terminal tails are facing the cytoplasmic side of the vesicular membrane (fig.1.4).

Mutation studies found the residues $\mathrm{His}^{128}, \mathrm{Arg}^{184}$ and $\mathrm{Glu}^{191}$, which are highly conserved among VGLUTs to play a decive role glutamate translocation. Remarkably, these mutations did not seem to alter $\mathrm{Na}^{+} / \mathrm{P}_{\mathrm{i}}$ transport, indicating two distinct transport machineries for L-glutamate and $\mathrm{Na}^{+} / \mathrm{P}_{\mathrm{i}}[62]$.

A modelling study based on a remote bacterial homolog of VGLUTs showed that $\mathrm{Arg}^{80}, \mathrm{Arg}^{314}, \mathrm{Arg}^{176}$ and $\mathrm{His}^{120}$ as key residues for glutamate binding. The residue directly involved in $\mathrm{P}_{\mathrm{i}}$ binding was found to be $\mathrm{Arg}^{314}$ (fig.1.4) [63], which further affirms the presence of two independent transport mechanisms in VGLUTs for Lglutamate and $\mathrm{Na}^{+} / \mathrm{P}_{\mathrm{i}}$. Moreover, in the original study on the identification of VGLUT1 $\mathrm{P}_{\mathrm{i}}$ did not inhibit L-glutamate uptake in SVs [38], consistent with the view on two binding sites.

VGLUT1 has one putative N-glycosylation site predicted by computational tools (NetNGlyc 1.0). Beyond that, there is no clear experimental evidence for glycosylation. 


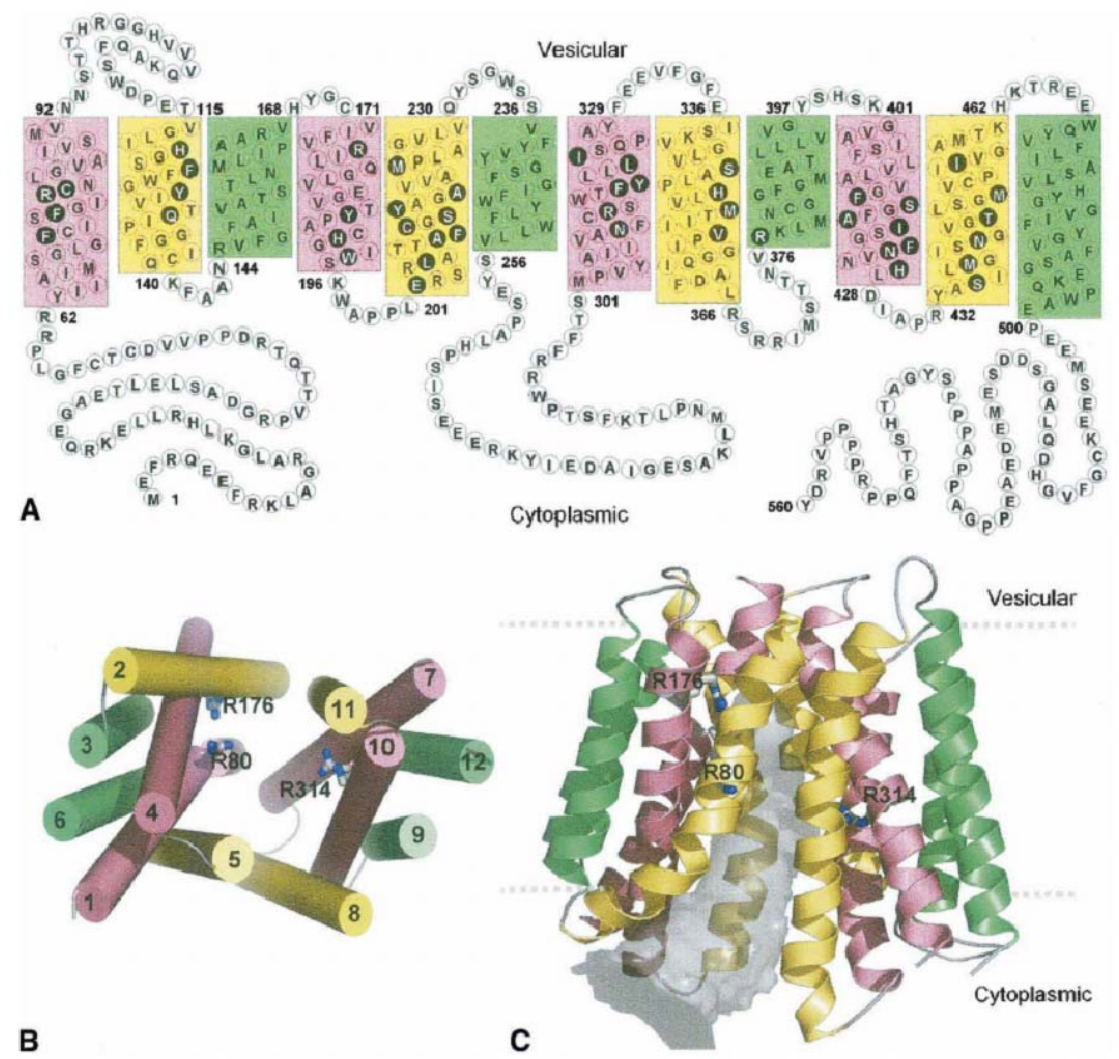

Figure 1.4 Predicted model of VGLUT1 structure. A. Transmembranal domain prediction based on topology of bacterial MFS proteins. According to this, VGLUT1 would exhibit 12 putative transmembrane segments. B. Cytoplasmic view on the packing of helices. Marked residues are supposed to be involved in glutamate binding. C. Cartoon representation of human VGLUT1 structure. The transmembrane helices are predicted to form a pore which is open towards the cytoplasmic side. Taken from [63].

Despite their spatially and temporally distinct expression patterns, which suggest specific roles for each isoform, not much is known about their functional differences. Transport rates, substrate affinity and pharmacological responses are similar, implying the same glutamate transport mechanism. However, neurons that express VGLUT1 or 2 show varying probabilities in glutamate release [40] [64]. Recently, Weston and coworkers demonstrated that differences in glutamate release probability are in fact attributed to the VGLUT isoform expressed in that specific neuron. In particular, alterations in release probability were induced by the interaction of VGLUT1 with endophilinA1 [57], which had been previously described [65] [66] [67]. 
Introduction

\subsubsection{Transport Mechanisms and Regulation of VGLUT1}

Glutamate transport by VGLUTs mainly depends on $\Delta \Psi$ [68]. An intriguing feature of VGLUT is its biphasic dependence on $\mathrm{Cl}^{-}$with maximal activity between 4-6 $\mathrm{mM}$ [69] and inhibition of glutamate uptake with increasing $\mathrm{Cl}^{-}$concentrations (fig.1.3) [69] [70].

\subsubsection{Allosteric Regulation of VGLUT1 and the Contribution of $\Delta \mathrm{pH}$ to Glutamate Filling}

The stimulatory effect on glutamate uptake at low $\mathrm{Cl}^{-}$concentrations has been proposed to be related to allosteric regulation of VGLUT by $\mathrm{Cl}^{-}$[68] [71] [70] whereas some studies suggest the stimulating effect originates from an increase in $\Delta \mathrm{pH}$ evoked by $\mathrm{Cl}^{-}$influx [69] [72]. Inhibition of glutamate uptake at high $\mathrm{Cl}^{-}$concentrations is believed to be related to the dissipation of $\Delta \Psi$ and predominance of $\Delta \mathrm{pH}$ [70]. Dissipation of $\Delta \mathrm{pH}$ at $4 \mathrm{mM} \mathrm{Cl}^{-}$and low glutamate concentrations $(50 \mu \mathrm{M})$ enhanced steady state glutamate filling in SVs showing that glutamate uptake can solely be driven by $\Delta \Psi$ [73] [70]. However, at physiological glutamate concentrations (4 mM) a decrease in glutamate uptake was observed in the presence of $20 \mathrm{mM} \mathrm{Cl}^{-}$when $\Delta \mathrm{pH}$ was abolished. The decrease originated from a net efflux of glutamate in the presence of high $\mathrm{Cl}^{-}$. Thus, $\Delta \mathrm{pH}$ was found to be important for retaining glutamate in the SV lumen [70]. Glutamate uptake dependence on $\Delta \mathrm{pH}$ is suggestive of a glutamate/ $\mathrm{H}^{+}$antiport mechanism underlying VGLUT1. Exchange of a luminal $\mathrm{H}^{+}$for one glutamate results in neutralisation of two positive luminal charges, which is explaining the strong dependence of VGLUT on $\Delta \Psi$.

\subsubsection{2 $\mathrm{Cl}^{-}$Conductance by VGLUT1}

A first indication for $\mathrm{Cl}^{-}$transport by VGLUT was found when VGLUT1 was heterologously overexpressed in $\mathrm{PC1} 2$ cells resulting in an increase of the $\mathrm{Cl}^{-}$ conductance [38]. Recent work using a reconstituted in vitro system containing a bacterial proton pump and VGLUT1, observed chloride conductance mediated by VGLUT1 [21]. $\mathrm{Cl}^{-}$and glutamate were competing with each other for entering the liposome lumen. On the other hand, Evans Blue, a VGLUT inhibitor, did not abolish $\mathrm{Cl}^{-}$ 
Introduction

transport by VGLUT1, indicating two independent transport machineries for glutamate and $\mathrm{Cl}^{-}$. By contrast, in a later study $\mathrm{Cl}^{-}$transport by VGLUT2 reconstituted in liposomes was not observed [74]. Furthermore, a study on small synaptic-like microvesicles (SLMVs) from astrocytes expressing VGLUT2 did not exhibit $\mathrm{Cl}^{-}$ dependent acidification, a unique phenomenon which has never been observed in SVs (unpublished work). This finding suggests that $\mathrm{Cl}^{-}$conductance in $\mathrm{SVs}$ is mediated by a molecule other than VGLUT. Regarding the conflicting reports on $\mathrm{Cl}^{-}$transport by VGLUT1, it remains to be resolved whether $\mathrm{Cl}^{-}$conductance on SVs is mediated by VGLUT or by other molecules such as ClCs.

\subsubsection{Counter Transport of Glutamate and $\mathrm{Cl}^{-}$}

SVs are filled with $\sim 130 \mathrm{mM} \mathrm{NaCl}$ during endocytosis. An exchange of a luminal $\mathrm{Cl}^{-}$for glutamate is thus physiologically and bioenergetically plausible, as it would prevent osmotic swelling of SVs. Several studies suggested an exchange mechanism of luminal $\mathrm{Cl}^{-}$with cytosolic glutamate [75] [70]. However, luminal SV contents are difficult to manipulate which is why an enhancing effect on glutamate uptake in presence of high luminal $\mathrm{Cl}^{-}$was not shown until the recent work by Schenck and co-workers. Using proteoliposomes containing VGLUT1 and a bacterial proton pump they observed dramatically enhanced glutamate uptake in presence of high luminal chloride [21]. In this system $\mathrm{Cl}^{-}$exchange could solely be mediated by VGLUT1 supporting a $\mathrm{Cl}^{-} /$glutamate exchange mechanism.

\subsubsection{4 $\mathrm{Na}^{+} / \mathbf{P}_{\mathrm{i}}$ Co-transport by VGLUT}

Despite the fact that VGLUTs were initially identified as $\mathrm{Na}^{+} / \mathrm{P}_{\mathrm{i}}$ transporters by detecting uptake in Xenopus laevis oocytes transfected with VGLUT mRNA [47], little is known about the $\mathrm{Na}^{+} / \mathrm{P}_{\mathrm{i}}$ transport properties by VGLUTs. More recently, a $\mathrm{Na}^{+}-$ dependent $\mathrm{P}_{\mathrm{i}}$ uptake in liposomes reconstituted with a bacterial proton pump and VGLUT2 was reported [62], implicating that $\mathrm{Na}^{+} / \mathrm{P}_{\mathrm{i}}$ transport is indeed an intrinsic property of VGLUTs. However, the effect of the $\mathrm{Na}^{+} / \mathrm{P}_{\mathrm{i}}$ transport mechanism on glutamate uptake is still unclear (see also section 1.7.4). 
Introduction

\subsubsection{Enhancement of Glutamate Uptake Underlying a $\mathbf{H}^{+} / \mathrm{K}^{+}$Exchange Mechanism in SVs}

A novel glutamate uptake transport mode involving a $\mathrm{K}^{+} / \mathrm{H}^{+}$exchange mechanism has also recently been described [76]. Exchange of cytosolic $\mathrm{K}^{+}$with luminal $\mathrm{H}^{+}$decreases $\Delta \mathrm{pH}$ allowing more $\mathrm{H}^{+}$to enter the vesicle lumen, thus increasing $\Delta \Psi$ and promoting glutamate uptake. Yet, the protein mediating $\mathrm{K}^{+} / \mathrm{H}^{+}$exchange has not been identified. Putative VGLUT transport modes are depicted in figure 1.5.

VGLUTs

(Glutamate)

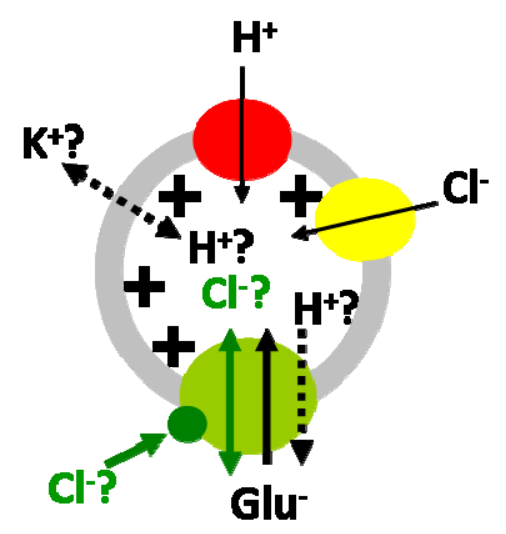

$\Delta \Psi>\Delta p H$
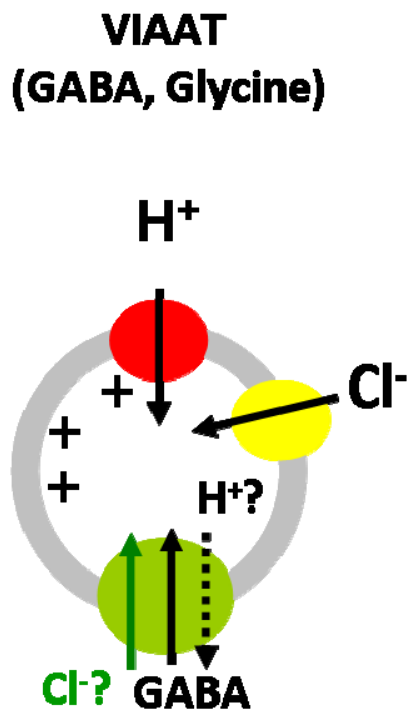

$\Delta \Psi \approx \Delta \mathrm{pH}$
VMATs/VAchT

(Monoamines,

Acetylcholine)

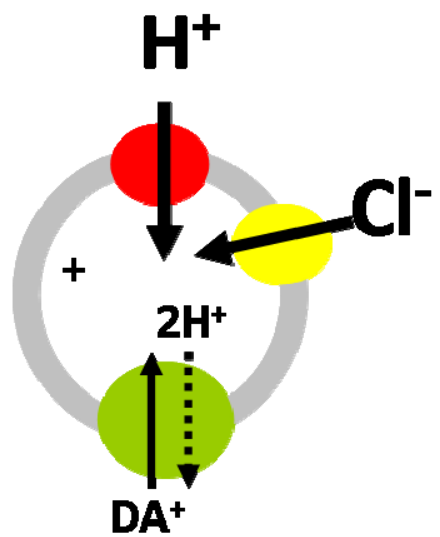

$\Delta \Psi<\Delta p H$

Figure 1.5 Transport modes of vesicular neurotransmitter transporters. Schematic representation of current models on neurotransmitter ionic coupling in VMATs/VAchT, VIAAT and VGLUTs and its dependencies on $\Delta \mu \mathrm{H}^{+}$. Taken from [75] [11] [77] [22] [54].

\subsection{Motivation and Aim of the Study}

Vesicular neurotransmitter transporters play a key role in quantal size modification, as they fill SVs with transmitter. VGLUTs are expressed in about $80 \%$ of all central nervous system (CNS) neurons. Various questions addressing VGLUT regulation remain unanswered, such as the stoichiometry of ionic coupling, in which $\mathrm{Cl}^{-}$ is proposed to be involved. Studies with contradicting findings regarding $\mathrm{Cl}^{-}$ conductance by VGLUT1 have been reported [21] [74]. Furthermore, a $\mathrm{K}^{+} / \mathrm{H}^{+}$exchange mechanism affecting the bioenergetics of glutamate transport has been described [76]. 
Introduction

This work in particular aimed to clarify the role of chloride in VGLUT function and the identification of a putative $\mathrm{K}^{+} / \mathrm{H}^{+}$exchanger in order to elucidate the ionic mechanism of glutamate filling.

Due to their organellar localisation transporters are scarcely accessible to physiological studies. Successful isolation of SVs from torpedo marmorata electromotor synapses and rat brain [5] [6] permitted to conduct pioneering work on SV transporters [78] [69] [79]. However, studies involving the manipulation of SV luminal content and the investigation of intrinsic transporter properties are limited.

In this work, an in vitro setup composed of liposomes reconstituted with mouse VGLUT1 and an ATP synthase from Bacillus thermophilus used as proton pump to generate an energizing $\Delta \mu \mathrm{H}^{+}$was used as model system (fig.1.6). This minimal artificial system simplifies the study of intrinsic VGLUT transport modes and permits the investigation of effects on glutamate uptake based on the luminal ionic composition.

The second focus of this work was the identification of a putative $\mathrm{K}^{+} / \mathrm{H}^{+}$ exchanger promoting glutamate uptake by SVs. For this study native SVs isolated from rat brain were used.

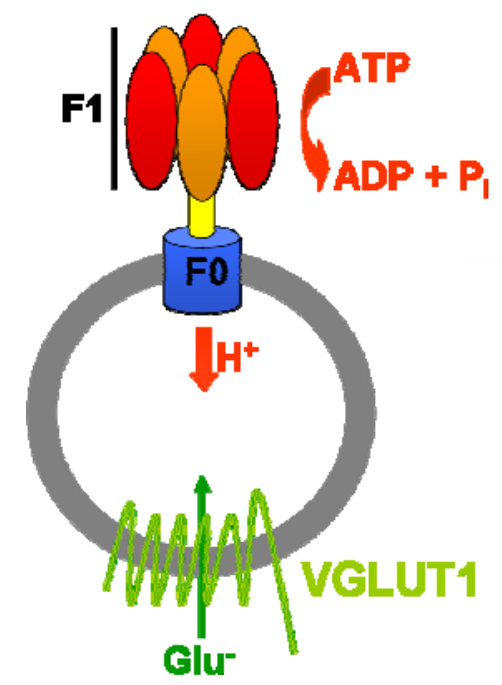

Figure 1.6 Model system to study VGLUT function. A Bacillus thermophilus ATP synthase is reconstituted with mus musculus VGLUT1 in artificial membranes. 


\section{Material and Methods}

\subsection{Material}

Standard chemicals were purchased at analytical grade. Specific chemicals and buffers are individually mentioned in the method descriptions.

\subsubsection{Buffers and Media}

\begin{tabular}{|c|c|}
\hline Buffer/media & Composition \\
\hline Homogenisation buffer & $320 \mathrm{mM}$ sucrose, $5 \mathrm{mM}$ HEPES, pH 7.4 \\
\hline Glycine buffer & 300mM glycine, 5 mM HEPES, pH 7.4 \\
\hline Transfer buffer & $\begin{array}{l}200 \mathrm{mM} \text { glycine, } 25 \mathrm{mM} \text { Tris, } 0.04 \% \\
\text { SDS, } 20 \% \text { Methanol }\end{array}$ \\
\hline TBST & $\begin{array}{l}15 \mathrm{mM} \text { Tris- } \mathrm{HCl}, \mathrm{pH} 7.4,150 \mathrm{mM} \mathrm{NaCl} \text {, } \\
0.5 \% \text { (v/v) Tween } 20\end{array}$ \\
\hline SDS running buffer (anode) & 200 mM Tris-HCl, $\mathrm{pH} 8.9$ \\
\hline SDS running buffer (cathode) & $\begin{array}{l}100 \mathrm{mM} \text { Tris, } 100 \mathrm{mM} \text { Tricin, } 0.1 \% \text { SDS, } \\
\text { pH } 8.2\end{array}$ \\
\hline Terrific Broth (TB) & $\begin{array}{l}12 \mathrm{~g} \text { tryptone, } 24 \mathrm{~g} \text { yeast extract, } 4 \mathrm{ml} \\
\text { glycerol, } 2.31 \mathrm{~g} \mathrm{KH}_{2} \mathrm{PO}_{4}, 12.54 \mathrm{~g} \mathrm{~K}_{2} \mathrm{HPO}_{4} \\
\text { per } 11\end{array}$ \\
\hline Luria-Bertani medium (LB) & $\begin{array}{l}10 \mathrm{~g} \text { tryptone, } 5 \mathrm{~g} \text { yeast extract and } 10 \mathrm{~g} \\
\mathrm{NaCl} \text { per } 1 \mathrm{l}\end{array}$ \\
\hline YPTG media & $\begin{array}{l}3 \mathrm{~g} \mathrm{KH}_{2} \mathrm{PO}_{4}, 9.13 \mathrm{~g} \mathrm{~K}_{2} \mathrm{HPO}_{4}, 10 \mathrm{~g} \text { yeast } \\
\text { extract, } 16 \mathrm{~g} \text { bactotryptone, } 5 \mathrm{~g} \mathrm{NaCl}, 19.8 \\
\text { g glucose per } 11\end{array}$ \\
\hline ExpressFive, Sf900 media & $\begin{array}{l}\text { Unknown composition, purchased from } \\
\text { Invitrogen }\end{array}$ \\
\hline Cell culture medium & $\begin{array}{l}\text { DMEM, } 10 \% \text { FCS, } 4 \mathrm{mM} \text { glutamine, } 100 \\
\mathrm{U} / \mathrm{ml} \text { penicillin and streptomycin }\end{array}$ \\
\hline
\end{tabular}

Table 2.1 Buffers and media and their compositions.

\subsubsection{Mammalian and Insect Cell Lines and Bacterial Strains}

Spodoptera frugiperda (Sf9) insect cell line was used for virus amplification and Trichoplusia ni (High5) insect cell line for VGLUT1 expression. The Human 
Embryonic Kidney 293 cell line (HEK293) was used for large scale overexpression of VGLUT1. E.coli DH5 $\alpha$ strain was used for molecular cloning and E.coli BL21 (DE3) was used for T7 RNA Polymerase overexpression. A19 bacterial strain was used for isolation of E.coli S30 extract.

\subsubsection{DNA Constructs}

\begin{tabular}{|l|l|l|}
\hline Construct & Vector & Source \\
\hline $\begin{array}{l}\text { Streptavidin binding peptide } \\
\text { (SBP) tagged VGLUT1 (mus } \\
\text { musculus) }\end{array}$ & pDEST8 & $\begin{array}{l}\text { VGLUT1 cDNA (GeneArt), } \\
\text { vector (Invitrogen) }\end{array}$ \\
\hline $\begin{array}{l}\text { His } 6 \text {-tagged VGLUT1 (mus } \\
\text { musculus) }\end{array}$ & pDEST10 & $\begin{array}{l}\text { VGLUT1 } \\
\text { (GeneArt), } \\
\text { (Invitrogen) }\end{array}$ \\
\hline His $_{6}$-tagged $\mathrm{TF}_{0} \mathrm{~F}_{1}$ & $\begin{array}{l}\text { Masasuke Yoshida (Tokyo } \\
\text { Institute of Technology } \\
\text { /Japan) }\end{array}$ \\
\hline $\begin{array}{l}\text { SBP-tagged VGLUT1 (mus } \\
\text { musculus) }\end{array}$ & pcDNA6.2 \\
\hline $\begin{array}{l}\text { His }{ }_{10} \text {-tagged VGLUT1 } \\
\text { (rattus norvegicus) }\end{array}$ & pET29a(+) & $\begin{array}{l}\text { VGLCtor (Invitrogen) } \\
\text { vectoned by Maria Druminski }\end{array}$ \\
\hline $\begin{array}{l}\text { T7 RNA Polymerase } \\
\text { (T7RNAP) }\end{array}$ & pAR1219 & $\begin{array}{l}\text { Frank Bernhard (University } \\
\text { of Frankfurt) }\end{array}$ \\
\hline
\end{tabular}

Table 2.2 Plasmids used for protein expression. 


\subsection{Methods}

\subsubsection{LP2 and CPG-SV Isolation from Rat Brain}

Crude SVs (LP2) and CPG SVs (additionally purified by size exclusion chromatography) were purified as described in [7] based on the protocol by [6] using the homogenisation buffer. Glycine buffer was used for the size exclusion chromatography step. A scheme of the protocol is depicted in figure 2.7. LP2 and CPG-SVs were adjusted to a protein concentration of $\sim 15 \mu \mathrm{g} / \mu \mathrm{l}$ and $\sim 6$ $\mu \mathrm{g} / \mu 1$, snap frozen and stored at $-80^{\circ} \mathrm{C}$.

\subsubsection{Protein Expression and Purification}

\subsubsection{Purification of Bacillus thermophilus ATP-Synthase $\left(\mathrm{TF}_{0} \mathrm{~F}_{1}\right)$}

The purification protocol for $\mathrm{TF}_{0} \mathrm{~F}_{1}$ is based on [21]. The bacterial strain DK8 carrying the plasmid pTR19ASDS [80] contains a His $_{6}$-tagged $\beta$-subunit allowing

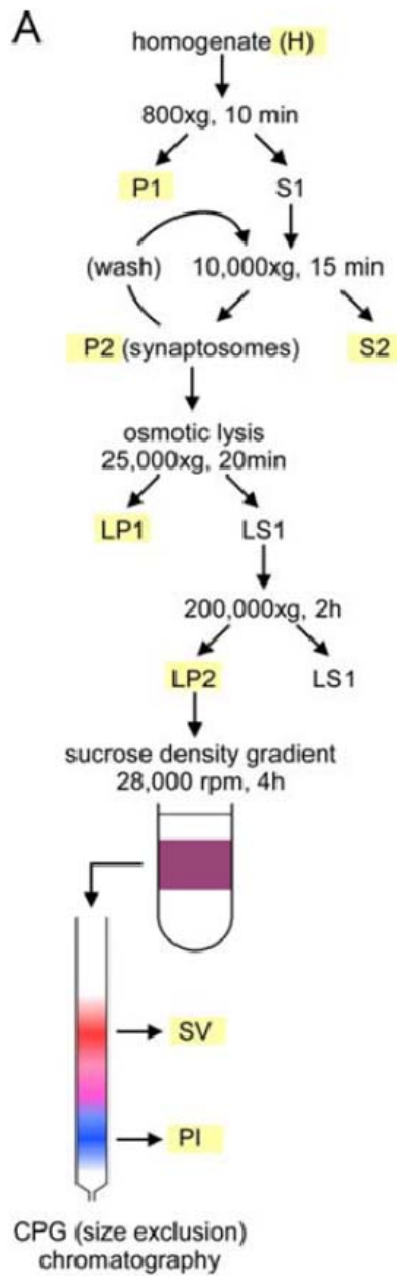

Figure $2.7 \mathrm{SV}$ purification from rat brain. Flow scheme of the isolation of crude SVs (LP2) and pure SVs via size exclusion chromatography. Taken from [7].

affinity purification. Bacteria were grown in $21 \mathrm{~TB}_{\mathrm{Amp}}$ (terrific broth) to an $\mathrm{OD}_{600}=1.3$ -1.7 and harvested by centrifugation. The pellets were resuspended in $50 \mathrm{mM}$ Tris-HCl (pH 8.0), $0.5 \mathrm{mM}$ EDTA, 1 x protease inhibitor complete (PIs) (Roche) and $1 \mathrm{mg} / \mathrm{ml}$ lysozyme and incubated for 1 hour at $37{ }^{\circ} \mathrm{C}$. After addition of $5 \mathrm{mM} \mathrm{MgCl}_{2}$ (final conc.), the cells were sonicated on ice 4 x $30 \mathrm{sec}$ with $30 \mathrm{sec}$ break in between with a 50 $\%$ output. The suspension was stirred for $20 \mathrm{~min}$ at room temperature (rt) after 
supplementation with $1 \mu \mathrm{g} / \mathrm{ml}$ DNaseI, $250 \mathrm{mM} \mathrm{Na}_{2} \mathrm{SO}_{4}$ and $0.7 \%$ (w/v) NaCholate, and centrifuged at $20000 \mathrm{x}$ g for $30 \mathrm{~min}$ at $4{ }^{\circ} \mathrm{C}$. The resulting pellet was resuspended in $20 \mathrm{mM}$ HEPES, $100 \mathrm{mM} \mathrm{KCl}, 20 \mathrm{mM}$ Imidazole, $5 \mathrm{mM} \mathrm{MgCl}$ (HEPES buffer) and 1 $\%$ n-dodecyl- $\beta$-D-maltopyranoside (DDM), $\mathrm{pH} 7.6$, stirred for $45 \mathrm{~min}$ at $\mathrm{rt}$ and centrifuged at $20000 \mathrm{x}$ g for $30 \mathrm{~min}$ at $4{ }^{\circ} \mathrm{C}$. The supernatant was batch incubated with Talon beads (Clontech) for 2 hours at $4{ }^{\circ} \mathrm{C}$ to bind the His-tagged $\mathrm{TF}_{0} \mathrm{~F}_{1}$ complex. The beads were washed with 20 column volumes (CVs) of HEPES buffer containing $0.08 \%$ DDM. Elution of the protein was performed in $5 \times 1 \mathrm{CV}$, using $20 \mathrm{mM}$ HEPES, 250 $\mathrm{mM}$ Imidazole, $5 \mathrm{mM} \mathrm{MgCl}_{2}$ and $0.05 \%$ DDM. Although the purified protein was already of high purity, an additional anion exchange step was performed in order to concentrate the sample and loose minor contaminants. Prior to binding the solubilised protein onto the MonoQ HR 5/5 column (GE), the sample was dialysed into $20 \mathrm{mM}$ $\mathrm{NaCl}, 20 \mathrm{mM}$ HEPES and $5 \mathrm{mM} \mathrm{MgCl}$, $\mathrm{pH} 7.5$ (buffer A) over night at $4{ }^{\circ} \mathrm{C}$. For the anion exchange purification an ÄKTA-system (ÄKTA purifier, GE) was used at rt with an elution step gradient (4 CV 0-18 \% buffer B, 3 CV 18-60 \% buffer B, 11 CV 60-100 $\%$ buffer B) and a flow rate of $1 \mathrm{ml} / \mathrm{min}$. Buffer $\mathrm{B}$ corresponds to buffer $\mathrm{A}$ supplemented with $1 \mathrm{M} \mathrm{NaCl}$. The fraction size between 18 and $65 \%$ buffer B was 300 $\mu$ l. The peak fractions were pooled, aliquoted and snap frozen with $10 \%$ glycerol.

\subsubsection{Cell-Free Expression of Rat VGLUT1}

For the cell-free expression setup, most of the required components were purchased except for the T7 RNA Polymerase (T7RNAP) and E.coli S30 extract. Isolation protocols are described in the following sections.

\subsection{Purification of T7RNAP}

An over night culture of the bacterial strain BL21 containing the T7RNAP carrying plasmid pAR1219 [81] was added to 41 of $\mathrm{LB}_{\text {Amp }}$ media and grown at $37{ }^{\circ} \mathrm{C}$ under vigorous shaking until an $\mathrm{OD}_{600}$ of 0.6 - 0.8 was obtained. T7RNAP expression was induced by adding Isopropyl- $\beta$-D-thiogalactopyranosid (IPTG) to a final concentration of $1 \mathrm{mM}$. For expression, the cultures were incubated at $37^{\circ} \mathrm{C}$ for another $5 \mathrm{~h}$ and harvested by centrifugation. The resulting cell pellet was resuspended in $120 \mathrm{ml}$ 
of buffer A (30 mM Tris, pH 8.0, $10 \mathrm{mM}$ EDTA, $50 \mathrm{mM} \mathrm{NaCl}, 5 \%$ glycerol and 10 $\mathrm{mM}$ of $\beta$-mercaptoethanol). The cells were disrupted with a french press device at $20,000 \mathrm{psi}$ and centrifuged at $20,000 \mathrm{x}$ g for $30 \mathrm{~min}$ at $4{ }^{\circ} \mathrm{C}$ to remove the cell debris. DNA was precipitated by dropwise addition of a $10 \%$ streptomycin sulfate solution to a final concentration of $2 \%$. The precipitated DNA was pelleted by centrifugation at $30,000 \mathrm{x}$ g for $30 \mathrm{~min}$ at $4{ }^{\circ} \mathrm{C}$. The cleared supernatant was additionally filtered through a $0.45 \mu \mathrm{m}$ filter and further purified by anion exchange chromatography using a MonoQ HR 10/10 column on an ÄKTA purifier system (GE). For this, the T7RNAP containing sample was applied to the column with a flow rate of $1 \mathrm{ml} / \mathrm{min}$ followed by elution with a continuous gradient from buffer A to buffer B in $15 \mathrm{CVs}$ (buffer B = buffer A with $500 \mathrm{mM} \mathrm{NaCl}$ ). The elution fractions were analysed by SDS-PAGE and coomassie staining. Fractions containing T7RNAP were pooled, dialysed in buffer C (10 mM Tris, pH 8.0, $1 \mathrm{mM}$ EDTA, $10 \mathrm{mM} \mathrm{NaCl}$ and $1 \mathrm{mM}$ DTT), snap frozen with $50 \%$ glycerol and stored at $-80{ }^{\circ} \mathrm{C}[82]$.

\subsection{Isolation of E.coli S30 Extract}

S30 extract was isolated from A19 bacterial strain. 51 of YTPG medium were supplemented with A19 over night culture and grown under vigorous shaking at $37^{\circ} \mathrm{C}$. The cells were harvested during logarithmic growth phase at $\mathrm{OD}_{600}$ 2.5-3.0, cooled down rapidly to avoid further growing and pelleted at $5000 \mathrm{x}$ g for $15 \mathrm{~min}$. The cell pellet was resuspended in $150 \mathrm{ml}$ of ice cold S30 A buffer (10 mM Tris, pH 8.2, $14 \mathrm{mM}$ $\mathrm{MgAc}_{2}, 0.6 \mathrm{mM} \mathrm{KCl}$ and $6 \mathrm{mM} \beta$-mercaptoethanol) and repelleted at $8,000 \mathrm{x}$ g for 10 min and $4{ }^{\circ} \mathrm{C}$. Resuspension and pelleting was repeated twice with a final centrifugation step of $30 \mathrm{~min} .25 \mathrm{~g}$ of wet weight cell pellet were resuspended in $28 \mathrm{ml}$ of S30 B buffer (10 mM Tris, $14 \mathrm{mM} \mathrm{MgAc} 2,0.6 \mathrm{mM} \mathrm{KCl,} 1 \mathrm{mM}$ DTT, $0.1 \mathrm{mM}$ PMSF, pH 8.2), disrupted at 20,000 Psi using a french press and centrifuged at 30,000 x g for $30 \mathrm{~min}$ and $4{ }^{\circ} \mathrm{C}$. The upper, non-turbid part of the supernatant was removed and spun down using the same settings. Again, the upper clear part of the supernatant was removed, supplemented with $\mathrm{NaCl}$ to a final concentration of $400 \mathrm{mM}$ and incubated at $42{ }^{\circ} \mathrm{C}$ for $45 \mathrm{~min}$. The supernatant, which turned turbid, was dialysed in two steps over night in $\mathrm{S} 30 \mathrm{C}$ buffer (10 mM Tris, $\mathrm{pH} 8.2,14 \mathrm{mM} \mathrm{MgAc}_{2}, 0.6 \mathrm{mM} \mathrm{KAc}$ and $0.5 \mathrm{mM}$ DTT) at 
$4{ }^{\circ} \mathrm{C}$ and centrifuged on the next day at $30,000 \times \mathrm{g}$ for $30 \mathrm{~min}$. The upper, non-turbid part of the supernatant was aliquoted, snap frozen and stored at $-80{ }^{\circ} \mathrm{C}$ [82].

\subsection{Cell-Free Reaction Setup for Rat VGLUT1 Expression}

The reaction setup contained a reaction mixture $(\mathrm{RM})$ and a feeding mixture (FM), which supplemented the RM with components. RM (70 $\mu 1)$ and FM (980 $\mu 1)$ were separated by a dialysis membrane with a molecular weight cut-off (MWCO) of 12-14 $\mathrm{kDa}$. The components of RM and FM and their concentrations are listed in detail in [82]. His 10 -tagged rat VGLUT1 in $\mathrm{pET} 28 \mathrm{a}(+)$ vector was used as a plasmid. The expression was optimised by varying incubation temperatures $\left(27\right.$ and $\left.30^{\circ} \mathrm{C}\right)$ and time.

\subsubsection{Heterologous Expression and Purification of VGLUT1 in Insect Cells}

\subsection{Expression of VGLUT1 in Insect Cells}

His $_{6-}$ and SBP-tagged mouse VGLUT1 (in pDEST10 and pDEST8 vector, respectively (section 1.2.9.3)) and inserted in the bacmid EMBacY (baculovirus coding DNA with an integrated yellow fluorescent protein (YFP) expression marker) via Tn7 transposition in DH10 bacterial strain [83]. $30 \mathrm{~min}$ prior to VGLUT1-bacmid transfection, $10^{6}$ Spodoptera frugiperda (Sf9) cells in $3 \mathrm{ml}$ of media were seeded in a 3 $\mathrm{cm}$ dish and kept at $27^{\circ} \mathrm{C}$. $20 \mu \mathrm{g}$ of VGLUT1-bacmid per $3 \mathrm{~cm}$ dish were transfected using FuGENE HD Transfection Reagent (Promega) and incubated for $72 \mathrm{~h}$ at $27{ }^{\circ} \mathrm{C}$ to acquire the first viral generation $\mathrm{V}_{0}$. The budded virus containing supernatant was used to infect $25 \mathrm{ml}\left(10^{6}\right.$ cells $\left./ \mathrm{ml}\right) \mathrm{Sf} 9$ suspension culture in order to obtain a higher viral titer. After $72 \mathrm{~h}$ of incubation at $27{ }^{\circ} \mathrm{C}$ the virus containing supernatant $\left(\mathrm{V}_{1}\right)$ was harvested and used to infect $400 \mathrm{ml}$ Trichoplusia ni (High5) suspension culture $(0.7 *$ $10^{6}$ cells $/ \mathrm{ml}$ ) for protein expression. VGLUT1 expression was monitored by measurement of YFP fluorescence and was highest $36 \mathrm{~h}$ post-infection (PI) with $10 \mathrm{mg} / \mathrm{l}$ expressed protein. High5 cells were harvested 36-48 h PI and processed for VGLUT1 isolation. Sf9 cells were cultured in Sf900 and High5 cells in ExpressFive medium supplemented with $2 \mathrm{mM}$ L-glutamine (Invitrogen).

\subsection{Detergent Screen for Solubilisation of VGLUT1 from Insect Cells}


Material and Methods

For the detergent screen the commercially available membrane protein kit (Qiagen) was used. Screen was performed according to the manufacturer's protocol.

\subsection{Purification of SBP-tagged VGLUT1 from Insect Cells}

High5 cells from 11 culture were suspended in $50 \mathrm{ml}$ ice cold buffer A (40 mM Tris, $\mathrm{pH}$ 7.3, $300 \mathrm{mM} \mathrm{KCl,} 2 \mathrm{mM}$ EDTA) with $1 \mathrm{x}$ PIs and $5 \mathrm{mM} \beta$-mercaptoethanol. DDM was added to a final concentration of $2 \%(\mathrm{w} / \mathrm{v})$ and cells were lysed for $1 \mathrm{~h}$ at 4 ${ }^{\circ} \mathrm{C}$ under constant rotation. Subsequently, insoluble cell debris were separated at $300,000 \mathrm{x} \mathrm{g}$ for $30 \mathrm{~min}$ at $4{ }^{\circ} \mathrm{C}$. The supernatant was supplemented with $1 \mathrm{ml}$ streptavidin beads (Pierce) which were capturing VGLUT1 via its SBP-tag [84] and rotated for $3 \mathrm{~h}$ at $4{ }^{\circ} \mathrm{C}$. The beads were washed with $2 \times 10 \mathrm{CVs}$ of wash buffer (buffer A containing $0.1 \% \mathrm{DDM}$ ) and the protein was finally eluted with $5 \times 1 \mathrm{CV}$ of elution buffer $(15 \mathrm{mM}$ Tris, $100 \mathrm{mM} \mathrm{KCl}, 0.6 \mathrm{mM}$ EDTA, $2 \mathrm{mM}(+)$ biotin, $5 \mathrm{mM} \beta$ mercaptoethanol and $0.05 \% \mathrm{DDM}$ ). The beads were incubated for $5 \mathrm{~min}$ on ice for each elution step. The elution fractions were pooled and concentrated using a $30 \mathrm{kDa}$ MWCO VivaSpin concentrator (Sartorius) to a final VGLUT1 concentration of $\sim 1$ $\mathrm{mg} / \mathrm{ml}$ ( 3-5 fold). DDM has a micellar size of $50 \mathrm{kDa}$, thus accumulates in the concentrated protein sample to a final concentration of $\sim 0.25 \%$. Concentrated VGLUT1 was aliquoted, snap frozen and stored at $-80{ }^{\circ} \mathrm{C}$. An average yield from 11 of High5 cell culture was $1 \mathrm{mg}$.

\subsubsection{Heterologous Expression and Purification of VGLUT1 in HEK293 cells}

HEK293 cells were cultured in DMEM (Dulbeccos's modified Eagle's medium, Lonza) supplemented with $10 \%$ fetal bovine serum (FBS), $2 \mathrm{mM}$ L-glutamine and $1 \mathrm{mM}$ sodium pyruvate, incubated at $37{ }^{\circ} \mathrm{C}$ and $5 \% \mathrm{CO}_{2}$. For large-scale expression of VGLUT1, typically 100 dishes (10 cm diameter containing $10 \mathrm{ml}$ of media) with $60 \%$ confluence were transfected with $20 \mu \mathrm{g}$ DNA per plate using the $\mathrm{Ca}_{3}\left(\mathrm{PO}_{4}\right)_{2}$ transfection method [85]. Mouse SBP-VGLUT1/pcDNA6.2 (section 1.2.9.3) was used as plasmid. $24 \mathrm{~h}$ prior to transfection, cells were split to $\sim 30 \%$ confluence and incubated at $37{ }^{\circ} \mathrm{C}$ and $2.5 \% \mathrm{CO}_{2}$. $1 \mathrm{~h}$ before transfection, the cells were supplemented with fresh media. 
For transfection of one dish, $20 \mu \mathrm{g}$ of DNA $(1 \mu \mathrm{g} / \mu \mathrm{l})$ were mixed with $500 \mu 1250 \mathrm{mM}$ $\mathrm{CaCl}_{2}$ (diluted from a $2.5 \mathrm{M}$ stock), subsequently, 2 x BBS (BES-buffered saline: 50 $\mathrm{mM}$ BES, $280 \mathrm{mM} \mathrm{NaCl}, 1.5 \mathrm{mM} \mathrm{Na} \mathrm{HPO}_{4}$ ) was added dropwise to the $\mathrm{DNA} / \mathrm{CaCl}_{2}$ mixture under constant agitation. DNA-Ca $\left.\mathrm{CO}_{3}\right)_{2}$ precipitant formation was observed by the turbid appearance of the solution. 5min later, the transfection mixture was carefully added to the cells and incubated for $24 \mathrm{~h}$ at $37{ }^{\circ} \mathrm{C}$ and $2.8 \% \mathrm{CO}_{2}$. On the following day, $\mathrm{CO}_{2}$ was increased to $5 \%$ and incubated for another $24 \mathrm{~h}$ before harvesting and processing the cells.

The purification of VGLUT1 was performed according to 2.2.2.3.2. The final concentration of DDM in the VGLUT1 sample was $\sim 1 \%$ ( 20 fold concentration). Typically, 60-100 $\mu \mathrm{g}$ of VGLUT1 were obtained from 100 dishes and 31 of used media in total.

\subsubsection{Reconstitution of VGLUT1 and $\mathrm{TF}_{0} \mathrm{~F}_{1}$ into Liposomes}

\subsubsection{VGLUT/TF $F_{1}$ Liposomes from Soybean Lipids formed by the Co- Micellisation Method}

Proteoliposomes produced by the co-micellisation method were formed by detergent removal after mixing of the detergent-solubilised components by dialysis [86]. The components were soybean phospholipids $(40 \mathrm{mg} / \mathrm{ml}$ in $5 \%$ n-Octyl- $\beta-\mathrm{D}-$ Glucopyranoside (OG)) (Sigma), cholesterol (5 $\mathrm{mg} / \mathrm{ml}, 7 \%$ OG) and proteins (VGLUT1, $\mathrm{TF}_{0} \mathrm{~F}_{1}$, both in DDM). The molar ratio of phospholipids:cholesterol was adjusted to $75: 25$ with an estimated MW of $800 \mathrm{~g} / \mathrm{mol}$ for the phospholipids. The ratio of lipids: $\mathrm{TF}_{0} \mathrm{~F}_{1}$ was set to 50 and for VGLUT1 to 25 . The final lipid concentration was adjusted to $2.5 \mathrm{mg} / \mathrm{ml}$. After mixing, the solution was dialysed (12-14 $\mathrm{kDa} \mathrm{MWCO}$, SpectraPor) over night at $4{ }^{\circ} \mathrm{C}$ in $10 \mathrm{mM}$ MOPS, pH 7.3, $2 \mathrm{mM} \mathrm{MgSO}_{4}$ and $100 \mathrm{mM}$ KGluconate, CholineGluconate, Choline $\mathrm{Cl}$ or $\mathrm{KCl}$, respectively. The dialysis buffer was additionally supplemented with $2 \mathrm{~g}$ BioBeads (BioRad) to adsorb detergent monomers. After dialysis, remaining DDM in the liposomes was complexed with 2,6-di-O-methyl$\beta$-cyclodextrin ( $\beta$-CD, Sigma) [87] by adding a few crumbs of solid $\beta$-CD to the liposomes and incubated on ice for $1 \mathrm{~h}$ by occasionally inverting the tubes. 
External buffer exchange was performed using prepacked size exclusion columns (PD10, GE). Up to $1 \mathrm{ml}$ of liposomes was applied on one column. The liposome fractions were identified by their viscous and turbid appearance and collected separately.

\subsubsection{VGLUT1/TF $F_{1}$ Liposomes from Synthetic Lipids formed by the Step- by-Step Method}

The step-by-step method for formation of proteoliposomes consists of 3 steps, which are 1) Preparation of unilamellar preformed liposomes, 2) Addition of proteins and detergent, 3) Removal of detergent [86].

Unilamellar liposomes with synthetic lipids 1,2-dioleoyl-sn-glycero-3phosphocholine (DOPC), 1,2-dioleoyl-sn-glycero-3-phospho-L-serine (DOPS) and cholesterol (Chol) (Avanti Polar Lipids) with varying molar ratios were prepared by reverse phase evaporation [88]. In brief, the organic solvent from lipids dissolved in chloroform:methanol 2:1 was evaporated forming a lipid film. The lipid film was solubilised by diethylether followed by addition of an equal volume of buffer, which resulted in a two-phase system that is sonicated to form inverted water in oil micelles. Diethylether is gradually removed with a rotary evaporator, resulting in a suspension of multilamellar vesicles, which are subsequently extruded (Avanti Polar Lipids) using 100 $\mu \mathrm{m}$ filters forming homogenous preformed liposomes of 90-130 nm diameter (confirmed by dynamic light scattering (DLS)). The lipid concentration was adjusted with buffer to $8 \mathrm{mM}$.

For reconstitution of proteins, an R value of 1 was adjusted for OG (DDM from proteins was not taken into account), the lipid:protein ratios were the same as in 1.2.3.1, the final lipid concentration was also $2.5 \mathrm{mg} / \mathrm{ml}$. Detergent was removed as described in 1.2.3.1.

\subsubsection{Liposome Co-flotation on a Density Gradient for Evaluation of Insertion Efficiency}

$50 \mu \mathrm{l}$ of $\mathrm{VGLUT1} / \mathrm{TF}_{0} \mathrm{~F}_{1}$ liposomes were mixed with $50 \mu \mathrm{l}$ of $80 \%$ Nycodenz (Axis Shield) in a $250 \mu 1$ centrifuge tube. The mixture was overlaid with $50 \mu 1$ of $30 \%$ Nycodenz and $50 \mu 1$ of reconstitution buffer. The density gradient was centrifuged using 
a Sorvall ultracentrifuge (S55S rotor, $48000 \mathrm{rpm}, 4{ }^{\circ} \mathrm{C}, 90 \mathrm{~min}$ ). After centrifugation, 20 $\mu \mathrm{l}$ fractions were taken from the top of the gradient and analysed by SDS-PAGE or western blot.

\subsubsection{Proteolytic Digestion for Evaluation of VGLUT1 Orientation}

Sections of membrane inserted VGLUT1 are partially accessible to proteases. In the inside-out orientation these sections are protected from proteolytic cleavage, whereas in the right side-out orientation they are digested. By comparing the amount of cleaved protein after proteolytic digestion to an untreated sample and proteolytically digested $\mathrm{SVs}$, the fraction of right side-out oriented protein can be estimated.

Proteolytic digestion reactions were performed in $20 \mu$ final volume. $1 \mu \mathrm{g}$ of VGLUT1 from proteoliposomes or SVs was digested with $0.1 \mu \mathrm{g} / \mu \mathrm{l}$ trypsin (final conc.) for $1 \mathrm{~h}$ at $37^{\circ} \mathrm{C}$. For the untreated sample, trypsin was omitted and replaced with liposome buffer. In order to estimate complete cleavage, an additional sample was trypsinised in presence of $1 \%$ TritonX-100. Samples were analysed by western blotting using $\alpha$ VGLUT1 antibody directed against the C-terminus of VGLUT1.

\subsubsection{Vesicle Acidification Measurement with Acridine Orange}

Acridine orange ( $\mathrm{AO})$ is a $\mathrm{pH}$ sensitive dye. It exhibits an absorption maximum at $492 \mathrm{~nm}$ and a fluorescence maximum at $530 \mathrm{~nm}$. It is a weak base and can pass membranes in its unprotonated form. Upon $\mathrm{pH}$ drop in the vesicle lumen it gets protonated and trapped in the vesicle due to its positive charge. Accumulating AO molecules in the lumen are self-quenching due to dimerization, which leads to a drop in absorbance and fluorescence [89]. This decrease can be used to monitor acidification of the vesicle lumen [68]. Acridine orange was purchased from Molecular Probes and stored as $1 \mathrm{mM}$ stock in $30 \% \mathrm{EtOH}$.

Measurements were performed using an Aminco dual-wavelength spectrophotometer. The dual-wavelength technique is enabling a stable and sensitive readout of small absorbance changes in turbid samples [90]. 
The photometer was equilibrated at $32{ }^{\circ} \mathrm{C}$ before use. Usually, $600-650 \mu 1$ buffer (10 mM MOPS, pH 7.3, $2 \mathrm{mM} \mathrm{MgSO}_{4}$, containing either $200 \mathrm{mM}$ Glycine, or $100 \mathrm{mM} \mathrm{KCl}, \mathrm{NaCl}$, KGluconate or CholineCl) were mixed in a $1 \mathrm{ml}$ glass cuvette with $50-100 \mu \mathrm{l}$ of SV or liposome sample containing $10 \mu \mathrm{M}$ AO. After a stable baseline was obtained, $1.2 \mathrm{mM}$ ATP, $4 \mathrm{mM}$ chloride (with varying counter ions), $10 \mathrm{mM}$ glutamate, $30 \mathrm{mM}$ chloride and $10 \mathrm{mM}\left(\mathrm{NH}_{4}\right)_{2} \mathrm{SO}_{4}$ were successively added after obtaining a baseline for each probe. Other ions or ionophores were added at individually indicated concentrations.

\subsubsection{Measurement of Membrane Potential Changes across Vesicular Membranes with Oxonol VI}

Oxonol VI is an anionic dye used to detect changes in membrane potential. A positive luminal potential attracts Oxonol VI due to its negative charge which leads to dye accumulation in the lumen and changes in absorbance. Absorbance changes are believed to occur due to association of the dye with membranes, but the precise mechanism is not understood [91]. OxonolVI was purchased from Molecular Probes and stored as a $1 \mathrm{mM}$ stock in EtOH. Absorbance changes at $625 \mathrm{~nm}$ with a reference wavelength at $587 \mathrm{~nm}$ were detected using the same Aminco dual wavelength spectrophotometer as for $\mathrm{AO}$ measurements.

The apparatus was equilibrated at $32{ }^{\circ} \mathrm{C}$. Initially, a stable baseline was obtained after mixing $600-650 \mu \mathrm{l}$ buffer $\left(10 \mathrm{mM}\right.$ MOPS, $\mathrm{pH} 7.3,2 \mathrm{mM} \mathrm{MgSO}_{4}$ containing either $200 \mathrm{mM}$ Glycine, or $100 \mathrm{mM} \mathrm{K} / \mathrm{Na} /$ CholineGluconate) with $50-100 \mu \mathrm{l}$ of SVs or liposomes and $15 \mu \mathrm{M}$ OxonolVI. $1.5 \mathrm{mM}$ ATP, $10 \mathrm{mM}$ glutamate, $30 \mathrm{mM}$ chloride, 10 $\mathrm{mM}\left(\mathrm{NH}_{4}\right)_{2} \mathrm{SO}_{4}$ and $50 \mu \mathrm{M}$ FCCP were gradually added. A baseline was obtained before adding the subsequent probe. Other ions or ionophores were added at individually indicated concentrations.

\subsection{8 ${ }^{3} \mathrm{H}$-Glutamate Uptake into SVs and Proteoliposomes}

Glutamate uptake into SVs and proteoliposomes was detected by radiolabelled

${ }^{3} \mathrm{H}$-glutamic acid (GE). The uptake was measured in presence of $4 \mathrm{mM}$ ATP, $50 \mu \mathrm{M} \mathrm{K}$ - 
glutamate or Choline-glutamate, $4 \mathrm{mM}$ chloride and $2 \mu \mathrm{Ci}{ }^{3} \mathrm{H}$-glutamic acid per data point.

The uptake buffer contained $10 \mathrm{mM}$ MOPS, pH 7.3, $2 \mathrm{mM} \mathrm{MgSO}_{4}$ and $100 \mathrm{mM}$ of KGluconate or $200 \mathrm{mM}$ Glycine. The reaction was started by mixing $50-100 \mu \mathrm{l}$ SVs/proteoliposomes with $10 \mathrm{x}$ uptake buffer and incubating for $20 \mathrm{~min}$ at $32{ }^{\circ} \mathrm{C}$. Pipetting the reaction mixture into $3 \mathrm{ml}$ of ice cold uptake buffer and filtering through a $0.45 \mu \mathrm{m}$ nitrocellulose filter stopped the reaction. The nitrocellulose filter was washed 3 times with $3 \mathrm{ml}$ ice cold uptake buffer and the remaining radioactivity trapped on the filter was detected by liquid scintillation. For SVs, typically 15-20 $\mu \mathrm{g}$ of total protein, and for proteoliposomes, $10 \mu \mathrm{g}$ VGLUT1 were assayed per data point.

\subsubsection{General Methods}

\subsubsection{SDS-PAGE and Coomassie Blue Staining}

$10 \%$ Polyacrylamide gels were prepared as described in [92]. After sample separation by electrophoresis gels were stained with Coomassie Brilliant Blue R250 in $50 \%$ methanol and $10 \%$ acetic acid for $20 \mathrm{~min}$. Destaining was performed using $50 \%$ ethanol and $10 \%$ acetic acid for $15 \mathrm{~min}$ and subsequently $10 \%$ ethanol and $5 \%$ acetic acid for 1 hour.

\subsubsection{Western Blotting}

After SDS-PAGE gels protein transfer on a nitrocellulose membrane was performed as described in [93]. The membrane was blocked in TBS-Tween $(0.05 \%)$ plus $5 \%$ milk powder (w/v) (blocking solution) for 1 hour at room temperature followed by addition of primary antibodies diluted in the same blocking solution. Antibodies used in this work were VGLUT1 (1:5000 dilution), synaptobrevin II (1:1000 dilution), SNAP25 (1:1000 dilution), all from Synaptic Systems and EF0F1 $\alpha$-b-subunit (1:1000) from Abcam. After primary antibody incubation, membranes were washed $3 \mathrm{x}$ 5 min with blocking solution and incubated with HRP-conjugated secondary antibody (1:2000 dilution) for $45 \mathrm{~min}$. The membranes were again washed $3 \times 5 \mathrm{~min}$ and visualised with a Western Lightning Ultra chemiluminescence kit according to the manufacturer's instruction (Perkin Elmer) using a LAS1000-reader (Fujifilm). 


\subsubsection{Molecular Cloning}

Mus musculusVGLUT1 DNA optimised for expression in Trichoplusia ni (High5) was synthesised by GeneArt. Cloning was performed using the Gateway cloning system according to the manufacturer's protocol (Invitrogen). In brief, VGLUT1 DNA was inserted into pENTR/D-TOPO vector and by subsequent recombination reaction into the destination vector of choice. Destination vectors used were pDEST10 (His 6 tag included) and pDEST8 (no tag included), both for insect cell expression, and pcDNA6.2 for mammalian cell expression. The N-terminal SBP tag was introduced by PCR.

\subsubsection{Electron Microscopy}

Electron microscopy of liposomes using negative staining was done as described in [94] and performed by Dietmar Riedel.

\subsubsection{Size Distribution Analysis by FFF-MALLS}

Field-flow-fractionation (FFF) coupled to a multiangle laser light scattering (MALLS) detector was used to determine liposome size distribution according to [95] and was performed by Matias Hernandez.

\subsubsection{Size Distribution Analysis by DLS}

Size and distribution of liposomes can also be determined by DLS. Particles in solution undergo Brownian motion which is depending on their size and weight. Thus, information on size and molecular weight of particles can be obtained from the intensity of scattered light as a function of time [96]. Liposomes were measured in $20 \mu 1$ cuvettes at $30{ }^{\circ} \mathrm{C}$ in a DynaProTitan device (Wyatt Technology). Average radius was determined from 10 x $10 \mathrm{sec}$ measurements.

\subsubsection{Fluorescence Dequenching for Lipid-Mixing Measurements}

SNARE-mediated fusion of $\mathrm{TF}_{0} \mathrm{~F}_{1} / \Delta \mathrm{N}$ liposomes $(\Delta \mathrm{N}$ complex consists of syntaxin, SNAP25 and a short stabilising fragment of synaptobrevin ${ }_{49-96}$ [97]) and SVs was monitored by a lipid-mixing assay. In this assay, lipids of the Q-SNARE containing liposomes $\left(\mathrm{TF}_{0} \mathrm{~F}_{1} / \Delta \mathrm{N}\right.$ liposomes $)$ were labelled with a self-quenched Förster resonance 
Material and Methods

energy transfer (FRET) pair (Nitrobenzoxadiazole (NBD) and Rhodamine (RHO)). Upon fusion with a non labelled R-SNARE containing sample (SVs) the labelled lipids were diluted expanding the distance between donor (NBD) and acceptor (RHO) dye. The cumulative donor - acceptor distance resulted in an increase of the donor dye fluorescence (NBD), which was monitored as a function of time [98] [99] [97]. The liposome - SV fusion reaction was measured with a spectrometer (Fluoromax-2) at an excitation wavelength of $460 \mathrm{~nm}$ and an emission wavelength of $538 \mathrm{~nm}$ at $30{ }^{\circ} \mathrm{C}$ in a 1 $\mathrm{ml}$ quartz cuvette. The reaction was started by mixing $50 \mu$ l of $\mathrm{TF}_{0} \mathrm{~F}_{1} / \Delta \mathrm{N}$ liposomes with $10 \mu \mathrm{SVS}(\sim 6 \mu \mathrm{g} / \mu \mathrm{l})$ in reconstitution buffer and stopped by addition of $0.05 \%$ TritonX-100 (final conc.). Fluorescence signals were normalised to the maximum fluorescence after solubilisation with TritonX-100. 


\section{Results}

\subsection{VGLUT1 Purification}

To study VGLUT1 transport mechanism in a minimal reconstituted system, single components had to be obtained in quantities, amenable for post-purification analysis.

High level expression of mammalian multispanners such as transporters still marks the major bottleneck for protein studies today. Expression in bacterial systems is particularly problematic due to impairment of cellular physiological functions by insertion into membranes, misfolding and lack of posttranslational modifications required for the activity of transporters [100] [101]. Expression systems most suitable for membrane protein (MP) expression are insect or mammalian cell hosts [100] [102]. Another emerging system is cell-free expression which bypasses cellular toxic effects caused by the expression of challenging heterogenous proteins. Previus reports of successful expression of functional mammalian multispanners [103, 104] were taken into account in order to attempt derivation of VGLUT1 using this method. Insect cell expression and purification of His ${ }_{6}$-tagged rat VGLUT2 has also been described and was taken as another reference for mouse VGLUT1 expression work along with the cell-free expression [62]. Lastly, mammalian cell expression of mouse VGLUT1 was additionally attempted in order to isolate a protein of higher activity due to an alleged low activity of VGLUT1 derived from insect cells [21].

\subsubsection{Cell-Free Expression}

The unique feature of cell-free (CF) expression is the possibility to control several variables and to individually optimize conditions to the requirements of each protein. In addition, toxic effects often caused by membrane proteins are circumvented. The hydrophobic environment required for MPs can be provided by direct expression into detergent micelles (D-CF) or even preformed liposomes (L-CF). In should be 
Results

considered that detergents can only be used up to certain concentrations as some are incompatible with the method [105].

The most powerful extract source, containing ribosomes and other translation factors currently used is E.coli S30 extract, which is not performing posttranslational modifications or eukaryotic folding [82]. However, the system allows supplementation with chaperones or co-factors for protein stability [106].

\subsubsection{Cell-Free Expression of VGLUT1}

For the CF expression setup the S30 E.coli extract was isolated and the T7 RNA polymerase was purified. The bacterial strain and plasmid including the isolation protocols was obtained from Frank Bernhard's group at the University of Frankfurt. Figure 3.8 shows a typical purification profile of the T7 RNA polymerase.
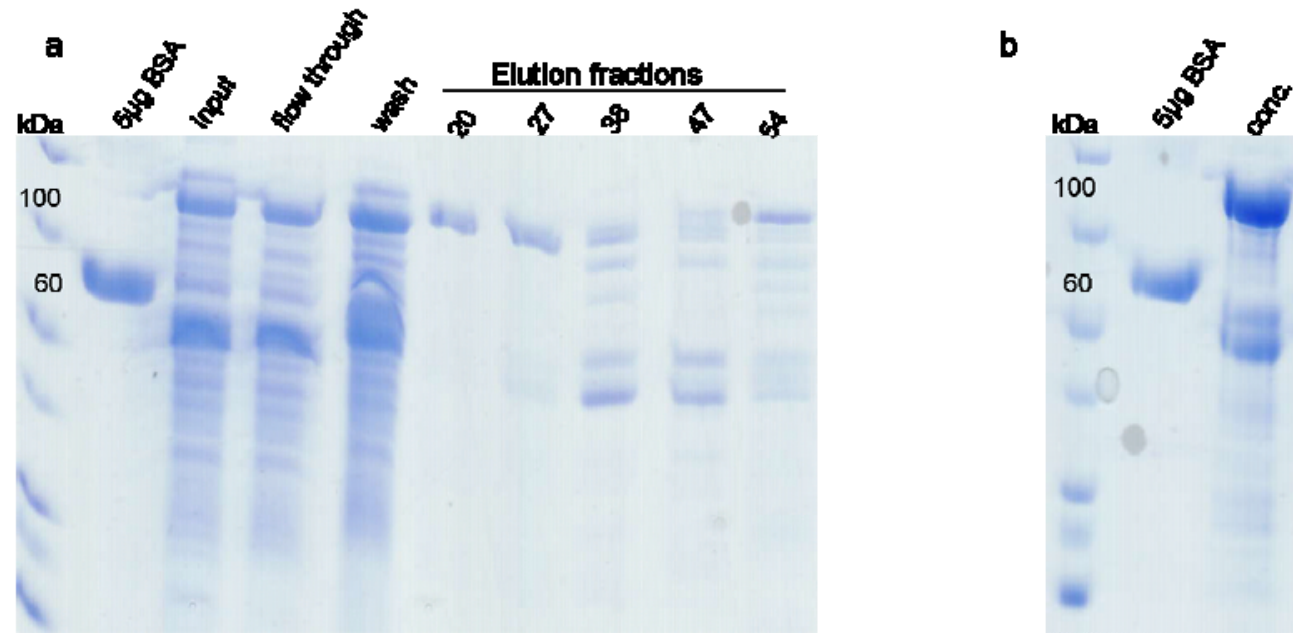

Figure 3.8 T7 RNA Polymerase purification. (a) Purification of the T7 RNA Polymerase $(100 \mathrm{kDa})$ by anion exchange chromatography using a MonoQ HR10/10 column. Elution fractions 20-27 were pooled and concentrated. (b) Concentration of elution fractions was estimated by comparing with bovine serum albumin (BSA) and resulted in approximately $2.5 \mathrm{mg} / \mathrm{ml}$.

Several components of the reaction and feeding mixture can be varied in order to optimize expression. Initially, expression of green fluorescent protein (GFP) and a control MP could be established confirming that the setup of the system including the purified E.coli extract and the T7 RNA polymerase was fully functional. Subsequent trials on expression of VGLUT1 using a pET28a(+) vector with His 10 -tagged rat VGLUT1 were indeed successful, as confirmed by western blot analysis. However, 
despite several optimization approaches the expression yields did not exceed $60 \mu \mathrm{g} / \mathrm{ml}$ (fig.3.9). Taking into account that $1 \mathrm{ml}$ of reaction mixture already represents a large scale production volume and that purification of the protein includes additional yield loss, the initial expression screens were not promising enough to conduct further optimizations like D-CF or supplementation with chaperones. Thus, CF expression was no longer followed.

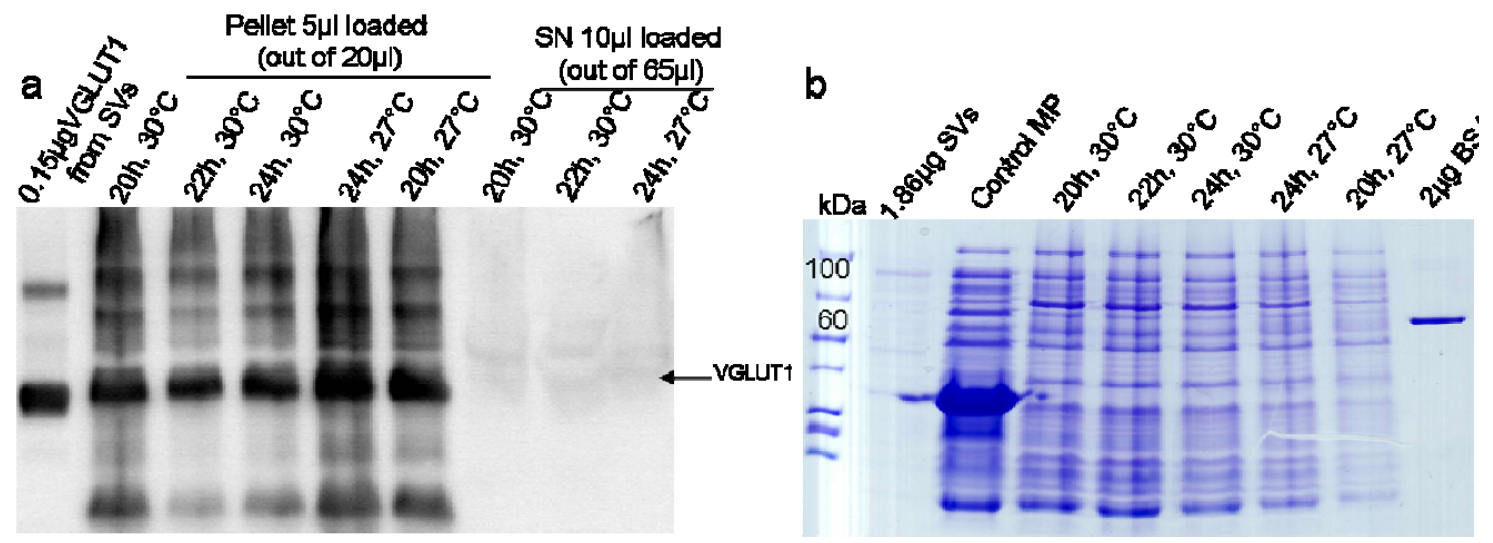

Figure 3.9 CF expression of VGLUT1. (a) Western blot analysis of VGLUT1 expression levels with varying expression conditions is depicted. A VGLUT1 antibody directed against the Cterminus was used. Synaptic vesicles (SVs) were loaded to estimate the amount of VGLUT1. The expressed protein was found in the pellet as no detergent was added to the reaction setup. (b) Coomassie blue staining of the varying expression conditions. VGLUT1 cannot be identified as a prominent band unlike the control membrane protein.

\subsubsection{Expression and Purification of VGLUT1 using Insect Cells}

The baculovirus expression system was used to express VGLUT1 in insect cells. This system is based on the application of recombinant baculoviruses, which contain genes (polyhedrin and p10) under the control of strong promoters. Replacement of these genes with the gene of interest induces expression of heterologous proteins resulting in high yields. A key benefit of using higher eukaryotes instead of bacteria for expression is its membrane composition and posttranslational modifications which resemble native mammalian modifications and therefore often result in biologically active protein. However, for more intricate proteins like transporters the higher expression rates may be detrimental because the vast amount of protein cannot be processed in the endoplasmic reticulum (ER) fast enough, resulting in protein misfolding. Partial enhancement of processing can be achieved by co-expression of ER molecular 
chaperones like calnexin or calreticulin [107] and by slowing down expression by using the weaker promoter p10 instead of polyhedrin [108]. The process of N-glycosylation in insect and mammalian cells is also different which could lead to structural changes in glycosylation [109].

For the establishment of the insect cell expression system we made use of the commercially available donor plasmid pDEST10 containing a $\mathrm{His}_{6}$-tag, as well of the bacmid originally engineered by Imre Berger (ETH, Zürich) for multiprotein complex expression. A convenient attribute of this bacmid is the linkage of yellow fluorescent protein (YFP) to the expression of the protein of interest which allows measuring expression levels peak by recording YFP fluorescence.

Insect cells were transfected with His-tagged mouse VGLUT1 containing bacmid. After obtaining a sufficient titer of virus Trichoplusia ni (High5), insect cells were infected and protein expression was monitored by YFP fluorescence and further verified by western blot analysis. Protein expression peaked at $36 \mathrm{~h}-48 \mathrm{~h}$ post infection (PI) (fig.3.10). As cell lysis continued beyond $48 \mathrm{~h}$ PI protein degradation predominated. Typically, an expression yield of $10 \mathrm{mg} / \mathrm{l}$ of High5 cell culture was obtained.

a

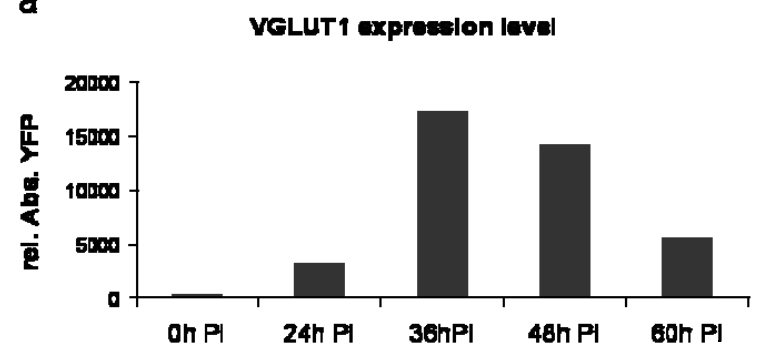

b

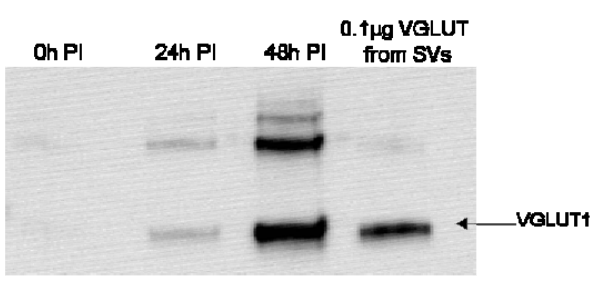

Figure 3.10 Expression of VGLUT1 in insect cells. (a) Expression of YFP was monitored within 60h post infection (PI) representing the expression levels of VGLUT1. (b) Expression levels of VGLUT1 analysed by Western Blot using a VGLUT1 antibody directed against the Cterminus. Amount of VGLUT1 was estimated by signal comparison with native VGLUT1 in SVs.

\subsubsection{Solubilisation of VGLUT1}

For a highly hydrophobic protein like VGLUT1 it is inevitable to make use of detergents in order to solubilise it in an aqueous environment. Detergents are amphipatic molecules containing a polar headgroup and a hydrophobic chain and can 
form micelles in aqueous solution above a certain concentration (cmc). The cmc decreases with the length of the alkyl chain. Importantly, the detergent has to have a mild effect on the maintenance of protein activity which mostly applies to non-ionic or zwitterionic detergents as they preferentially intrudes protein-lipid and lipid-lipid interactions more than protein-protein interactions. Further beneficial detergent properties are easy removal by dialysis or size exclusion chromatography and proper solubilisation of protein. Most of the time one has to compromise between one or the other property [110].

In order to find the most suitable detergent for solubilisation of VGLUT1 a screen involving structurally diverse non- or zwitterionic non-denaturing detergents was performed. n-Dodecyl- $\beta$-D-glucopyranoside (DDM) turned out to solubilise VGLUT1 best to about $50 \%$ of total expressed protein (fig. 3.11 ). DDM is a non-ionic detergent with a lipid-like structure known to be gentle and therefore appropriate for preserving VGLUT1 activity. However, its low cmc of $0.15 \mathrm{mM}$ and a micellar size corresponding almost to the protein size, complicated downstream applications. In order to completely exchange all native protein:lipid interactions to protein:detergent interactions a protein:detergent minimal ratio of 1:10 was chosen. Solubilisation times exceeding $1 \mathrm{~h}$ did not enhance solubilisation effiency.
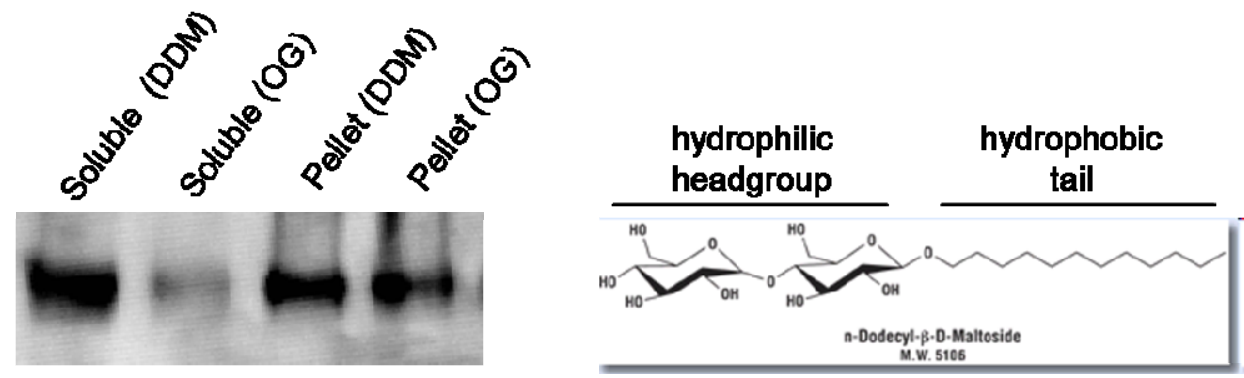

Figure 3.11 Solubilisation of VGLUT1 from insect cells. Immunoblot detection of VGLUT1 after solubilisation of insect cell membranes for $1 \mathrm{~h}$ in presence of $2 \%(\mathrm{w} / \mathrm{w})$ DDM (molecular structure depicted on the right taken from piercenet.com) or n-Octyl- $\beta-D-G l u c o p y r a n o s i d e ~(O G)$. Equal volumes were loaded. 
Results

\subsubsection{Affinity Purification of His - $^{-t a g g e d ~ V G L U T 1 ~}$}

Attempts to obtain enriched VGLUT1 resulted in highly contaminated elution fractions without a prominent VGLUT1 band. Elution using a continuous imidazole gradient did not improve purity of elution fractions (fig. 3.12).

The first description of the purification of VGLUT with a His 6 -tag was used as reference for the purification attempted here [62]. However, the His $6^{-}$tag only displays an affinity for $\mathrm{Ni}^{2+}$ in the higher micromolar range indicating that less prominently overexpressed proteins, like VGLUT1, will not bind with a high specificity, especially by taking into account the natural abundance of Histidine clusters in endogenous proteins. Despite the previously published His 6 -tag purification method a tag with a higher specificity towards its matrix was found to be imperative.

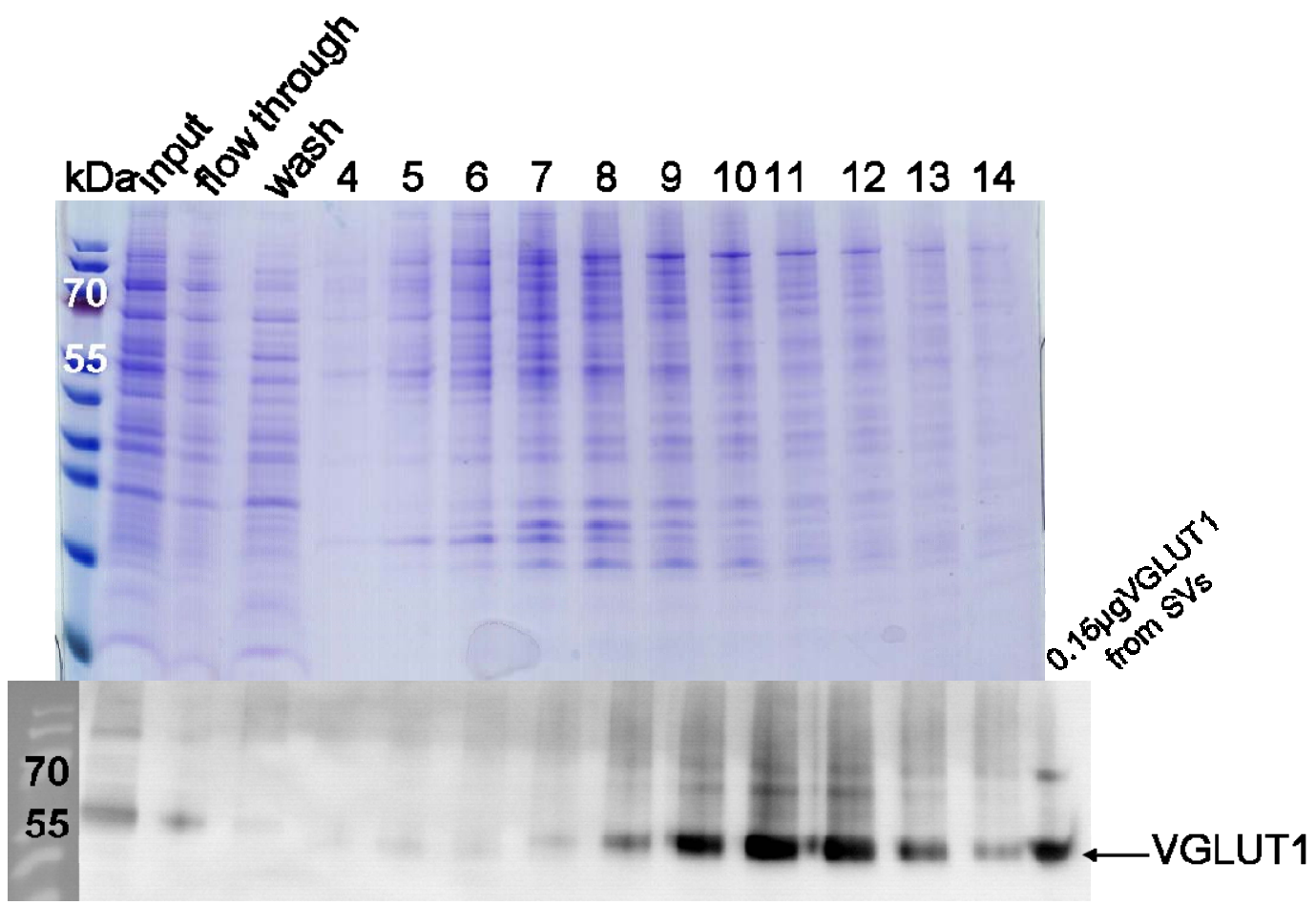

20CVs gradient: 5-500mM Imidazol

Figure 3.12 Purification of $\mathrm{His}_{6}$-tagged VGLUT1 from insect cells. Coomassie blue staining and immunoblot analysis of the elution profile from a HisTrap column using a continuous Imidazole gradient. 1/2000 of input, flow through and wash and 1/50 of the elution fractions (numbered) were loaded. SV VGLUT1 was used to evaluate the amount of protein. 


\subsubsection{Affinity Purification of Streptavidin Binding Peptide (SBP)-tagged VGLUT1}

In 2001, a novel tag with a $2.5 \mathrm{nM}$ affinity to Streptavidin was decribed [84]. The Streptavidin Binding Peptide (SBP)-tag is 38 amino acids long resulting in a molecular weight of $\sim 5 \mathrm{kDa}$, thus, much smaller than alternative tagging methods such as Maltose Binding Protein (MBP, $40 \mathrm{kDa}$ )- or Glutathion S-Transferase (GST, 26 $\mathrm{kDa}$ )-tag which display comparable affinities.

Based on previous reports, affinity purification of SBP-tagged VGLUT1 was attempted [21]. SBP-tagged VGLUT1 expressed similarly well as His-tagged VGLUT1 in insect cells. Direct solubilisation of the cells using $2 \%$ DDM and subsequent incubation with Streptavidin beads resulted in fairly pure elution fractions (fig.3.13a). Maximum yield of protein obtained was $1 \mathrm{mg}$ of insect cell expression culture corresponding to $10 \%$ of total expressed protein and $20 \%$ of the soluble protein fraction.

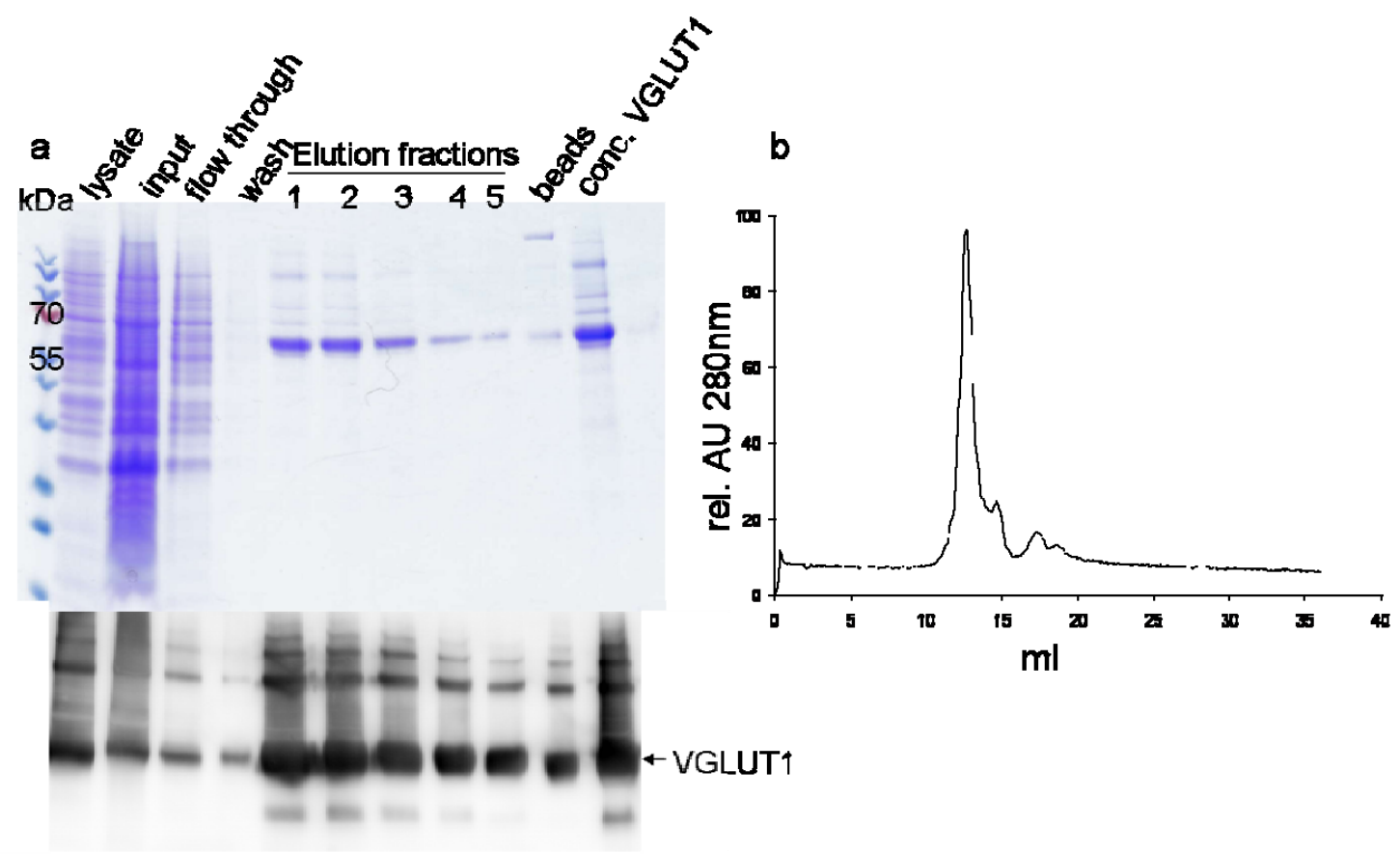

Figure 3.13 Purification of SBP-tagged VGLUT1 from insect cells. (a) Coomassie blue staining and immunoblot of the purification profile using Streptavidin beads. 1/100 of the elution fractions and beads and 1/5000 of the rest fractions was loaded. Concentrated VGLUT1 corresponds to $5 \mu \mathrm{g}$ of protein. (b) Size exclusion chromatography of affinity purified VGLUT1 using a Superdex 75 16/60 column. 
Results

\subsubsection{Size Exclusion Chromatography of VGLUT1}

To evaluate the protein dispersity of VGLUT1 a second purification step with size exclusion chromatography was performed. The elution peak was both symmetrical and sharp indicating a monodisperse protein-detergent complex. [111] (fig.3.13b). For reconstitution experiments, however, the additional purification step was not deemed necessary.

\subsubsection{Expression and Purification of VGLUT1 using Mammalian Cells}

Expression of VGLUT1 in mammalian cells was pursued in the later stages of this work after the activity of VGLUT1 derived from insect cells did not fulfil the requirements for certain measurements (section 3.3.2.5). Expressing a protein in a nearnative environment was expected to result in less protein misfolding and better resemblance of posttranslational modifications.

Experiments with rat VGLUT1 expressed in HEK293 cells were performed earlier [21]. The expression development attempted here was based on this protocol. SBP-VGLUT1 was cloned in the pcDNA6.2 mammalian expression vector. Transfection efficiencies ranged between $20-40 \%$ as monitored by parallel GFP transfection. $\mathrm{Ca}_{3}\left(\mathrm{PO}_{4}\right)_{2}$ is generally less efficient than Lipofectamine (Invitrogen) transfection, which would have been too costly for the required expression scale. Regardless of transfection efficiencies, the expression levels in HEK293 cells were lower than in insect cells, as had been anticipated. A peculiar difference is the band pattern of VGLUT1 where the VGLUT1 band appears more smeared than in insect cells suggesting a different glycosylation pattern. Interestingly, the band pattern of native VGLUT1 corresponds rather to insect cell derived VGLUT1 than to HEK cell derived VGLUT1 (fig.3.14c). HEK cell derived VGLUT1 appeared to be N-glycosylated in contrast to insect cell derived VGLUT1 (fig.3.14c). The maximum yield which could be obtained from 11 of cell culture was $100 \mu \mathrm{g}$, but varied because of differential transfection efficiencies. 

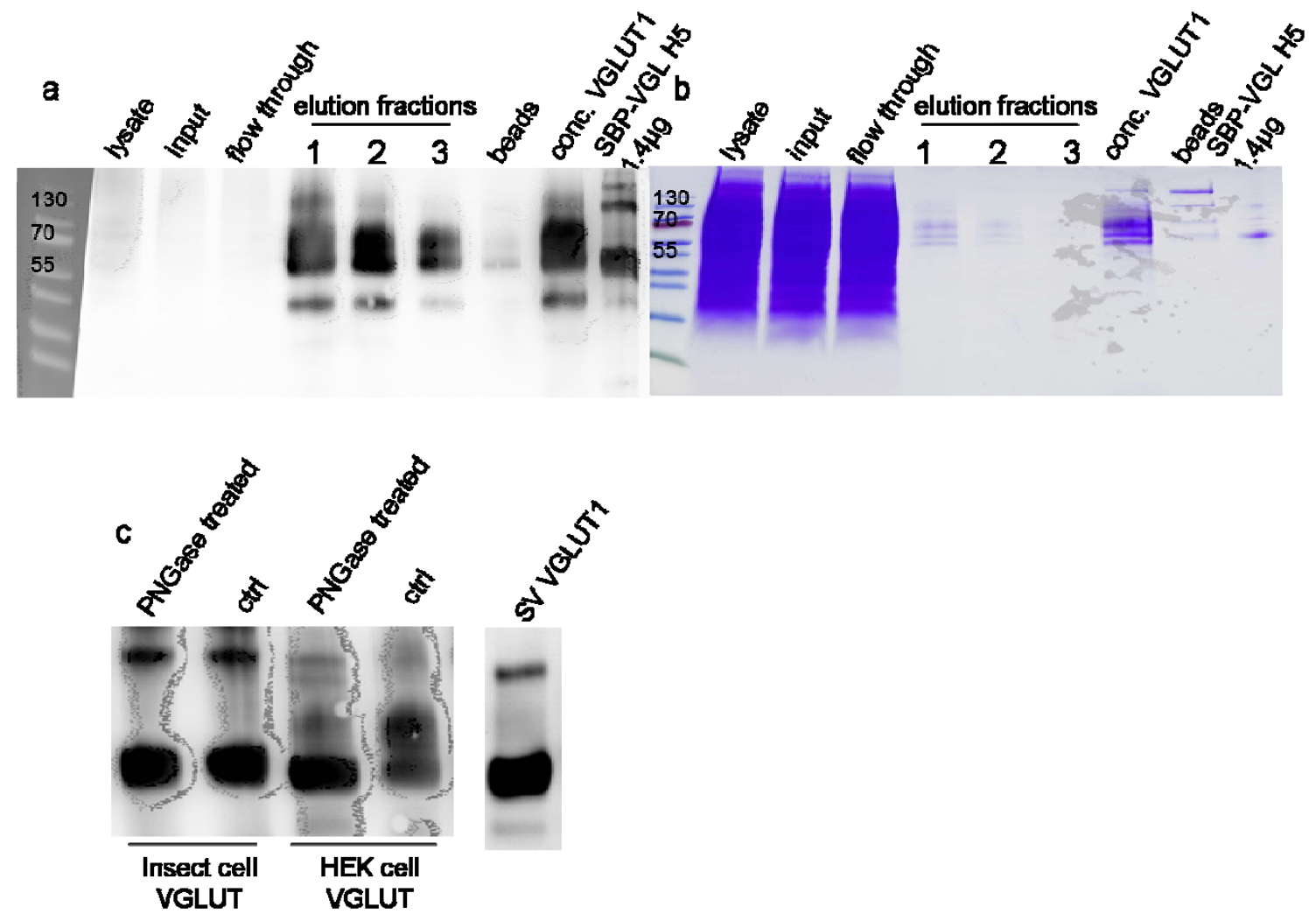

Figure 3.14 Purification of SBP-tagged VGLUT1 from mammalian cells. Immunoblot using a C-terminal antibody (a) and coomassie blue staining (b) of the affinity purification profile of VGLUT1. 1/20 of the elution fractions and beads and 1/5000 of the remaining fractions were loaded. Concentrated VGLUT1 corresponds to $10 \mu \mathrm{g}$ of protein. (c) Peptide N-Glycosidase F (PNGaseF) treated VGLUT1 expressed in insect and mammalian cells compared to untreated (ctrl) and native VGLUT1 from rat SVs. PNGaseF cleaves N-glycans from glycoproteins.

\subsection{Purification of Proton Pumps and Acidification}

Vesicular neurotransmitter transporters are secondarily active requiring an electrochemical gradient $\left(\Delta \mu \mathrm{H}^{+}\right)$to energize neurotransmitter transport. $\Delta \mu \mathrm{H}^{+}$consists of the $\mathrm{pH}$ gradient $(\Delta \mathrm{pH})$ and the membrane potential $(\Delta \Psi)$ formed across the membrane (section 1.4). $\Delta \mu \mathrm{H}^{+}$can be generated by ion gradients in combination with ionophores such as valinomycin or nigericin [112]. Unfortunately, the induced $\Delta \mathrm{pH}$ or $\Delta \Psi$ is short-lived constraining its application. Furthermore, it is possible to use bacteriorhodopsin as a light-driven proton pump [113]. However, due to its light sensitive-activity it is delicate to use for fluorescence based experiments. The most feasible energizing components are bacterial ATP synthases which synthesize ATP from ADP and inorganic phosphate $\left(\mathrm{P}_{\mathrm{i}}\right)$ using a proton gradient. They are highly 
Results

abundant and accessible to purification and in the presence of ATP they generate $\Delta \mu \mathrm{H}^{+}$ by hydrolysing ATP.

\subsubsection{Purification of E.coli ATP Synthase $\left(\mathrm{EF}_{0} \mathrm{~F}_{1}\right)$}

The first proton pump tested was an ATP synthase from E.coli provided by Peter Gräber (University of Freiburg). They routinely use $\mathrm{EF}_{0} \mathrm{~F}_{1}$ to study ATP synthesis rates and have an established purification protocol [114]. A typical elution profile of a $\mathrm{EF}_{0} \mathrm{~F}_{1}$ purification after the last size exclusion chromatography step is depicted in figure $3.15 \mathrm{a}$.

a

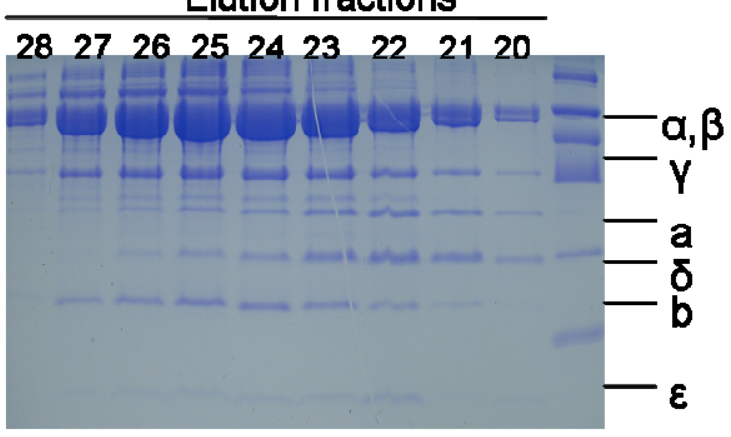

b

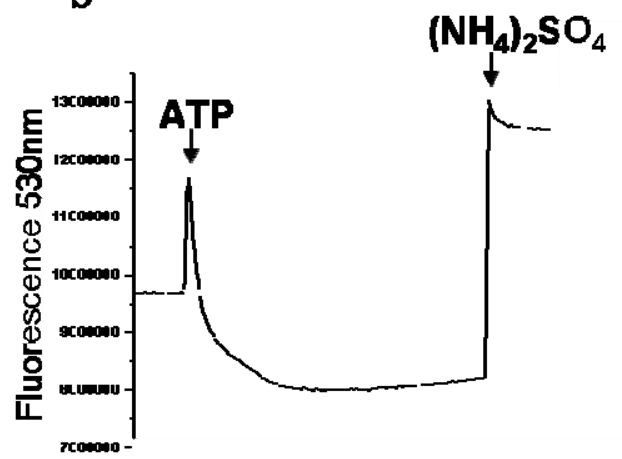

Figure 3.15 Purification and acidification properties of $E_{0} F_{1}$. (a) Elution profile of $E F_{0} F_{1}$ from the final size exclusion step using a Superdex 200 HiLoad 26/600 column. 1/200 of the elution fractions were loaded. (b) Acidification of $\mathrm{EF}_{0} \mathrm{~F}_{1}$ liposomes upon addition of ATP. $\mathrm{NH}_{4}{ }^{+}$ ions form a dynamic equilibrium. $\mathrm{NH}_{4}{ }^{+} \leftrightarrows \mathrm{NH}_{3}+\mathrm{H}^{+}$. Whilst $\mathrm{NH}_{4}{ }^{+}$is not membrane permeable due to its charge $\mathrm{NH}_{3}$ is and therefore diffuses into the $\mathrm{SV}$ lumen where the equilibrium is shifted back to $\mathrm{NH}_{4}{ }^{+}$ions due to $\mathrm{NH}_{3}$ excess neutralising the $\mathrm{pH}$.

\subsubsection{Electrogenic Properties of $\mathrm{EF}_{0} \mathrm{~F}_{1}$ in Reconstituted Liposomes}

$\mathrm{EF}_{0} \mathrm{~F}_{1}$ reconstituted liposomes did not exhibit tight ionic coupling. Bioenergetically, acidification of the liposome lumen upon addition of ATP is arrested due to the lack of a shunt which provides counter ion flux for $\mathrm{H}^{+}$. Thus, a large membrane potential across the liposome membrane is generated (fig. 1.3). Once an ion shunt is present, e.g. valinomycin, an ionophore which is highly selective for $\mathrm{K}^{+}$, a counter ion flux enables $\mathrm{EF}_{0} \mathrm{~F}_{1}$ to acidify the liposome lumen in the presence of luminal 
Results

$\mathrm{K}^{+}$(fig. 1.3). Yet, in $\mathrm{EF}_{0} \mathrm{~F}_{1}$ proteoliposomes a strong acidification was observed even without addition of an ionophore, indicating leakage of the liposomes (fig.3.15b).

\subsubsection{Properties of Liposomes}

In order to find the source of leakage, the properties of $\mathrm{EF}_{0} \mathrm{~F}_{1}$-free liposomes containing VGLUT1 (for reproducibility) were studied in the presence of different ionophores. First, an outwardly directed $\mathrm{K}^{+}$gradient in liposomes was created by encapsulating $\mathrm{K}^{+}$into the liposomes and exchanging the external buffer to $\mathrm{K}^{+}$-free buffer. If the liposomes are impermeable to $\mathrm{K}^{+}$and $\mathrm{H}^{+}$, addition of valinomycin alone will not mediate acidification due to a lack of counter ion flux. As soon as counter ion flux is induced by addition of the $\mathrm{H}^{+}$ionophore Carbonyl cyanide- $p$ trifluoromethoxyphenylhydrazone (FCCP) the $\mathrm{K}^{+}$gradient drives liposome acidification (fig. 3.16b). This was observed by successive addition of the mentioned ionophores (fig.3.17a), strongly indicating that the liposomes are not $\mathrm{K}^{+}$or $\mathrm{H}^{+}$permeable.

Nigericin is a $\mathrm{H}^{+} / \mathrm{K}^{+}$antiporter, merging the function of valinomycin and FCCP. The stability of the signal upon addition of nigericin to liposomes with an outwardly directed $\mathrm{K}^{+}$gradient represents the leakage properties of the liposomes with regard to $\mathrm{K}^{+}$and $\mathrm{H}^{+}$ions. The acidification signal after addition of nigericin in figure $3.17 \mathrm{~b}$ does not realkalinize, further supporting the view that the liposomes are non-leaky.

In addition to the acidification, $\Delta \Psi$ changes were measured in the presence of valinomycin using Oxonol VI as a $\Delta \Psi$-sensitive dye. In intact liposomes with an inwardly directed $\mathrm{K}^{+}$gradient, supplementation with valinomycin forms a stable $\Delta \Psi$ (fig. 3.16). 

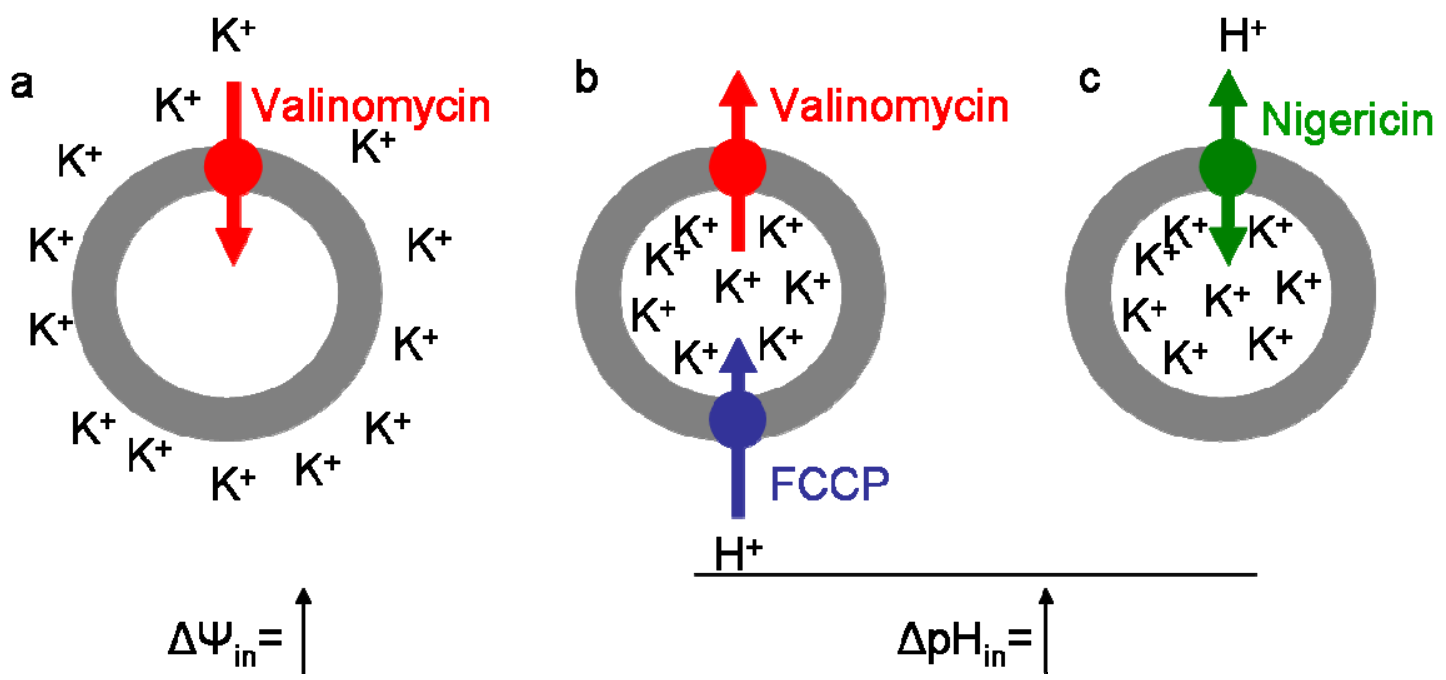

Figure 3.16 Illustration of $\Delta \Psi$ and $\Delta \mathrm{pH}$ formation in liposomes by artificial gradients. a) An inwardly directed $\mathrm{K}^{+}$gradient in the presence of the $\mathrm{K}^{+}$ionophore valinomycin generates an inside positive $\Delta \Psi$ by $\mathrm{K}^{+}$influx. b) An outwardly directed $\mathrm{K}^{+}$gradient in the presence of valinomycin and the $\mathrm{H}^{+}$ionophore FCCP acidifies the liposome lumen by efflux of $\mathrm{K}^{+}$and influx of $\mathrm{H}^{+}$. c) An outwardly directed $\mathrm{K}^{+}$gradient in the presence of the $\mathrm{K}^{+} / \mathrm{H}^{+}$antiporter nigericin evokes acidification of the liposomes by the same principle as in $b$ ).

The stability of the generated $\Delta \Psi$ is thus an indirect way to display the quality of the liposomes. Figure 3.17c-d illustrates the impact of valinomycin concentration on membrane integrity and exhibits a stably maintained $\Delta \Psi$ in liposomes with a certain valinomycin concentration. The performed measurements suggest that liposomes retain their structural integrity meaning that the occurring leakage in $\mathrm{EF}_{0} \mathrm{~F}_{1}$ proteoliposomes is probably caused by the presence of $\mathrm{EF}_{0} \mathrm{~F}_{1}$ and not by any permeability of the membrane. 


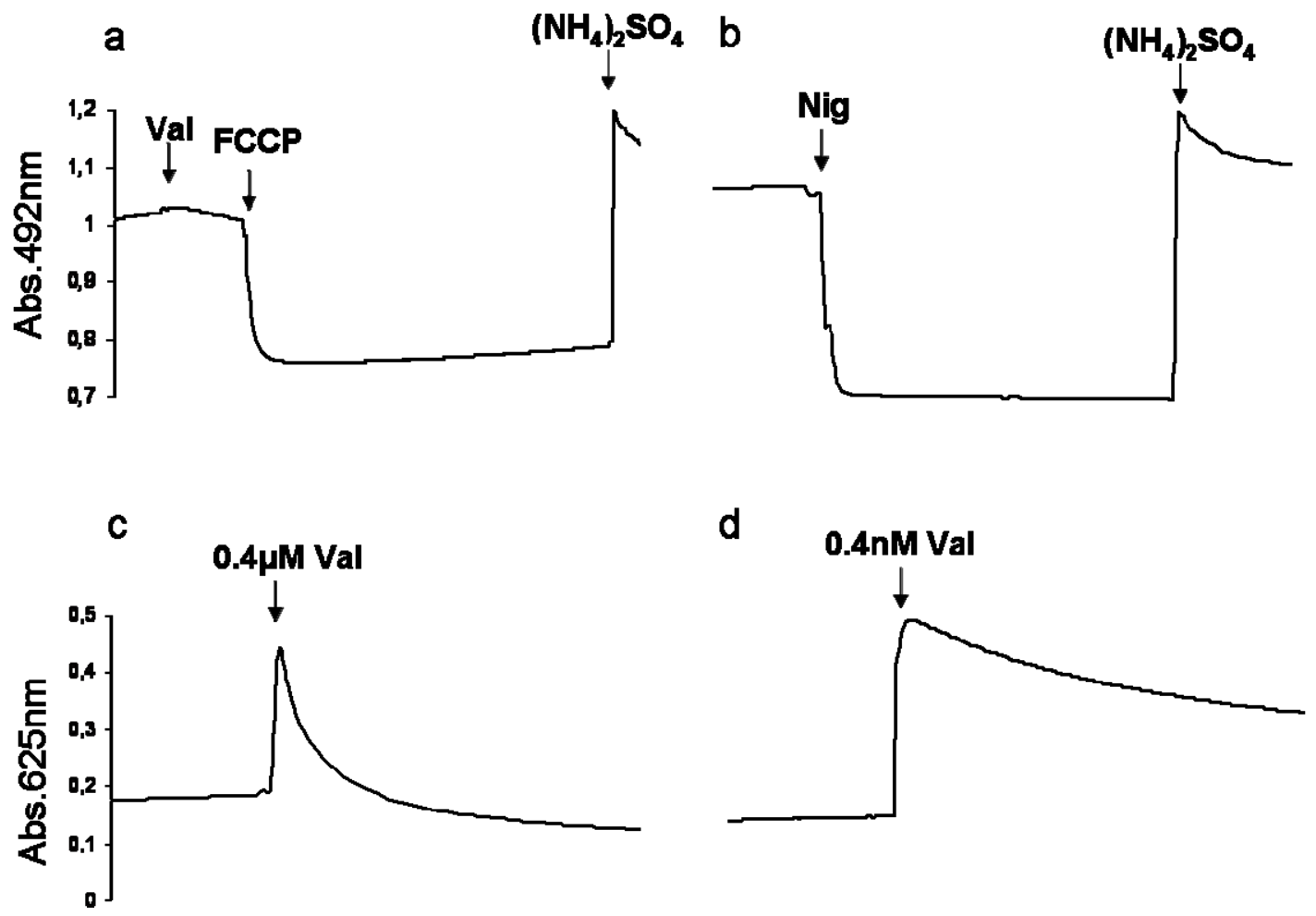

Figure 3.17 Properties of VGLUT1 liposomes regarding ion leakage. (a-b) Acidification of proteoliposomes upon addition of ionophores. (c-d) Membrane potential increase and stability in proteoliposomes with varying concentrations of Valinomycin. VGLUT1 was inserted to exclude leakage originating from VGLUT1. Val= Valinomycin, Nig= Nigericin.

\subsubsection{Purification of His-tagged $F_{0} F_{1} \quad\left(\begin{array}{lllll}\left.T_{0} F_{1}\right) & \text { from Bacillus }\end{array}\right.$ thermophilus}

$\mathrm{EF}_{0} \mathrm{~F}_{1}$ proteoliposomes did not display tight ionic coupling which was required for the $\Delta \mu \mathrm{H}^{+}$based measurements. An alternative approach for the energizing component had to be pursued.

A His ${ }_{6}$-tagged construct of a $\mathrm{F}_{0} \mathrm{~F}_{1}$ ATP synthase from Bacillus thermophilus was previously used as proton pump [21]. The E.coli DK8 strain carrying the pTR19ASDS plasmid was obtained from Masasuke Yoshida (Tokyo Institute of Technology/Japan) [80].

The purification protocol was adapted from [21] In figure 3.18 the elution profiles after affinity purification and anion exchange illustrate highly enriched protein complex, which is separated into its subunits already after the affinity purification step 
Results

and additionally enriched in the subsequent purification steps. One purification typically yielded $\sim 6 \mathrm{mg}$ of protein from 21 of expression culture.

a

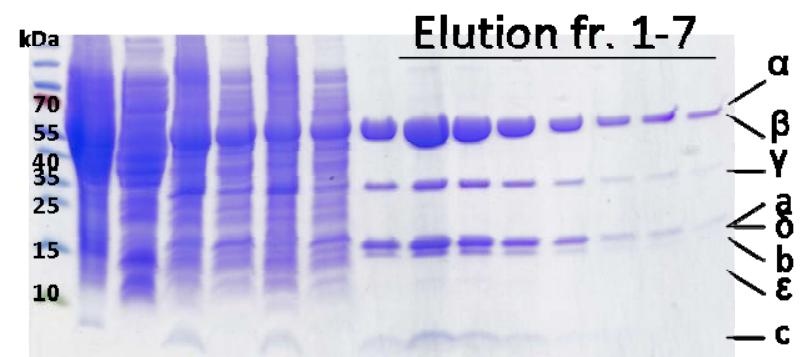

Affinity purification

b

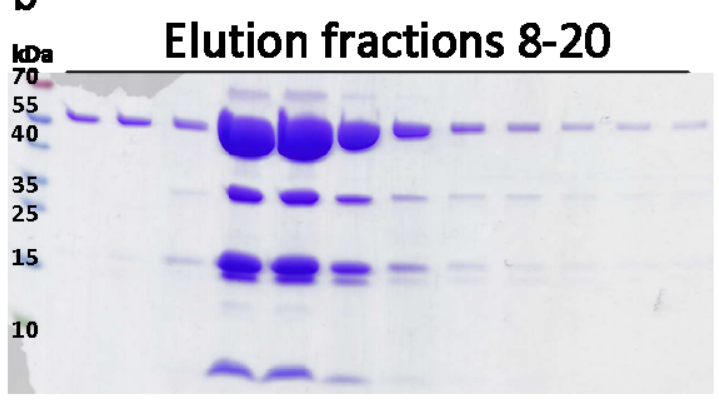

Anion exchange chromatography

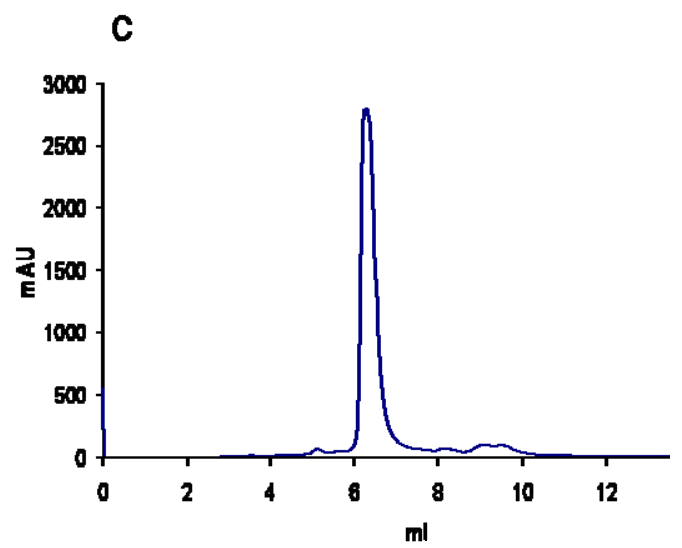

Figure 3.18 Purification of $\mathrm{TF}_{0} \mathrm{~F}_{1}$. (a) Elution profile of $\mathrm{TF}_{0} \mathrm{~F}_{1}$ affinity purification using Talon beads. (b) Coomassie Blue staining of anion exchange chromatography elution fractions using a MonoQ HR5/5 column. (c) Elution profile of the anion exchange chromatography. Absorbance at $280 \mathrm{~nm}$ was measured.

\subsubsection{Electrogenic Properties of $\mathrm{TF}_{0} \mathrm{~F}_{1}$}

Reconstitution of $\mathrm{TF}_{0} \mathrm{~F}_{1}$ into liposomes and subsequent activity analysis revealed that activity and impermeability properties were excellent. $\mathrm{TF}_{0} \mathrm{~F}_{1}$ did not acidify the liposomes until the addition of valinomycin which permits an efflux of $\mathrm{K}^{+}$(fig 3.19). This further confirmed the integrity of the generated proteoliposomes. 

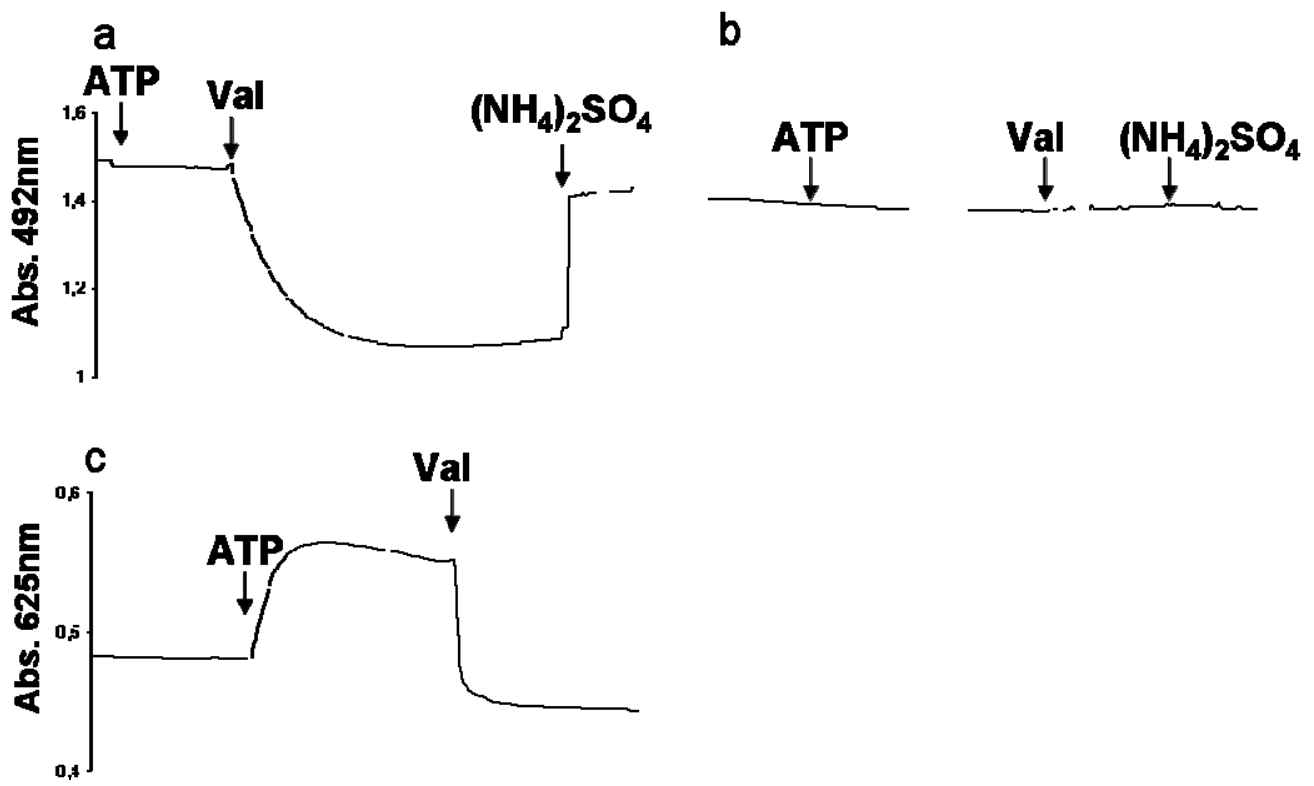

Figure 3.19 Activity of $\mathrm{TF}_{0} \mathrm{~F}_{1}$ proteoliposomes. (a-b) Acidification upon addition of ATP and Valinomycin in $+\mathrm{TF}_{0} \mathrm{~F}_{1}$ (a) and $-\mathrm{TF}_{0} \mathrm{~F}_{1}$ (b) liposomes. (c) Membrane potential response to ATP and Valinomycin in $\mathrm{TF}_{0} \mathrm{~F}_{1}$ liposomes. Val= Valinomycin.

\subsection{Co-Reconstitution of VGLUT1 Derived from Insect Cells and $\mathrm{TF}_{0} \mathrm{~F}_{1}$}

After successfully purifying VGLUT1 from insect cells and acquiring a fully functional proton pump co-reconstitution into liposomes was next attempted. Distinct techniques have been established to produce proteoliposomes. Essentially, there are two approaches which can be pursued. One is to use preformed liposomes which are supplemented in a second step with proteins and detergent for direct insertion into the bilayer (direct method), while the second consists of mixing lipids, proteins and detergent followed by removal of the detergent giving rise to spontaneous insertion and liposome formation (co-micellisation method) [86].

Depending on the detergent, it can either be removed by dilution (e.g. dialysis) or by size exclusion chromatography. BioBeads are macroporous adsorbents with a high surface area and can also be used for detergent removal [110].

For co-reconstitution into liposomes with VGLUT1 and $\mathrm{TF}_{0} \mathrm{~F}_{1}$ the presence of DDM in the protein stock solution has to be taken into account. DDM cannot be readily removed by dialysis due to its low $\mathrm{cmc}$ and high aggregation number. However, 
Results

BioBeads are capable of adsorbing DDM and cyclodextrin, a cyclic oligosaccharide, has been reported to complex DDM [87].

Lipids were dissolved in n-octyl- $\beta$-D-glucopyranosid (OG), a short chain nonionic detergent that, used in higher concentrations, can harm the biological activity of proteins. For co-reconstitution purposes the concentration therefore needed to be kept as low as possible.

Biological membranes are mainly composed of Phosphatidylcholine (PC), the most abundant phospholipid, Phosphatidylserine (PS), Phosphatidylethanolamine (PE), Phosphatidylinositols (PIs) and Cholesterol. The lipid composition shapes the bilayer architecture and can therefore dramatically affect protein structure and function [115]. The ideal liposome composition would mimic the native environment of the protein although the presence of lipid microdomains makes it difficult to actually determine the "native" environment of a specific protein.

For experimental applications synthetic lipids mimicking natural phospholipids are available. The benefit of synthetic lipids is the chemical consistency whereas natural lipid extracts exhibit differences that are preparation-dependent.

\subsubsection{Co-Reconstitution of VGLUT1 and $\mathrm{TF}_{0} \mathrm{~F}_{1}$ by the Co- Micellisation Method with Lipids from Soybean Extract}

Initially, liposomes were formed by the co-micellisation method using lipid extract from soybeans (containing mainly PC) and cholesterol in a ratio of 80:20. The protein:lipid ratios were adjusted to $1: 25$ for VGLUT1 and 1:50 for $\mathrm{TF}_{0} \mathrm{~F}_{1}$ [21]. Lipid stocks dissolved in OG and proteins dissolved in DDM were mixed and detergent was removed by dialysis and addition of spheric macroporous adsorbens (BioBeads) to enhance detergent removal. After complete removal of $\mathrm{OG}$, proteoliposomes were supplemented with cyclodextrin to complex residual DDM. The resulting proteoliposomes were then characterized with regard to incorporation efficiency, orientation of the proteins and size distribution. 


\subsubsection{Incorporation of Proteins into Liposomes Generated by the Co- Micellisation Method}

Incorporation efficiency was determined by centrifuging the proteoliposomes at high $\mathrm{g}$ forces in a density gradient and determining the fraction of protein that co-floated along with the low-density liposomes, while any unincorporated protein remains at the bottom of the gradient due to its higher density. VGLUT1 incorporated efficiently into liposomes most likely due to its strong hydrophobic character (fig. 3.20). Nonetheless, although care was taken to remove detergent as completely as possible, the presence of remaining detergent micelles cannot be fully excluded.

$\mathrm{TF}_{0} \mathrm{~F}_{1}$ incorporation was likewise successful. Western blot analysis directed against the $\beta$-subunit of $\mathrm{TF}_{0} \mathrm{~F}_{1}$ confirmed that it co-floated with the liposome fractions. Interestingly, in the corresponding coomassie stain a band was observed throughout the entire density gradient, supposedly representing the detached headgroup of $\mathrm{TF}_{0} \mathrm{~F}_{1}$ (fig. $3.20)$.

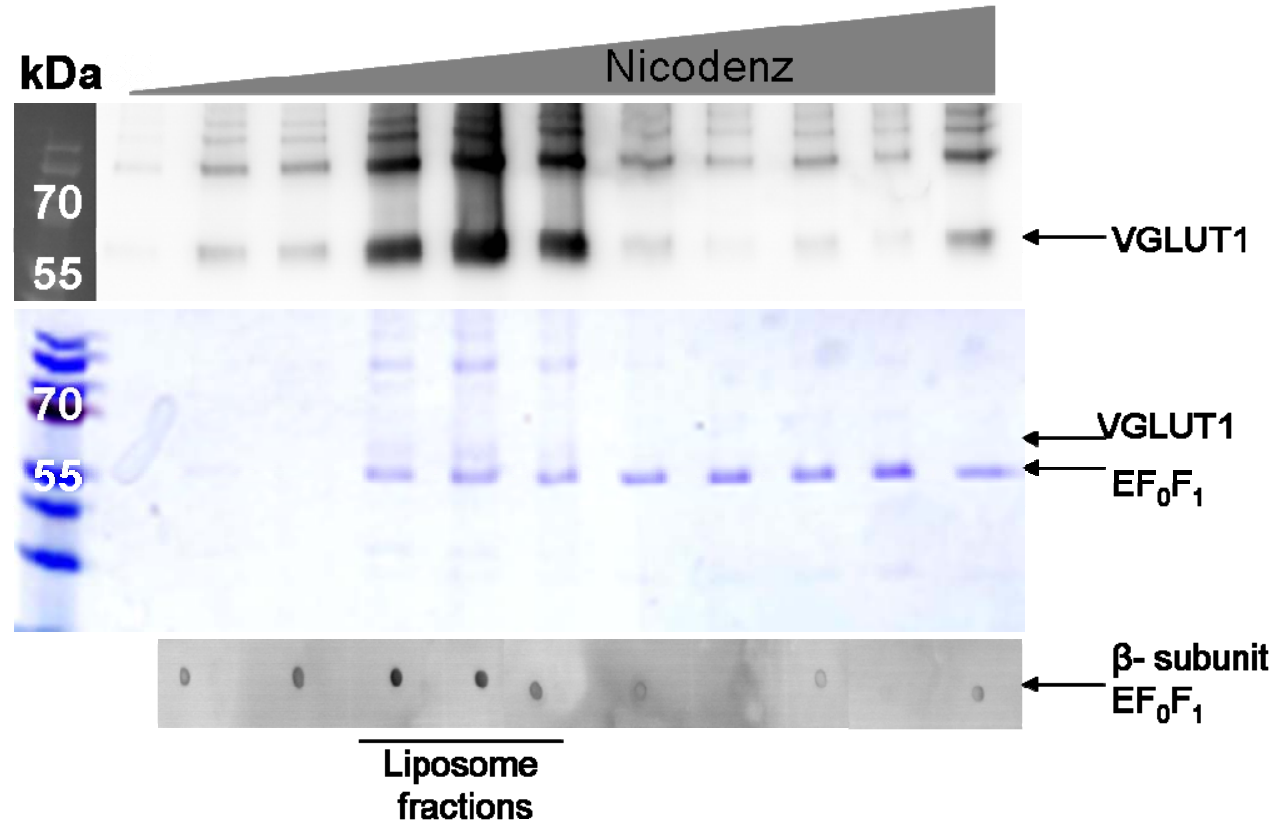

Figure 3.20 Co-flotation analysis of $\mathrm{VGLUT1}_{1} / \mathrm{TF}_{0} \mathrm{~F}_{1}$ liposomes generated by the comicellisation method. Equal volumes of gradient fractions were loaded and detected for VGLUT1 and $\mathrm{TF}_{0} \mathrm{~F}_{1}$ using immunoblot and coomassie blue stain analysis. Liposome fractions were identified by a turbid ring forming at the top of the gradient. 


\subsubsection{Orientation of Proteins in Liposomes Generated by the Co- Micellisation Method}

The right-side out orientation of the MPs is crucial for their proper function. The composition of lipids as well as the type and concentration of detergent, can affect the final orientation. To check for orientation, VGLUT1 liposomes were trypsinised and detected with an antibody directed against the C-terminus. If VGLUT1 tails are oriented into the liposome lumen (inside out orientation), the bilayer will protect the epitope and the signal will still be detectable. However, if the tails are oriented right-side out, trypsin will cleave the epitope and the signal vanishes. In liposomes digested by trypsin no VGLUT1 signal was detectable indicating that the protein is entirely inserted in the right-side out direction (fig. 3.21a). Partial influx of trypsin into the liposome cannot be fully excluded, however, the integrity of the generated liposomes towards several ions (section 3.2.3) suggests this is unlikely.

Right-side out orientation of $\mathrm{TF}_{0} \mathrm{~F}_{1}$ was determined by liposome acidification measurements as described in section 3.2.5.

\subsubsection{Size Distribution in Liposomes Generated by the Co-Micellisation Method}

Liposome size distribution was quantitatively analysed by Field Flow Fractionation coupled to Multi-Angle laser light scattering (FFF-MALLS) and qualitatively by electron microscopy (fig. 3.21b-c). The peak diameter of the liposomes determined by FFF was $160 \mathrm{~nm}$. Electron microscopy revealed a very broad size range of the formed liposomes from 50-300 $\mathrm{nm}$. Moreover, it is possible to see the headgroups of the $\mathrm{TF}_{0} \mathrm{~F}_{1}$ located on the membranes which are partially inhomogeneously distributed on the liposome surface. 
a

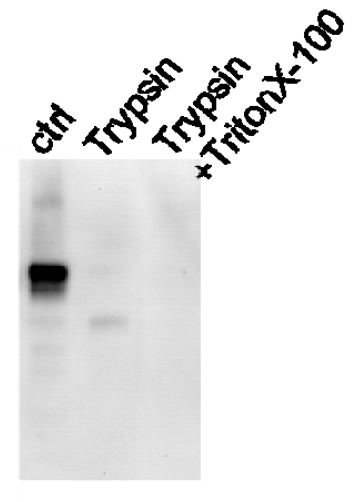

b
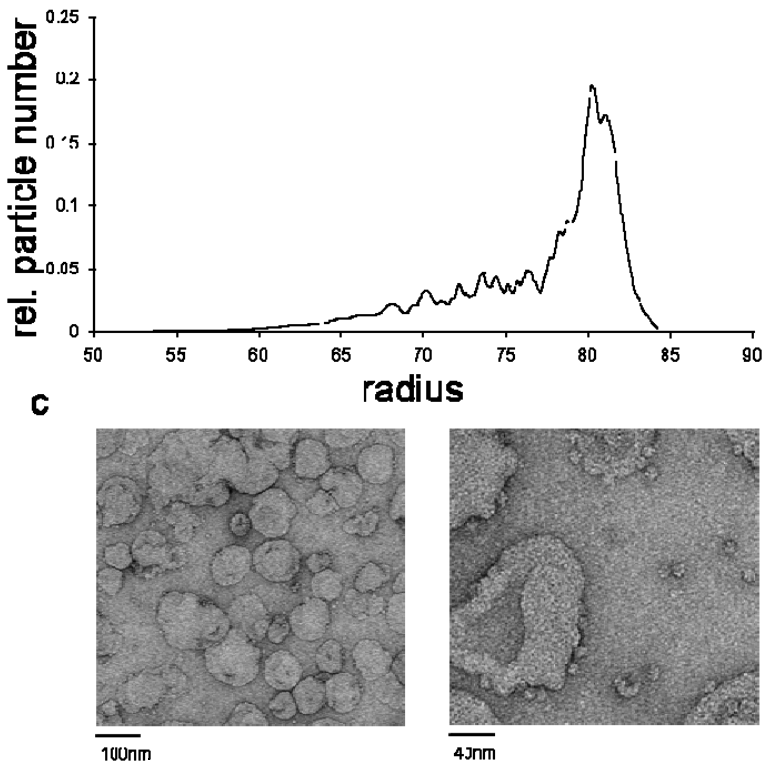

Figure 3.21 Characterisation of liposomes containing VGLUT1 derived from insect cells and $\mathrm{TF}_{0} \mathrm{~F}_{1}$ generated by the co-micellisation method. (a) Orientation study of VGLUT1 by trypsinisation of the proteoliposomes. Control liposomes do not contain any Trypsin and the Trypsin+TritonX-100 lane represents full digestion of solubilised VGLUT1 liposomes. (b) Size distribution of proteoliposomes determined by FFF-MALLS. (c) Electron microscopy images of soybean extract proteoliposomes.

\subsubsection{Glutamate Uptake as Control of Proper Orientation and Biological} Activity of VGLUT1 in Liposomes Generated by the Co-Micellisation

\section{Method}

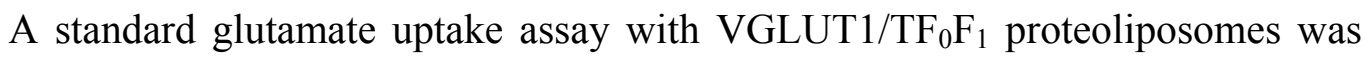
performed in order to determine the activity of VGLUT1. An approximate 3-fold accumulation of ${ }^{3} \mathrm{H}$-Glutamate in liposomes containing VGLUT1 was observed, strongly suggesting that recombinant VGLUT1 derived from insect cells is capable of mediating glutamate translocation. 


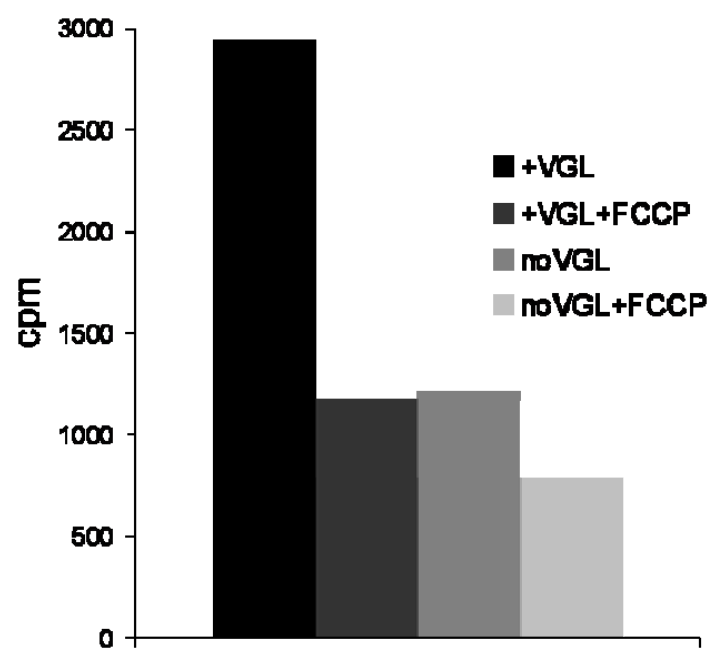

Figure 3.22 Glutamate uptake by insect cell expressed VGLUT1/TF $F_{0} F_{1}$ proteoliposomes. Glutamate uptake under standard conditions (see Methods) into soybean extract liposomes with or without VGLUT1 and in the presence of the $\mathrm{H}^{+}$ionophore FCCP. $10 \mu \mathrm{g}$ of VGLUT1 were assayed per datapoint.

\subsubsection{Co-Reconstitution of VGLUT1 and $\mathrm{TF}_{0} \mathrm{~F}_{1}$ by the Direct Method with Synthetic Lipids}

As an alternative reconstitution method liposomes were generated by the direct method with a defined diameter and lipid composition. This method allows studying effects related to the liposome diameter. Most notably, using a defined lipid composition the relevance of single lipid components to liposome properties and protein function can be estimated and the reproducibility of experiments is elevated.

On that account, preformed liposomes with a uniform size distribution of 100 $\mathrm{nm}$ (refer to methods) were used in an attempt to directly incorporate proteins. Furthermore, well-defined synthetic instead of crude soybean lipids were used with varying compositions of 1,2-dioleoyl-sn-glycero-3-phosphocholine (DOPC), 1,2dioleoyl-sn-glycero-3-phospho-L-serine (DOPS) and Cholesterol.

Preformed liposomes were permeabilised to facilitate incorporation of VGLUT1 and $\mathrm{TF}_{0} \mathrm{~F}_{1}$ using $\mathrm{OG}$ followed by detergent removal as described in section 3.3.1. Size and incorporation efficiency of the proteoliposomes was then determined. 


\subsubsection{Incorporation of Proteins into Liposomes Generated by the Direct} Method

Incorporation efficiency in preformed liposomes with altering DOPC/DOPS/Chol ratios was analysed using density gradient centrifugation as described in section 1.3.1.1. VGLUT1 was inserted efficiently into the liposomes independently of the lipid composition (fig.3.23). Incorporation of $\mathrm{TF}_{0} \mathrm{~F}_{1}$ was determined indirectly by acidification measurements.

a

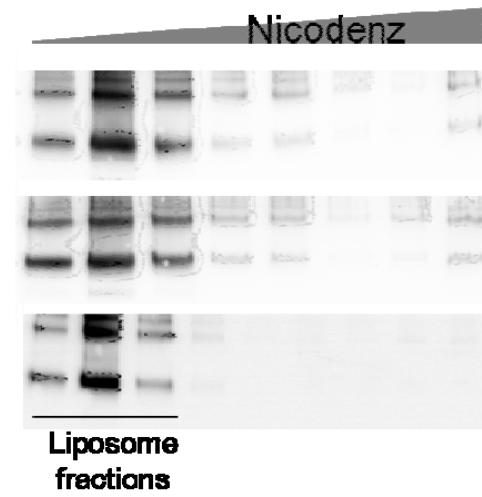

b

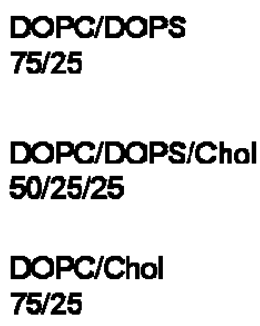

$75 / 25$

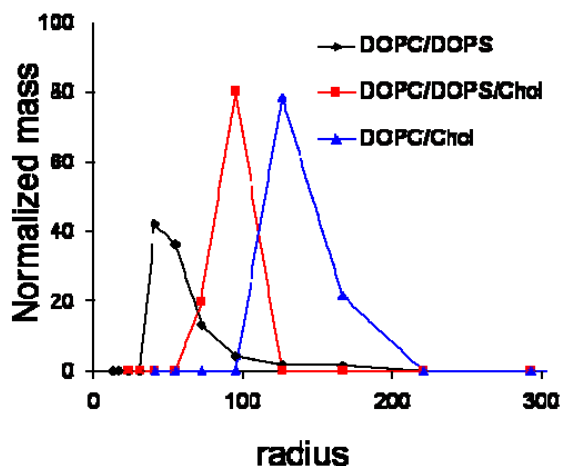

Figure 3.23 Reconstitution efficiency of VGLUT1 in preformed liposomes and size distribution of VGLUT1/TF $F_{0} F_{1}$ proteoliposomes. (a) Insertion efficiency of VGLUT1 into preformed synthetic lipid liposomes depending on the lipid composition analysed by co-flotation. (b) Proteoliposome size distribution of varying lipid compositions as measured by dynamic light scattering (DLS).

\subsubsection{Orientation of VGLUT1 in Proteoliposomes Generated by the Direct Method}

The orientation of VGLUT1 in liposomes of varying lipid compositions was analysed by trypsinisation and subsequent detection of the remaining epitope (fig 3.24). Interestingly, the insertion orientation seems to be slightly affected by the lipid composition. In liposomes without DOPS, VGLUT1 incorporates with inside-out orientation to some extent, however, the difference was considered to be largely negligible. 


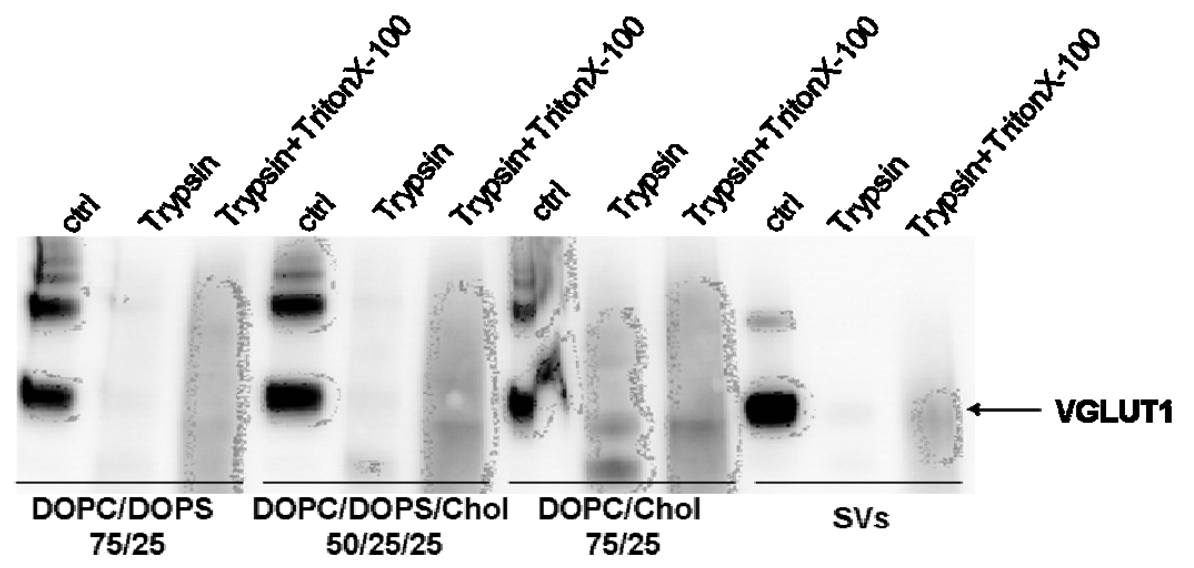

Figure 3.24 Orientation of VGLUT1 in liposomes generated by the direct method. Proteoliposomes prepared from synthetic lipids were digested with trypsin in the absence and presence of TritonX-100. In proteoliposomes without PS, a small amount of VGLUT1 is not trypsinated, indicating it is oriented in the inside-out direction.

\subsubsection{Size Distribution of Proteoliposomes Generated by the Direct Method}

The size of the liposomes was determined by Dynamic Light Scattering (DLS), an alternative method to determine liposome diameter. The diameter of the proteoliposomes was found to be always larger than the initial diameter of the preformed liposomes and strongly depended on the detergent (OG) concentration used. This dependence can be rationalised in terms of the $\mathrm{R}$ value, representing the ratio of detergent molecules in excess of the cmc to the number of lipid molecules:

$$
\mathrm{R}=([\text { detergent }]-[\mathrm{cmc}]) /[\text { lipids }]
$$

An $\mathrm{R}$ value of 1 produced proteoliposomes of a size closest to the original $100 \mathrm{~nm}$ (fig.3.23b) and was sufficient to insert VGLUT1. OG concentration had to be kept low for maintaining maximal protein activity. In figure 3.23 average liposome radii for varying lipid compositions are depicted. Liposome radius is increasing with addition of Cholesterol and removal of DOPS. Most likely decreasing DOPS headgroupheadgroup resulsion evokes clustering of liposomes. 


\subsubsection{Glutamate Uptake as Control of Proper Insertion of VGLUT1 in Liposomes Generated by the Direct Method}

VGLUT1 inserted in preformed liposomes composed of synthetic lipids maintained its glutamate transport activity. In figure 3.25 the dependence of glutamate transport on lipid composition is depicted. The most striking finding is that VGLUT1 does not exhibit glutamate transport activity in the absence of Cholesterol.
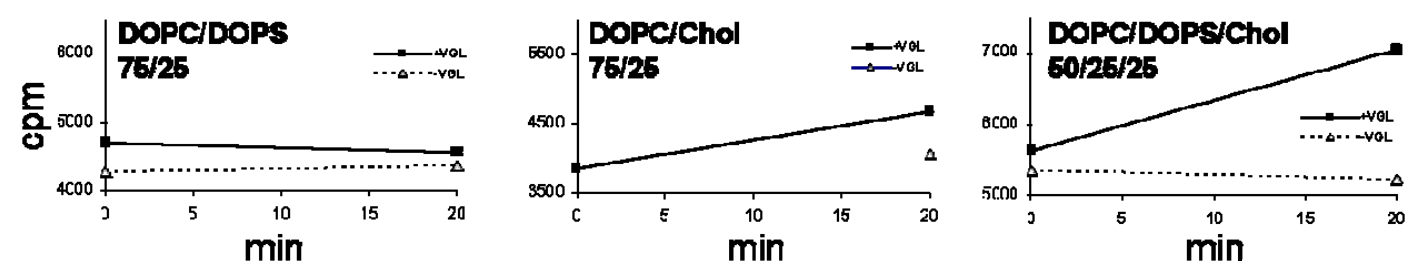

Figure 3.25 Glutamate translocation in $\mathrm{VGLUT}_{1 / T F_{0}} \mathrm{~F}_{1}$ liposomes generated by the direct method using synthetic lipids. (a-c) Time course of glutamate uptake in +/- VGLUT1

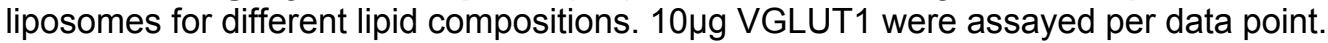

\subsubsection{5 $\mathrm{Cl}^{-}$Conductance of $\mathrm{VGLUT1} / \mathrm{TF}_{\mathbf{0}} \mathrm{F}_{1}$ Proteoliposomes}

Recently, $\mathrm{Cl}^{-}$conductance by VGLUT1 in reconstituted liposomes has been shown [21]. By contrast, another work was published in which $\mathrm{Cl}^{-}$transport by VGLUT1 reconstituted in liposomes was not observed [74]. To clarify the conflicting results $\mathrm{Cl}^{-}$conductance by VGLUT1 was investigated using VGLUT1 liposomes containing $\mathrm{TF}_{0} \mathrm{~F}_{1}$. This was attempted by monitoring $\mathrm{Cl}^{-}$dependent acidification of the proteoliposome lumen in the presence of the $\mathrm{pH}$ sensitive dye acridine orange. If VGLUT1 was permeable to $\mathrm{Cl}^{-}$, supplementation with $\mathrm{Cl}^{-}$should promote acidification of the lumen by providing counter ions for $\mathrm{H}^{+}$. However, no $\mathrm{Cl}^{-}$induced acidification in liposomes containing VGLUT1 was observed (fig. 3.26). The measurements were conducted in $\mathrm{K}^{+}$containing buffer $\left(\left[\mathrm{K}^{+}\right]_{\text {in }}=\left[\mathrm{K}^{+}\right]_{\text {out }}\right)$ allowing determination of $\mathrm{TF}_{0} \mathrm{~F}_{1}$ activity by supplementing the liposomes with valinomycin, thus facilitating exchange of luminal $\mathrm{K}^{+}$for $\mathrm{H}^{+}$from $\mathrm{TF}_{0} \mathrm{~F}_{1}$. Taken together, $\mathrm{TF}_{0} \mathrm{~F}_{1}$ liposomes with VGLUT1 derived from insect cells did not exhibit any $\mathrm{Cl}^{-}$conductance. 


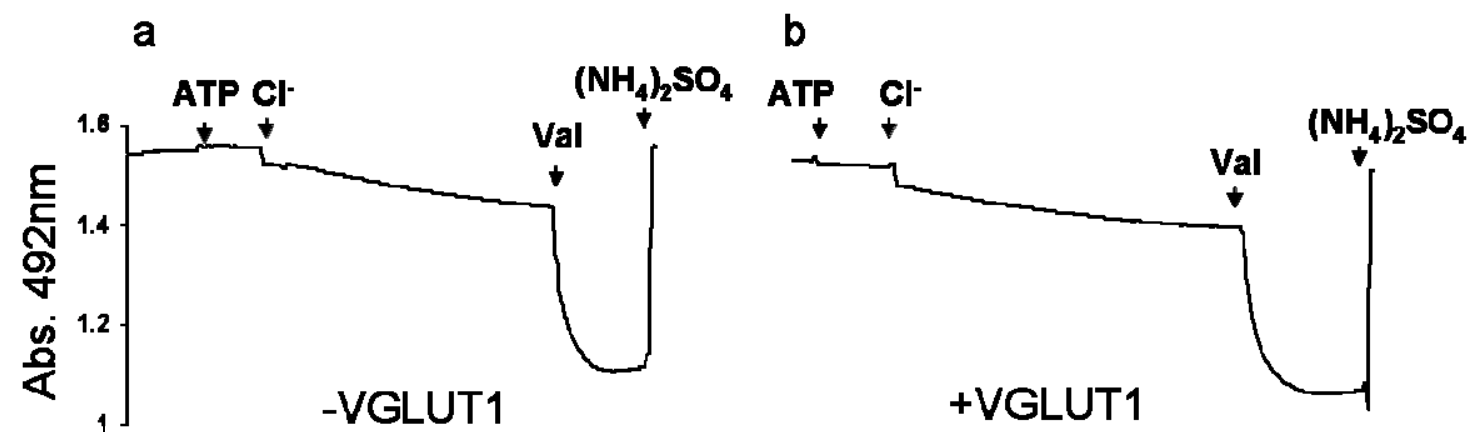

Figure $3.26 \mathrm{Cl}^{-}$dependent acidification of VGLUT1 liposomes. (a-b) $\mathrm{Cl}^{-}$induced acidification in liposomes lacking (a) and containing (b) VGLUT1. $\mathrm{TF}_{0} \mathrm{~F}_{1}$ activity control was determined by subsequent addition of valinomycin.

\subsubsection{Dependence of Glutamate Uptake on Luminal $\mathrm{Cl}^{-}$}

A strong enhancement of glutamate uptake in $\mathrm{VGLUT1} / \mathrm{TF}_{0} \mathrm{~F}_{1}$ proteoliposomes in the presence of high luminal $\mathrm{Cl}^{-}$has been previously shown (section 1.5.5) [21]. High luminal $\mathrm{Cl}^{-}$concentration originating from endocytosis of $\mathrm{SVs}$ is physiologically relevant and would promote glutamate uptake. In the $\mathrm{VGLUT}_{1} / \mathrm{TF}_{0} \mathrm{~F}_{1}$ in vitro system without the presence of $\mathrm{Cl}^{-}$channels an enhancement of glutamate uptake strongly implicates $\mathrm{Cl}^{-}$transport by VGLUT1. However, any enhancing effect mediated by luminal $\mathrm{Cl}^{-}$was not observed in this study (fig. 3.27). This further disagrees with the role of $\mathrm{Cl}^{-}$conductance by VGLUT1 but not necessarily the effect of luminal $\mathrm{Cl}^{-}$on glutamate uptake in $\mathrm{SVs}$ where the $\mathrm{Cl}^{-}$conductance is mediated by $\mathrm{Cl}^{-}$channels such as ClC3 [116]. The luminal composition of isolated SVs is largely unknown and difficult to manipulate, making studies investigating the effect of luminal content on glutamate uptake challenging. 
Results

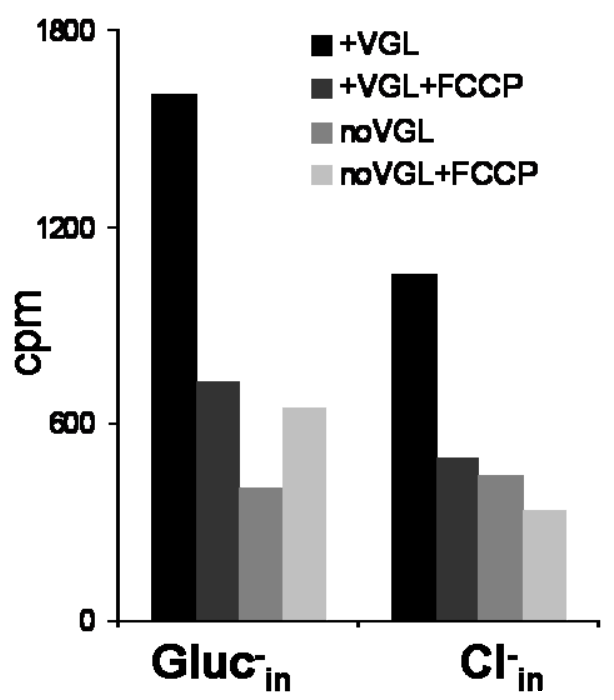

Figure 3.27 Glutamate uptake in the presence and absence of luminal chloride. Glutamate uptake of +/- VGLUT1 proteoliposomes with high or no luminal chloride and in presence and

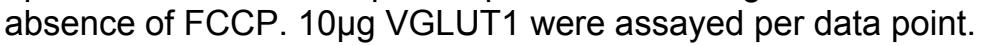

\subsection{Co-Reconstitution of VGLUT1 from Mammalian Cells and $\mathrm{TF}_{0} \mathrm{~F}_{1}$}

In the previous sections (3.3.2.4-3.3.2.6) it was shown that VGLUT1 derived from insect cells exhibited glutamate uptake activity but no $\mathrm{Cl}^{-}$conductance, in contrast to [21] but also in agreement with [74] previous reports. Nevertheless, in order to rule out a lack of activity in insect cell derived VGLUT1 it was additionally expressed and purified from mammalian cells (fig. 3.14) as processing of mouse VGLUT1 in mammalian cells was anticipated to rather resemble native posttranslational modifications and protein folding.

\subsubsection{Co-reconstitution of VGLUT1 and $\mathrm{TF}_{0} \mathrm{~F}_{1}$ by the Direct Method with Synthetic Lipids}

Mammalian cell-derived VGLUT1 was reconstituted in liposomes by the direct method using synthetic lipids as decribed in 3.3.2. 


\subsubsection{Characterisation of Liposomes Containing VGLUT1 Derived from Mammalian Cells and $\mathrm{TF}_{0} \mathrm{~F}_{1}$ Generated by the Direct Method}

Figure 3.28a shows VGLUT1 insertion efficiency of approximately 95\%. Orientation study was performed following the same procedure as in chapter 3.3.1. Right side out direction of VGLUT1 is displayed in figure $3.28 \mathrm{~b}$. The average diameter of the VGLUT1/TF $\mathrm{F}_{1}$ proteoliposomes was determined using DLS (fig. 3.28c).

\subsubsection{Glutamate Uptake in Liposomes Containing VGLUT1 Derived from Mammalian Cells and TF0F1 as Control of VGLUT1 Activity}

Unlike expected, glutamate uptake of the liposomes containing mammalian cell derived VGLUT1 lagged behind the uptake by insect cell-derived VGLUT1 (fig.3.28d). Ultimately, using mammalian cell-derived VGLUT1 glutamate uptake and $\mathrm{Cl}^{-}$ dependent acidification were not improved compared to insect cell derived VGLUT1.

a

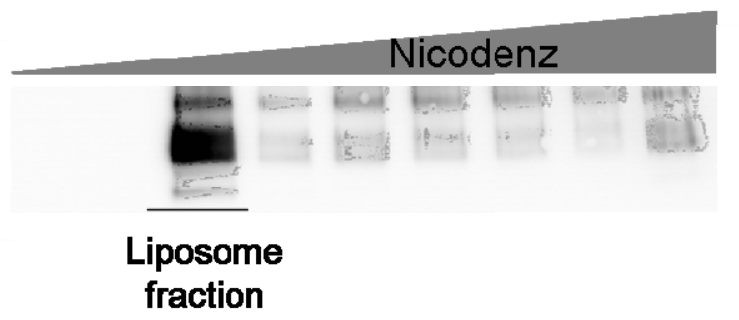

C

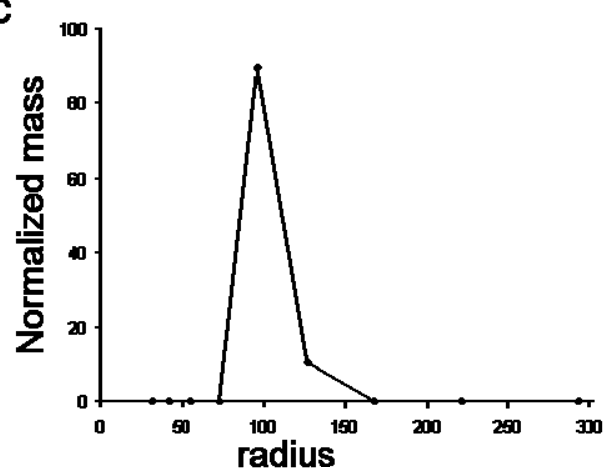

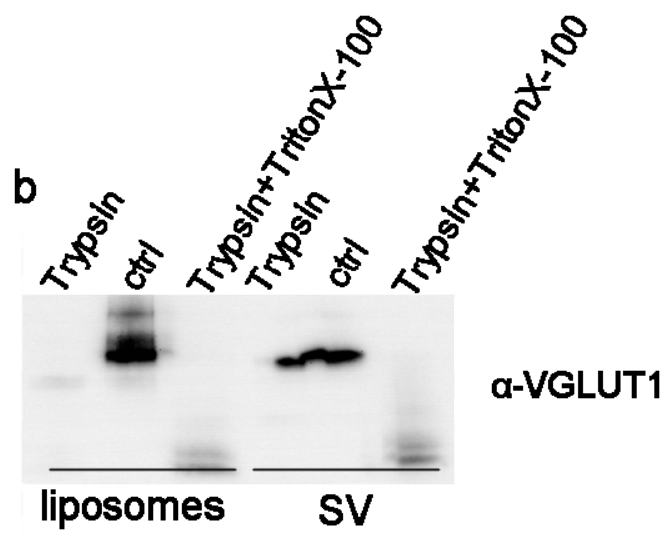

d

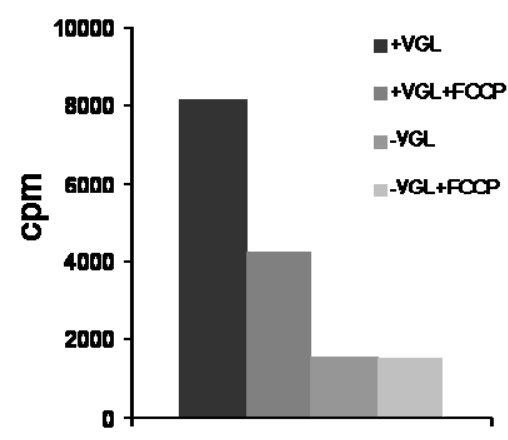

Figure 3.28 Characterisation of liposomes containing mammalian cell expressed VGLUT1 and $\mathrm{TF}_{0} \mathbf{F}_{1}$. (a) Insertion efficiency of VGLUT1 into preformed liposomes with DOPC/DOPS/Chol 50/25/25 for $\mathrm{R}=1$. (b) Orientation analysis of VGLUT1 by Trypsinisation. Trypsin+TritonX-100 represents the fully digested VGLUT1 epitope (right and wrong side orientation) and Trypsin only represents the portion of 
VGLUT1 epitopes pointing outwards (right side orientation). (c) Size distribution of proteoliposomes determined by DLS. (d) Glutamate accumulation in +/- VGLUT1 liposomes in the presence and

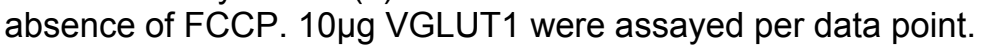

\subsection{Identification of a Putative $\mathrm{K}^{+} / \mathrm{H}^{+}$Exchanger Affecting the Bioenergetics of Glutamate Transport}

Recently, a novel finding regarding the glutamate loading mechanism was reported [76], with various data suggesting that a vesicular $\mathrm{K}^{+} / \mathrm{H}^{+}$exchanger promotes glutamate uptake. However, the exchange mediating molecule could not be identified with certainty although $\mathrm{Na}^{+} / \mathrm{H}^{+}$exchangers (NHEs) 6 and 9 as putative candidates have been proposed. The exchange of luminal $\mathrm{H}^{+}$for cytosolic $\mathrm{K}^{+}$on SVs can increase $\Delta \Psi$ generated across the vesicle membrane and therefore enhance glutamate uptake which is mainly dependent on $\Delta \Psi$. Thus, it was attempted to study $\mathrm{K}^{+} / \mathrm{H}^{+}$exchange and to identify the putative exchanger.

\subsubsection{Changes in SV $\Delta \mathrm{pH}$ Evoked by Monovalent Cations}

A $\mathrm{K}^{+} / \mathrm{H}^{+}$exchange mechanism on $\mathrm{SVs}$ is expected to affect $\Delta \mu \mathrm{H}^{+}$. In order to investigate the presence of $\mathrm{K}^{+} / \mathrm{H}^{+}$exchange on $\mathrm{SVs}$, the effect of monovalent cations on $\Delta \mathrm{pH}$ was analysed in an environment free of monovalent cations. For this, $\mathrm{Na}^{+}, \mathrm{K}^{+}$and Choline $^{+}$dependent changes in luminal $\mathrm{pH}$ using acridine orange as $\mathrm{pH}$ sensitive dye (method described in 2.2.6) were monitored. A decrease in acridine orange absorbance at $492 \mathrm{~nm}$ represents $\mathrm{pH}$ drop in the SV lumen. Initially, $\mathrm{SVs}$ displayed $\mathrm{Cl}^{-}$and glutamate dependent acidification suggesting proper activity. Strikingly, supplementation with $\mathrm{Na}^{+}$evoked a rapid realkalinisation of the SVs (fig. 3.29a), strongly indicating an exchange of luminal $\mathrm{H}^{+}$with $\mathrm{Na}^{+}$by enhancing luminal $\mathrm{pH}$. Addition of $\mathrm{K}^{+}$also evoked realkalinisation (fig. 3.29b), albeit weaker than $\mathrm{Na}^{+}$, whereas addition of the membrane impermeable Choline ${ }^{+}$did not exhibit any effect on $\Delta \mathrm{pH}$ (fig. 3.29c). The extent of $\mathrm{Na}^{+}$or $\mathrm{K}^{+}$mediated realkalinisation was dose dependent (data not shown). Clearly, the $\mathrm{Na}^{+} / \mathrm{K}^{+}$specific response in $\mathrm{SVs}$ supports the described $\mathrm{K}^{+}\left(\mathrm{Na}^{+}\right) / \mathrm{H}^{+}$exchange mechanism on $\mathrm{SVs}$ [76]. $\mathrm{Na}^{+}$was preferred over $\mathrm{K}^{+}$in the exchange with $\mathrm{H}^{+}$(fig. 3.29a-b). However, it should be noted that $\mathrm{K}^{+}$in the 
$\mathrm{H}^{+} /$monovalent cation exchange mechanism is physiologically more relevant because of very low cytosolic $\mathrm{Na}^{+}$concentrations [117].

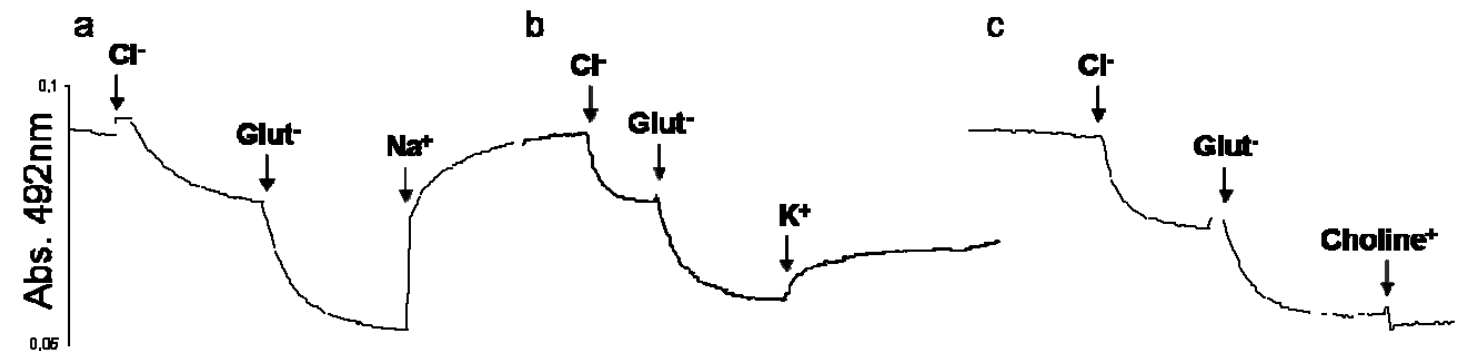

Figure 3.29 Monovalent cation effect in $\mathrm{K}^{+}$free buffer. (a-c) Acidification of SVs after addition of $4 \mathrm{mM}$ chloride $\left(\mathrm{Cl}^{-}\right)$and $10 \mathrm{mM}$ glutamate (Glut) and subsequent realkalinisation by $30 \mathrm{mM} \mathrm{Na}^{+}(\mathrm{a}), \mathrm{K}^{+}(\mathrm{b})$ and Choline ${ }^{+}(\mathrm{c})$. Gluconate as membrane impermeable anion was used.

$\mathrm{Cl}^{-}$promotes acidification of the $\mathrm{SV}$ lumen by serving as counter ion for $\mathrm{H}^{+}$. The extent of $\mathrm{Cl}^{-}$dependent acidification depending on the cation was studied. First, $\mathrm{KCl}-$ and CholineCl- evoked acidification in SVs in buffer containing $100 \mathrm{mM} \mathrm{K}^{+}$was monitored. It was observed that CholineCl- evoked acidification was more pronounced than KCl- evoked acidification (fig. 3.30a). Remarkably, in $\mathrm{K}^{+}$- free buffer the difference in $\mathrm{Cl}^{-}$- evoked changes on $\Delta \mathrm{pH}$ much more drastically depended on the cation used (fig. 3.30b). CholineCl mediated moderate acidification of the SVs whereas $\mathrm{KCl}$ directly realkalinised SV lumen without provoking any acidification. Taken together, these findings provide a compelling evidence for a concentration gradientdriven $\mathrm{K}^{+} / \mathrm{H}^{+}$exchange mechanism on SVs.

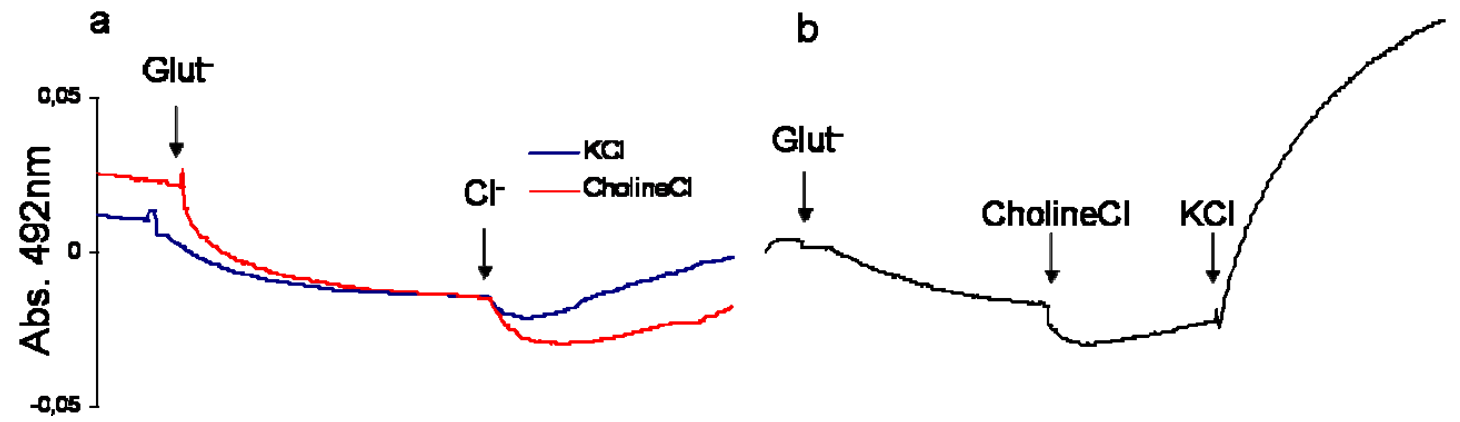

Figure $3.30 \mathrm{~K}^{+}$dependent SV realkalinisation. (a-b) Impact of $100 \mathrm{mM} \mathrm{KCl}$ and CholineCl respectively on acidification of SVs in $\mathrm{K}^{+}$-containing (a) and $\mathrm{K}^{+}$-free (b) buffer. 


\subsubsection{Changes of SV $\Delta \Psi$ Evoked by Monovalent Cations}

In the previous section a $\mathrm{K}^{+} / \mathrm{H}^{+}$exchange mechanism was found to affect the $\Delta \mathrm{pH}$ component of $\Delta \mu \mathrm{H}^{+}$. An exchange of luminal $\mathrm{H}^{+}$for external $\mathrm{K}^{+}$increases the luminal $\mathrm{pH}$ showed by $\mathrm{K}^{+}$-dependent realkalinisation (fig. 3.29 and 3.30). This enables $\mathrm{TF}_{0} \mathrm{~F}_{1}$ to transport more $\mathrm{H}^{+}$into the SVs which is expected to increase the overall $\Delta \Psi$. This effect was experimentally accessed by monitoring the response of $\Delta \Psi$ in SVs to $\mathrm{Na}^{+}, \mathrm{K}^{+}$and Choline ${ }^{+}$using the $\Delta \Psi$ sensitive dye OxonolVI (method described in 2.2.7). Preliminary measurements using SVs in monovalent ion-free buffer show an increase in $\Delta \Psi$ mediated by $\mathrm{Na}^{+}$and $\mathrm{K}^{+}$. By contrast, addition of membrane-impermeable Choline ${ }^{+}$ did not induce any changes in $\Delta \Psi$ (data not shown). These initial trials support a $\Delta \Psi$ enhancing effect by exchange of luminal $\mathrm{H}^{+}$with external $\mathrm{K}^{+}$.

\subsubsection{Dependence of Glutamate Uptake on $\mathrm{K}^{+}$}

The findings in the previous sections (3.5.1 and 3.5.2) showed a dramatic effect of $\mathrm{K}^{+}$and $\mathrm{Na}^{+}$on the $\Delta \mu \mathrm{H}^{+}$, in agreement with the work of Goh and colleagues [76]. VGLUTs are mainly driven by $\Delta \Psi$, thus, an increase of $\Delta \Psi$ by $\mathrm{H}^{+} / \mathrm{K}^{+}$exchange can promote glutamate uptake. Consequently, glutamate uptake in SVs was measured in presence and absence of $\mathrm{K}^{+}$. Clearly, an enhancing effect by $\mathrm{K}^{+}$ions on glutamate uptake was detected (fig. 3.31) showing that the increase in $\Delta \Psi$ by $\mathrm{H}^{+} / \mathrm{K}^{+}$exchange enhances steady state glutamate filling, consistent with the previously published study [76].

NHEs were suggested to mediate $\mathrm{H}^{+} / \mathrm{K}^{+}$exchange [76]. However, in contrast to previous reports it was not found that the NHE inhibitor EIPA (5-(N-ethyl-Nisopropyl)amiloride) [118], reduced glutamate uptake (fig. 3.31) as it would be expected for an NHE-mediated $\mathrm{K}^{+} / \mathrm{H}^{+}$exchange. Therefore, identification of the molecule mediating $\mathrm{K}^{+} / \mathrm{H}^{+}$exchange was pursued. A potential candidate was VGLUT1. Initially described as a $\mathrm{Na}^{+} / \mathrm{PO}_{4}{ }^{3-}$ transporter [47] [119], it is capable of transporting $\mathrm{Na}^{+}$. Furthermore, $\mathrm{H}^{+}$transport by VGLUT is also discussed [70] [77]. 


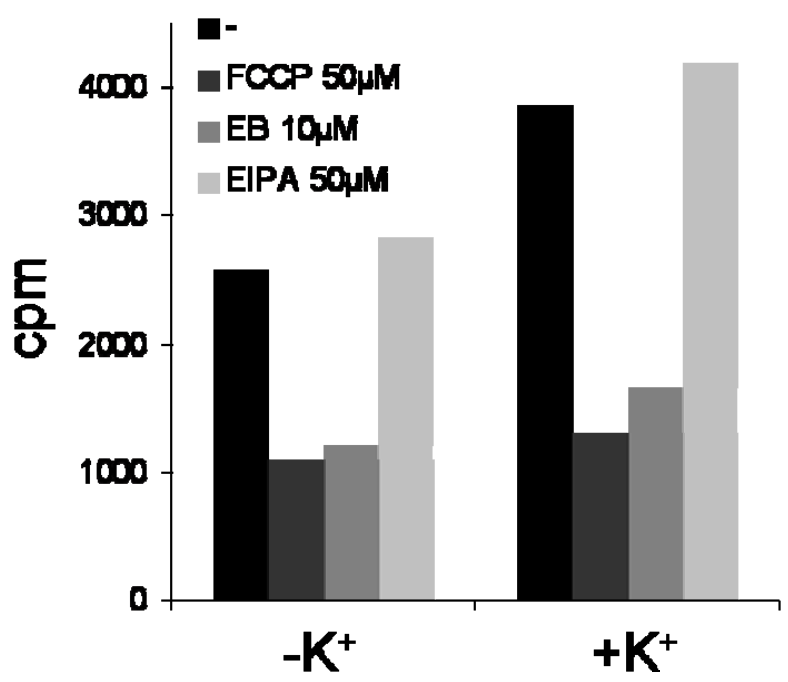

Figure $3.31 \mathrm{~K}^{+}$effect on glutamate translocation in SVs. SV standard glutamate uptake (20 min, steady state level) was measured in the presence and absence of $100 \mathrm{mM} \mathrm{K}^{+} . \Delta \mu \mathrm{H}^{+}$was dissipated by $40 \mu \mathrm{M}$ FCCP, VGLUT1 was inhibited by $10 \mu \mathrm{M}$ Evans Blue and $50 \mu \mathrm{M}$ EIPA was added to block putative NHEs. $20 \mu \mathrm{g}$ of total SV protein was assayed per data point.

\subsubsection{Enrichment of NHE6/9 in SVs}

In the previous section it was found that $\mathrm{K}^{+}$mediated enhancement in glutamate uptake was not reduced by the NHE inhibitor EIPA (fig. 3.31) indicating that $\mathrm{H}^{+} / \mathrm{K}^{+}$ exchange on SVs is not driven by NHEs. However, as NHEs 6 and 9 were suggested to mediate $\mathrm{H}^{+} / \mathrm{K}^{+}$exchange [76], their localisation and enrichment on SVs was analysed. NHE6 has been identified in glutamatergic and gabaergic SVs by mass spectrometry [120] and NHE9 which was reported to be involved in brain related disorders [121] [122].

Commercially available antibodies for NHE6 and 9 were used to detect putative localisation in SVs (fig. 3.32). Enrichment was not observed. However, using the NHE9 antibody a band at $\sim 130 \mathrm{kDa}$ could be detected in SVs, not corresponding to the predicted NHE9 size of about $70 \mathrm{kDa}$. A faint band with the correct size of $\sim 70 \mathrm{kDa}$ could be detected with the NHE6 antibody. An evaluation on the quality of the antibodies is difficult due to a lack of positive control. 


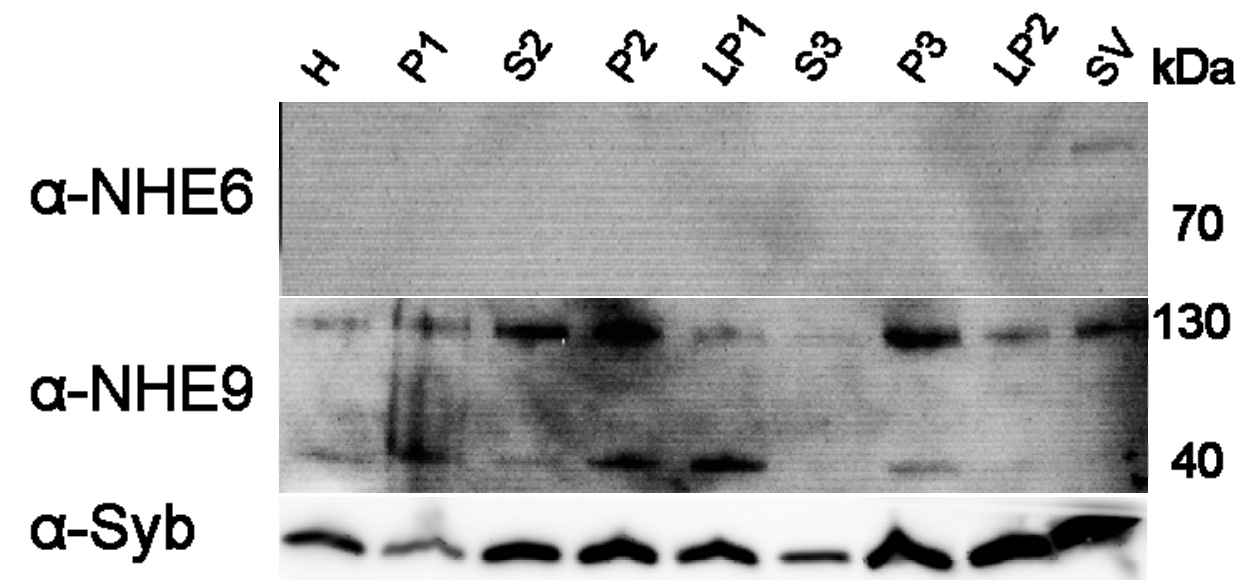

Figure 3.32 Enrichment of NHE6 and 9 in SVs. Immunoblot analysis of NHE6 and 9 localisation in SV purification fractions. $40 \mu \mathrm{g}$ total protein was loaded per fraction. Enrichment of Synaptobrevin in the same blot is depicted in the bottom part.

\subsubsection{Changes of $\Delta \mathrm{pH}$ in Dense Core Vesicles Mediated by Monovalent Cations}

Dense core vesicles (DCVs) isolated from bovine adrenal glands are aminergic and routinely isolated in our laboratory. Hitherto, the $\mathrm{K}^{+} / \mathrm{Na}^{+}$effect has only been studied in whole brain SVs but not in aminergic chromaffin granules without any VGLUTs. Hence, it was somewhat intruguing to look for a $\mathrm{K}^{+} / \mathrm{Na}^{+}$mediated alkalinisation in those organelles. $\mathrm{Cl}^{-}$dependent acidification was very pronounced but an alkalinisation after addition of $\mathrm{Na}^{+}$ions was indeed absent (fig. 3.33a). To prevent the powerful V-ATPase from masking the putative alkalinisation effect, $\Delta \mu \mathrm{H}^{+}$was dissipated by blocking the V-ATPase with BafilomycinA1. Subsequent addition of $\mathrm{Na}^{+}$ still did not induce any enhanced realkalinisation (fig. 3.33b) implicating that $\mathrm{K}^{+} / \mathrm{H}^{+}$ exchange may be a specific characteristic of glutamatergic/gabaergic vesicles or perhaps be mediated by VGLUT itself. 
a

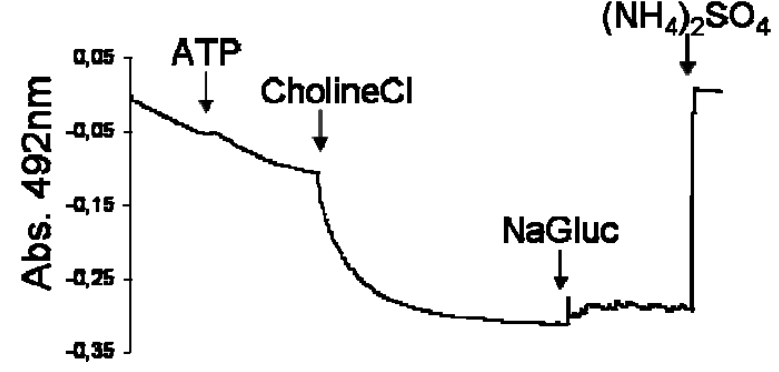

b

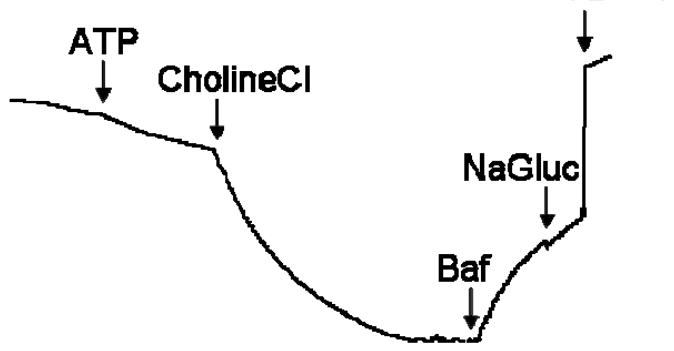

Figure 3.33 Monovalent cation effect in DCVs. (a) $\mathrm{Cl}^{-}$dependent acidification DCVs and $\mathrm{Na}^{+}$ effect. (b) V-ATPase was blocked after chloride-dependent acidification with BafilomycinA1 which induces realkalinisation. $\mathrm{Na}^{+}$was added subsequently.

\subsubsection{VGLUT1 Dependent Monovalent Cation Effect on $\Delta \mathrm{pH}$ in SVs}

To compile more evidence for VGLUT's $\mathrm{K}^{+} / \mathrm{H}^{+}$operating mode we inhibited VGLUT by Evans Blue and monitored $\mathrm{Cl}^{-}$dependent acidification and $\mathrm{Na}^{+}$-dependent alkalinisation as described in section 3.5.1. First, $\mathrm{Cl}^{-}$dependent acidification and $\mathrm{Na}^{+}$ induced realkalinisation in SVs in absence of Evans Blue was monitored (fig. 3.34a). Addition of Evans Blue did not inhibit $\mathrm{Cl}^{-}$dependent acidification but it dramatically inhibited the alkalinisation mediated by $\mathrm{Na}^{+}$(fig.3.34a-b). Blocking of V-ATPase by Bafilomycin induced realkalinisation of the vesicle lumen and was accelerated upon $\mathrm{Na}^{+}$addition. However, in the presence of Evans Blue the stimulating effect of $\mathrm{Na}^{+}$ vanished (fig.3.34c-d). Suppression of $\mathrm{Na}^{+}$-induced alkalinisation by Evans Blue strongly indicated that VGLUT1 is involved in $\mathrm{Na}^{+}\left(\mathrm{K}^{+}\right) / \mathrm{H}^{+}$exchange. 


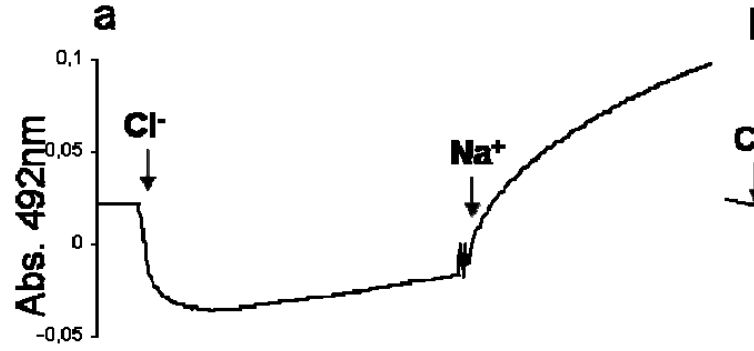

b
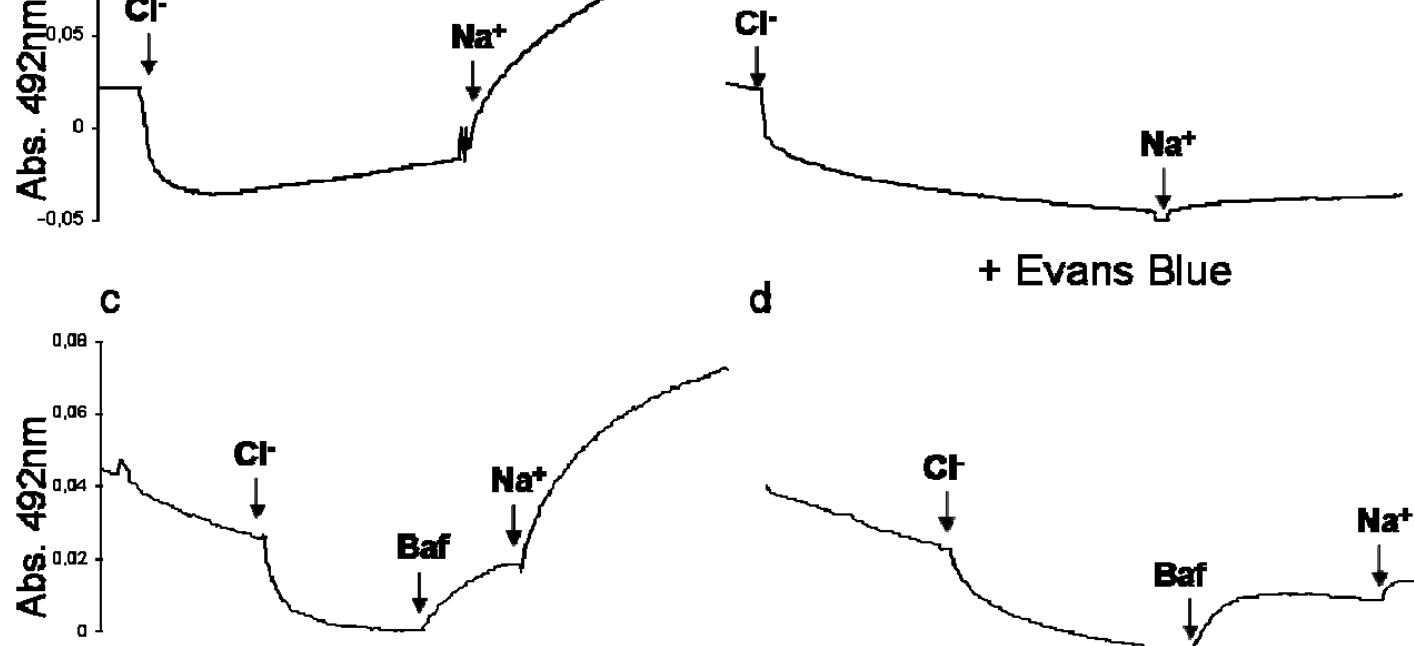

d

+ Evans Blue

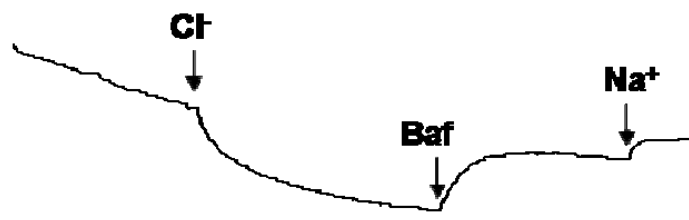

+ Evans Blue

Figure 3.34 VGLUT1 dependent effect on $\mathrm{Na}^{+} / \mathrm{K}^{+}$induced realkalinisation. (a-b) $\mathrm{Cl}^{-}$ dependent acidification and $\mathrm{Na}^{+}$dependent realkalinisation in the presence and absence of 10 $\mu \mathrm{M}$ Evans Blue. (c-d) Evans Blue-dependent $\mathrm{Na}^{+}$induced realkalinisation after V-ATPase inhibition with BafilomycinA1.

\subsubsection{VGLUT1 Dependent Monovalent Cation Effect on $\Delta \Psi$ in SVs}

Inhibition of VGLUT1 by Evans Blue suppressed $\mathrm{Na}^{+}$evoked $\mathrm{pH}$ increase in SVs indicating that VGLUT1 is mediating $\mathrm{H}^{+} / \mathrm{Na}^{+}$exchange. Consequently, the inhibition of VGLUT1 was expected to suppress $\mathrm{Na}^{+}$evoked increase in $\Delta \Psi$ which was observed in preliminary measurements in section 3.5.2. $\mathrm{Na}^{+}$mediated changes in $\Delta \Psi$ in presence and absence of Evans Blue were monitored using OxonolVI as $\Delta \Psi$ sensitive dye (method described in 2.2.7). Preliminary $\Delta \Psi$ measurements are depicted in figure 3.35. First, $\mathrm{Cl}^{-}$induces a drop in $\Delta \Psi$, consistent with the decrease in luminal $\mathrm{pH}$ (fig. 1.3 and 3.34). This drop was independent of Evans Blue indicating maintained SV function. Remarkably, $\mathrm{Na}^{+}$mediated increase in $\Delta \Psi$ was inhibited in the presence of Evans Blue. Altogether, the inhibiting effect of Evans Blue on $\mathrm{Na}^{+} / \mathrm{K}^{+}$induced changes in $\Delta \Psi$ substantially reinforce VGLUT1 as a key player involved in $\mathrm{K}^{+} / \mathrm{H}^{+}$exchange. 

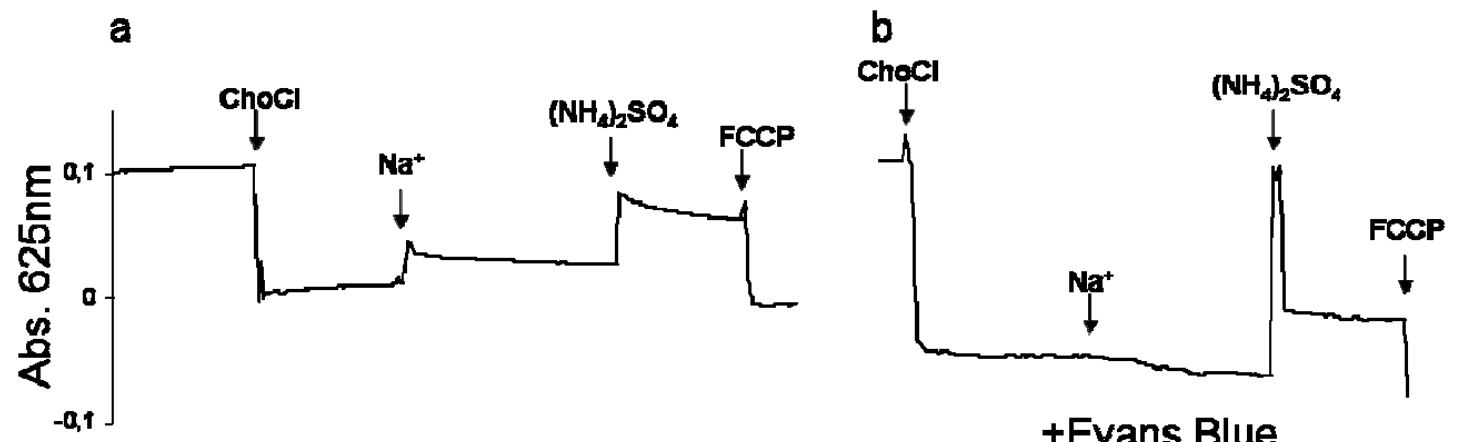

Figure 3.35 VGLUT1 dependent $\mathrm{Na}^{+}$effect on $\Delta \Psi$. (a-b) $\mathrm{Na}^{+}$induced changes in SVs in absence (a) and presence (b) of Evans Blue.

\subsection{Study of VGLUT Function using "Fused SVs"}

As already mentioned previously manipulation of the vesicular lumen is a challenging task which has not been satisfyingly resolved. "Fused SVs" as a novel and promising approach addressing this issue were used to study VGLUT1 function.

The approach is based on previously published work, in which liposomes reconstituted with syntaxin 1/SNAP-25, the plasma membrane components of the core fusion machinery, were shown to efficiently fuse with SVs [123]. Generation of such "fused SVs" provides a unique way to modify SV luminal composition by preloading the proteoliposomes with defined components. For this purpose, the proteoliposomes containing syntaxin 1 and SNAP-25 were additionally co-reconstituted with $\mathrm{TF}_{0} \mathrm{~F}_{1}$ as external energy source and fused with SVs. By selectively inhibiting the native SV VATPase with Bafilomycin Al only fused SVs which are energized by $\mathrm{TF}_{0} \mathrm{~F}_{1}$ with accordingly modified content are addressed in the measurements.
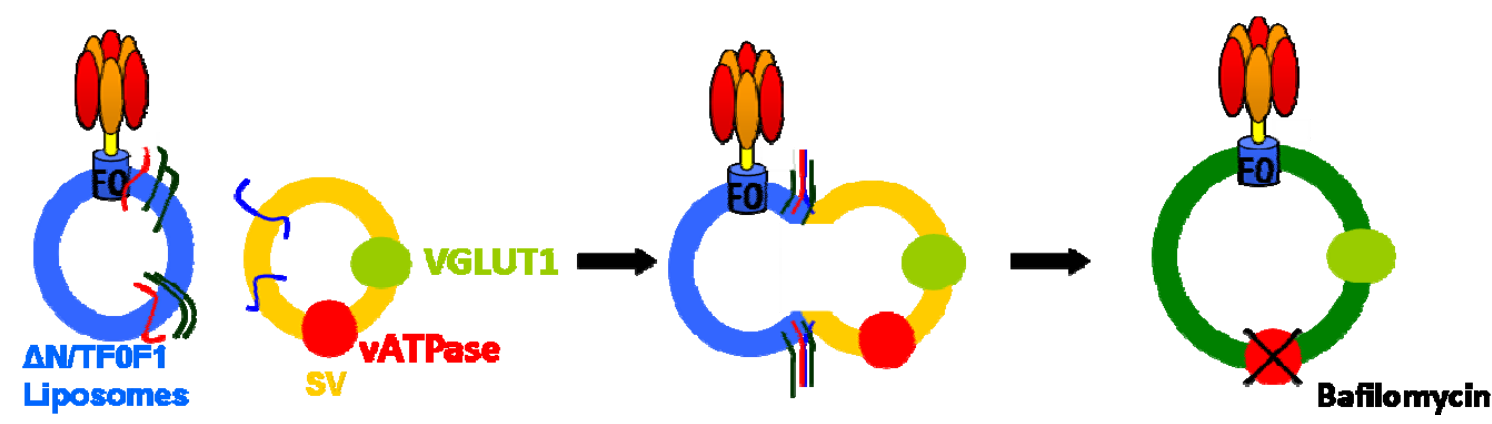
Figure 3.36 Schematic representation of fusion SV formation. Liposomes containing Syntaxin (red line) and SNAP25 (green lines) with a short stabilising Synaptobrevin fragment in addition to TFOF1 fuse with SVs containing Synaptobrevin (blue line) which is displacing the stabilising short fragment. V-ATPase of SVs is blocked by Bafilomycin excluding non-fused vesicles from measurements.

Another characteristic of fused SVs is the more physiological environment of VGLUT1. Unlike in the in vitro system containing only VGLUT1 and a bacterial pump, the function of VGLUT1 is studied in presence of all additional vesicular components. However, intrinsic VGLUT functions are difficult to study with this method. Preliminary characterisation of this approach will be described.

\subsubsection{Co-Reconstitution of the Fusion $\Delta \mathrm{N}$ Complex and $\mathrm{TF}_{0} \mathrm{~F}_{1}$ by the Direct Method}

Liposomes containing SNAP25 and Syntaxin 1 with a short stabilising Cterminal fragment of Synaptobrevin ( $\Delta \mathrm{N}$ complex) [97], and $\mathrm{TF}_{0} \mathrm{~F}_{1}$ were generated by the direct method. Preformed liposomes were doped with $\mathrm{OG}$ at $\mathrm{R}=1$ and detergent was subsequently removed by dialysis and additional supplementation with BioBeads. The insertion efficiency of the $\Delta \mathrm{N}$ complex was analysed by co-flotation with liposomes and accounted for $\sim 80 \%$ (fig. 3.37a). Remarkably, the $\Delta \mathrm{N} / \mathrm{TF}_{0} \mathrm{~F}_{1}$ proteoliposomes acidified in the presence of ATP and the $\mathrm{K}^{+}$ionophore valinomycin suggesting proper $\mathrm{TF}_{0} \mathrm{~F}_{1}$ insertion and maintenance of thighly coupled activity (fig. 3.37b).

a

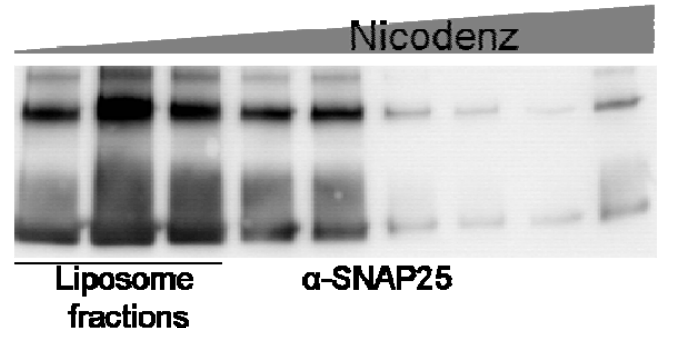

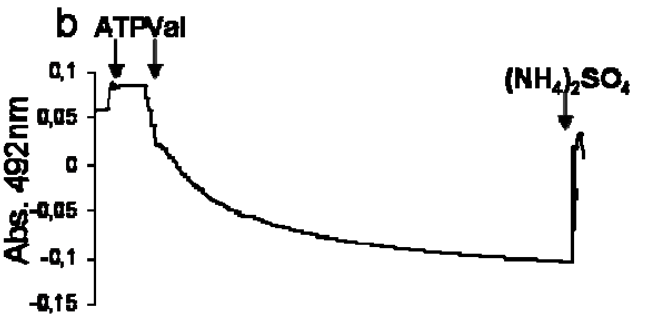

Figure 3.37 Characterisation of fusion SVs. (a) Incorporation analysis of the $\Delta \mathrm{N}$ complex into preformed liposomes by detection of SNAP25 by western blotting. (b) Insertion and activity analysis of $T F_{0} F_{1}$ in $\Delta N$ complex/TF $F_{0} F_{1}$ liposomes by acidification measurement in presence of the $\mathrm{pH}$ sensitive dye acridine orange. 
Furthermore, the liposomes containing $\Delta \mathrm{N}$ complex and $\mathrm{TF}_{0} \mathrm{~F}_{1}$ fused with $\mathrm{SVs}$ (fig. 3.38). However, the estimated fraction of non-fused SVs, represented in $3.38 \mathrm{~b}$ in the unboiled lane by monomeric synaptobrevin, is $\sim 50 \%$.
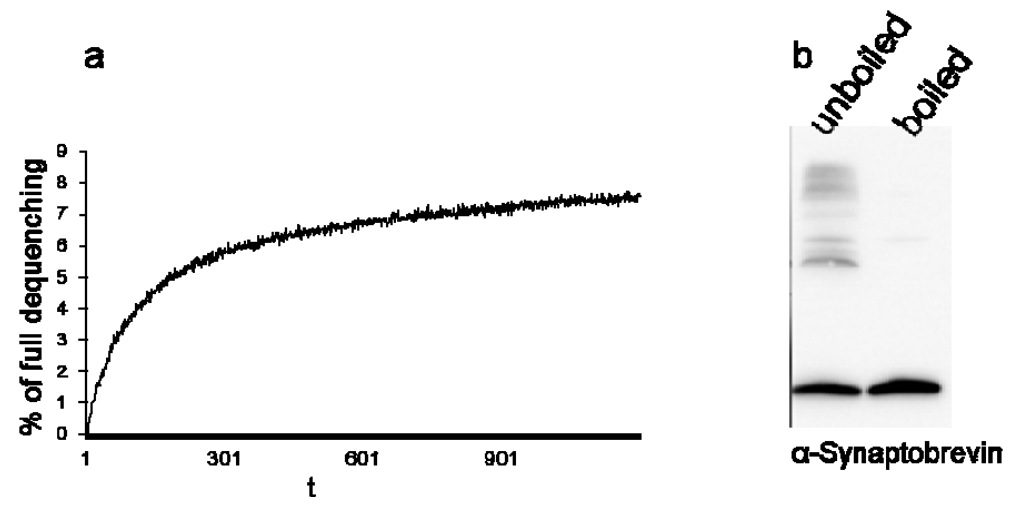

Figure 3.38 Analysis of $\Delta N / T F_{0} F_{1}$ liposome fusion with SVs. (a) Fusion of $S V s$ and $\Delta N$ complex $/ \mathrm{TF}_{0} \mathrm{~F}_{1}$ liposomes containing lipids labelled with a FRET dye pair (NBD/Rhodamine) was monitored by dequenching of the NBD signal induced by lipid mixing. (b) Detection of the SDS resistant core complex formation after 20 min incubation at room temperature $(\Delta N: S b \approx 4: 1$ $(\mathrm{mol} / \mathrm{mol}))$ as an indicator for SV and proteoliposome fusion. Monomeric Synaptobrevin in the non-boiled lane approximately represents the non-fused fraction of SVs compared to the overall Synaptobrevin (boiled lane).

\subsection{2 $\mathrm{Cl}^{-}$and Glutamate Dependend Acidification in Fused SVs}

The $\mathrm{Cl}^{-}$and glutamate dependent acidification in fused SVs was assessed. First, it was shown, that the V-ATPase inhibitor BafilomycinAl efficiently impaired $\mathrm{Cl}^{-}$and glutamate dependend acidification in SVs (3.39b). Consequently, glutamate and $\mathrm{Cl}^{-}$ dependent acidification in presence of BafilomycinA1 was monitored in fused SVs (fig. 3.39c). Indeed, fused SVs exhibited $\mathrm{Cl}^{-}$and glutamate dependend acidification driven by $\mathrm{TF}_{0} \mathrm{~F}_{1}$ alone. This clearly demonstrates, that the function of $\mathrm{TF}_{0} \mathrm{~F}_{1}$ and VGLUT is preserved in fused SVs. However, the acidification was not pronounced which might be due to relatively high amounts of unfused SVs as can be concluded from the high abundance of monomeric synaptobrevin in figure 3.37b. Moreover, SV proteins might affect $\mathrm{TF}_{0} \mathrm{~F}_{1}$ activity. Therefore, additional optimization of this approach has to be undertaken, including increasing the fraction of fused vesicles while simultaneously maintaining VGLUT1 and $\mathrm{TF}_{0} \mathrm{~F}_{1}$ activity. Nevertheless, for the first time $\mathrm{TF}_{0} \mathrm{~F}_{1}$ 
containing $\Delta \mathrm{N}$ liposomes were generated and successfully fused with SVs by maintaining VGLUT activity solely driven by the external $\mathrm{TF}_{0} \mathrm{~F}_{1}$.

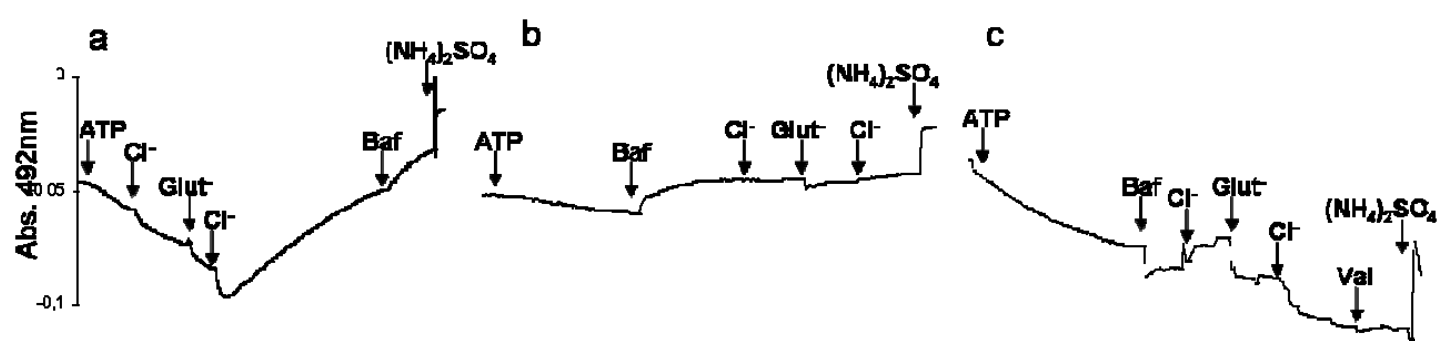

Figure 3.39 Acidification activity of fused SVs. (a) Acidification of SV lumen after addition of $4 \mathrm{mM} \mathrm{Cl}, 10 \mathrm{mM}$ glutamate and $30 \mathrm{mM} \mathrm{Cl}$. Vesicular realkalinisation is promoted by blocking V-ATPase with BafilomycinA1 $(0.5 \mu \mathrm{M})$. (b) Inhibition of V-ATPase with BafilomycinA1 blocks $\Delta \mu \mathrm{H}^{+}$-dependent acidification. (c) Acidification of fusion SVs in the presence of $4 \mathrm{mM} \mathrm{Cl}, 10 \mathrm{mM}$ glutamate, $30 \mathrm{mM} \mathrm{Cl}^{-}$and $10 \mathrm{nM}$ Valinomycin. 
Results 
Discussion

\section{Discussion}

The aim of this study was to clarify the stoichiometry of ionic coupling by which VGLUTs translocate glutamate. In particular, the role of $\mathrm{Cl}^{-}$and a putative $\mathrm{K}^{+} / \mathrm{H}^{+}$ exchange mechanism involved in the regulation of VGLUTs was investigated. These questions were addressed in a minimal system with recombinant mouse VGLUT1 and $\mathrm{TF}_{0} \mathrm{~F}_{1}$ in artificial membranes, in SVs and a "hybrid" system of artificial liposomes fused with SVs. For the remainder of this chapter, results on VGLUT1 mechanism obtained using these tools will be discussed.

\subsection{Properties of VGLUT1/TF $\mathrm{TF}_{1}$ Liposomes}

\subsubsection{Establishing an Electrogenic Proton Pump System}

The general framework to study VGLUT in a reconstituted system was to create a system that fulfills the energetic requirements of the secondary active transporter. Membrane potential $(\Delta \Psi)$ and $\mathrm{pH}$ gradients $(\Delta \mathrm{pH})$ which are necessary for transport can be generated by artificial ion gradients [112] [74], but are not long-lived and generate only one component of the electrochemical gradient $\left(\Delta \mu \mathrm{H}^{+}\right)$at a time. A system containing a proton pump generates $\Delta \mu \mathrm{H}^{+}$which is stable and contains both components. The proton pump has to be electrogenic, transporting protons only when charge balance is provided. A tight ionic coupling was not observed for E.coli $\mathrm{F}_{0} \mathrm{~F}_{1}$ (fig. 3.15) suggesting leakage through the liposomes. However, the His-tagged $\mathrm{TF}_{0} \mathrm{~F}_{1}$ exhibited ideal properties regarding activity and electrogeneity and was used as energy source in VGLUT1 liposomes (fig. 3.19).

\subsubsection{Expression and Purification of Differentially Tagged VGLUT1 and its Activity}

For the investigation of VGLUT1 function in a reconstituted system active and pure VGLUT1 in sufficient quantities had to be obtained, which was a challenging task. 


\section{Discussion}

Thus, a considerable fraction of this work was invested in expression and particularly purification optimisation of VGLUT1. Physiological expression levels are too low, making heterologous expression inevitable. Several strategies for recombinant VGLUT1 expression and purification were followed. Cell free (CF) expression of VGLUT1 did not result in sufficient yields (fig. 3.9), whereas heterologous expression in insect cells yielded high quantities of transporter (fig. 3.10). Protein enrichment using His-tagged VGLUT1 was not successful (fig. 3.12), in contrast to previous reports [62] [74]. Two factors might have prevented sufficient enrichment of His $_{6}$-tagged VGLUT1: 1) The expression levels of VGLUT1 were not high enough to prevent binding of contaminants and 2) the micromolar affinity of the $\mathrm{His}_{6}$-tag to $\mathrm{Ni}^{2+}$ was not sufficient to selectively bind VGLUT1. However, purification of VGLUT1 ultimately succeeded overcoming factor 2). VGLUT1 was tagged with the SBP-tag, which exhibits nanomolar affinity to streptavidin and therefore selectively binds the tagged protein. The tag enabled enrichment of VGLUT1 in the milligram range by a single affinity purification step (fig. 3.13).

Another major obstacle apart from purification was the activity of VGLUT1 derived from insect cells. When reconstituted with $\mathrm{TF}_{0} \mathrm{~F}_{1}$ in liposomes it clearly exhibited glutamate translocation activity (fig. 3.22). Additionally, the size exclusion elution profile showed a sharp and uniform VGLUT1 peak indicating properly folded monodisperse protein (fig. 3.13). However, $\mathrm{Cl}^{-}$-dependent acidification was not observed in liposomes (fig. 3.26) and luminal chloride did not enhance glutamate uptake (fig. 3.27), in contrast to previous findings [21]. In light of the negative results regarding $\mathrm{Cl}^{-}$transport, mammalian cell expression was pursued in order to exclude a lack of activity in VGLUT1 derived from insect cells. Surprisingly, in terms of glutamate uptake mammalian cell VGLUT1 exhibited a slightly lower activity than insect cell VGLUT1 (fig. 3.28) and did not display any $\mathrm{Cl}^{-}$dependent acidification (data not shown). Glutamate uptake of $10 \mu \mathrm{g}$ recombinant VGLUT1 from insect cells was comparable to the glutamate uptake from $20 \mu \mathrm{g}$ of SVs, corresponding to $\sim 3 \mu \mathrm{g}$ VGLUT1+2 [7]. Consequently, VGLUT1 activity derived from insect cells can be estimated to be $\sim 3$ fold lower than VGLUT activity from isolated SVs. However, $\mathrm{Cl}^{-}$ dependent acidification in VGLUT1/TF $\mathrm{F}_{1}$ liposomes was not observed even when the 
amount of liposomes was increased suggesting that the lack of $\mathrm{Cl}^{-}$conductance in VGLUT1 does not originate from low VGLUT1 activity.

\subsection{Role of $\Delta \mathrm{pH}$ and $\mathrm{Cl}^{-}$in the Regulation of VGLUT1}

\subsubsection{VGLUT1 Does Not Exhibit $\mathrm{Cl}^{-}$Conductance}

The role of $\mathrm{Cl}^{-}$and the biphasic dependence of glutamate uptake on $\mathrm{Cl}^{-}$has been the focus of research for many years. On the one hand, it was suggested that low millimolar $\mathrm{Cl}^{-}$concentrations stimulate uptake by allosterically activating VGLUT1 [71] [70] [74], and on the other, the stimulatory effect was assumed to originate from partial contribution of $\Delta \mathrm{pH}$ to glutamate uptake [72] [21]. Although several studies have shown that glutamate transport primarily depends on $\Delta \Psi$ [68] [124] [37] [38], the reduction of glutamate uptake by dissipating $\Delta \mathrm{pH}$ implies that it is, at least partially, also dependent on $\Delta \mathrm{pH}$, suggestive of glutamate/ $\mathrm{H}^{+}$antiport by VGLUT [70]. However, loading of SVs by glutamate $/ \mathrm{H}^{+}$antiport would generate osmotic imbalance and induce $\mathrm{SV}$ swelling. Furthermore, when the effect of $\Delta \mathrm{pH}$ is included in the bioenergetic calculations, the resulting driving force would concentrate glutamate $\sim 1000$ fold or more [125] [77]. The concentration of glutamate in the cytoplasm is $\sim 10 \mathrm{mM}$ [117] and the concentration in SVs is estimated to be $100 \mathrm{mM}$ [126] [49], resulting in only a 10 fold increase. Hence, the role of $\Delta \mathrm{pH}$ in glutamate uptake and in its biphasic dependence on $\mathrm{Cl}^{-}$remains unresolved.

Clearly, $\mathrm{Cl}^{-}$induces acidification of SVs supposedly by providing counter charge for $\mathrm{H}^{+}$ [68]. However, whether a $\mathrm{Cl}^{-}$channel such as $\mathrm{ClC} 3$ or VGLUT1 mediates $\mathrm{Cl}^{-}$ translocation is still under debate [70] [116] [21] [74]. A recent study showed a severe impairment in $\mathrm{Cl}^{-}$dependent acidification in SVs from VGLUT1 ko mice, indicating $\mathrm{Cl}^{-}$ transport by VGLUT1. Furthermore, $\mathrm{Cl}^{-}$transport by VGLUT1 in liposomes reconstituted with VGLUT1 and a bacterial proton pump was observed [21]. On the other hand, $\mathrm{Cl}^{-}$transport by VGLUT2 incorporated in liposomes was not observed [74]. And strikingly, synaptic-like microvesicles (SLMVs) from astrocytes did not exhibit $\mathrm{Cl}^{-}$ dependent acidification although expressing VGLUT2, which indicates that $\mathrm{Cl}^{-}$is not transported by VGLUT2 (unpublished data). Based on these conflicting reports on $\mathrm{Cl}^{-}$ 
conductance by VGLUTs, it was attempted to clarify whether VGLUT is involved in $\mathrm{Cl}^{-}$transport. The results obtained in this work with reconstituted VGLUT1 do not support $\mathrm{Cl}^{-}$conductance by VGLUT1, as $\mathrm{Cl}^{-}$dependent acidification in liposomes was not observed (fig. 3.26). Although activity of insect cell derived VGLUT1 was $\sim 3$ fold lower than VGLUT activity from SVs (4.1.2) the lack of $\mathrm{Cl}^{-}$dependent acidification in VGLUT1/TF $F_{0}$ liposomes appears not to emerge from low VGLUT1 activity levels as increase of VGLUT1 amount did not affect the measurements. The observations in this work rather indicate that $\mathrm{Cl}^{-}$transport in $\mathrm{SVs}$ is mediated by another molecule than VGLUT1.

\subsubsection{Role of Luminal $\mathrm{Cl}^{-}$in the Regulation of Glutamate Uptake}

High luminal $\mathrm{Cl}^{-}$was early proposed to enhance glutamate uptake by exchanging luminal $\mathrm{Cl}^{-}$for cytosolic glutamate [75] [70]. During endocytosis, SVs are filled with $\sim 130 \mathrm{mM} \mathrm{NaCl}$. Concentration gradient driven exchange of luminal $\mathrm{Cl}^{-}$for cytosolic glutamate would facilitate accumulation of glutamate preventing osmotic imbalance and SV swelling. Additionally, storage of the neurotransmitter as NaGlutamate would prevent luminal $\mathrm{pH}$ drop induced by storage as glutamic acid. Storage of glutamate as free acid would result in a luminal $\mathrm{pH}$ of $\sim 3$, which is two units lower than reported [127]. Unfortunately, the luminal content of SVs is difficult to manipulate and luminal ionic effects can only be addressed in a reconstituted system. Using such a reconstituted system containing VGLUT1 and a bacterial proton pump, a recent study indeed observed a stimulatory effect of high concentrations of luminal $\mathrm{Cl}^{-}$on glutamate uptake [21]. This finding supports a $\mathrm{Cl}^{-} /$glutamate exchange which is mediated by VGLUT1. By contrast, in this study an enhancing effect by high luminal $\mathrm{Cl}^{-}$on glutamate uptake was not observed (fig. 3.27). Essentially, this observation supports a lack of $\mathrm{Cl}^{-}$ conductance by VGLUT1 but does not necessarily exclude the promoting effect of $\mathrm{Cl}^{-}$ glutamate exchange, as $\mathrm{Cl}^{-}$conductance in SVs could be mediated by a $\mathrm{Cl}^{-}$channel. Particularly in this point the "hybrid" system of fused SVs (section 3.6) provides unique features, as it allows altering the SV lumen by simultaneously maintaining all native SV components. 


\subsection{Role of $\mathrm{K}^{+} / \mathrm{H}^{+}$Exchange in the Regulation of VGLUT1}

\subsubsection{Investigation of the $\mathrm{K}^{+} / \mathrm{H}^{+}$Exchange Mode on SVs}

The exchange of a luminal $\mathrm{H}^{+}$for a cytosolic monovalent cation can increase $\Delta \Psi$, therefore stimulate glutamate uptake [76]. Indeed, a $\mathrm{Na}^{+} / \mathrm{K}^{+}$-induced effect on glutamate uptake and $\Delta \mu \mathrm{H}^{+}$in $\mathrm{SVs}$ was observed, supporting the $\mathrm{K}^{+} / \mathrm{H}^{+}$exchange mechanism. More precisely, addition of external $\mathrm{K}^{+}$or $\mathrm{Na}^{+}$diminished $\Delta \mathrm{pH}$ (fig. 3.29) and preliminary measurements showed an increase in $\Delta \Psi$ in the presence of $\mathrm{Na}^{+}$(fig. 3.35a). Furthermore, glutamate uptake was increased in the presence of $\mathrm{K}^{+}$(fig. 3.31), which indicates a promoting effect on uptake by enhanced $\Delta \Psi$. However, EIPA, a blocker of $\mathrm{Na}^{+} / \mathrm{H}^{+}$exchangers (NHEs), did not inhibit the $\mathrm{K}^{+}$effect on glutamate uptake (fig. 3.31) and it did not suppress $\mathrm{Na}^{+} / \mathrm{K}^{+}$-induced realkalinisation of SVs (data not shown). These data suggest that NHEs might not be responsible for $\mathrm{K}^{+} / \mathrm{H}^{+}$exchange. Based on these findings, the identification of the exchanger and the analysis of whether $\mathrm{K}^{+} / \mathrm{H}^{+}$exchange is an intrinsic property of glutamatergic SVs were pursued. A putative candidate is VGLUT as it was reported to transport $\mathrm{Na}^{+}$and $\mathrm{Pi}$ [47] and was suggested to implement glutamate $/ \mathrm{H}^{+}$antiport [70]. Exchange of $\mathrm{K}^{+}$and $\mathrm{H}^{+}$by VGLUT would make this mechanism specific to glutamatergic SVs.

\subsubsection{Indications for VGLUT1 Mediating $\mathrm{K}^{+} / \mathrm{H}^{+}$Exchange}

In order to investigate VGLUT's role in $\mathrm{K}^{+} / \mathrm{H}^{+}$exchange, the $\mathrm{K}^{+}$effect in dense core vesicles (DCVs) was inspected. Interestingly, DCVs, which express VMAT1, did not exhibit any $\mathrm{K}^{+} / \mathrm{Na}^{+}$-dependent realkalinisation (fig. 3.33). This finding strongly suggests that $\mathrm{K}^{+} / \mathrm{H}^{+}$exchange is a specific characteristic of glutamatergic and/or gabaergic SVs. Bioenergetically this is plausible, as monoamine uptake is mainly driven by $\Delta \mathrm{pH}$, a $\Delta \Psi$ enhancing mechanism which could even diminish uptake. By immunoisolating glutamatergic and gabaergic SVs it would be possible to explore whether the $\mathrm{K}^{+} / \mathrm{Na}^{+}$effect is an exclusive property of glutamatergic SVs.

The most striking finding supporting VGLUT's role as a $\mathrm{K}^{+} / \mathrm{H}^{+}$exchanger was the inhibition of $\mathrm{K}^{+}$mediated effects on $\Delta \mu \mathrm{H}^{+}$by Evans Blue. $\mathrm{K}^{+}$induced 


\section{Discussion}

realkalinisation in the presence Evans Blue was suppressed (fig. 3.34) as well as $\mathrm{K}^{+}$induced increase of $\Delta \Psi$ (fig. 3.35). Although unspecific inhibition of SV functions by EB cannot be fully excluded, the maintenance of $\mathrm{Cl}^{-}$-dependent acidification and Bafilomycin A1-induced realkalinisation (fig. 3.34) suggest that SVs were still functionally intact. Certainly, further evidence confirming this VGLUT mechanism is needed.

The minimal reconstituted system established in this work is particularly suitable to address this question. Glutamate uptake stimulation in the presence of $\mathrm{K}^{+}$in VGLUT1/TF $\mathrm{F}_{1}$-reconstituted liposomes would support VGLUT1 as a $\mathrm{K}^{+} / \mathrm{H}^{+}$ exchanger. Furthermore, VGLUT transfection of PC12 cells, rat adrenal medulla cells which contain aminergic chromaffin granules, and monitoring $\mathrm{K}^{+}$-mediated effects on $\Delta \mu \mathrm{H}^{+}$in these granules will give insight to VGLUT mediated $\mathrm{K}^{+} / \mathrm{H}^{+}$exchange.

\subsection{Conclusion}

In this work, a reconstituted system containing recombinant mouse VGLUT1 derived from insect cells and a tightly coupled proton pump was established. Using reconstituted VGLUT1/TF $F_{1}$ liposomes it was found that VGLUT1 does not function as $\mathrm{Cl}^{-}$shunt in contrast to previous reports [21] indicating that another molecule is transporting $\mathrm{Cl}^{-}$in SVs. However, studies on $\mathrm{SVs}$ exhibited a $\mathrm{K}^{+} / \mathrm{H}^{+}$exchange mechanism which increases $\Delta \Psi$ and therefore stimulates glutamate uptake which is supporting a recently published study [76]. Strikingly, the present work provides novel preliminary evidence that VGLUT functions as $\mathrm{K}^{+} / \mathrm{H}^{+}$exchanger as inhibition of VGLUT1 suppressed $\mathrm{K}^{+}$evoked $\mathrm{pH}$ increase in SVs. Furthermore, by fusing SVs with proteoliposomes containing the fusion core machinery and $\mathrm{TF}_{0} \mathrm{~F}_{1}$ a unique system was established, that allows luminal manipulation of SVs. It was shown that $\mathrm{SVs}$ and $\mathrm{TF}_{0} \mathrm{~F}_{1}$ maintain their activity after fusion. By inhibiting the V-ATPase only fused SVs with changed luminal contents are addressed in measurements. Fused SVs are particularly suitable for analysis of the putative stimulating effect of high luminal $\mathrm{Cl}^{-}$on glutamate uptake. In figure 4.40 changes in VGLUT1 transport modes derived from the present study are depicted. 
Discussion

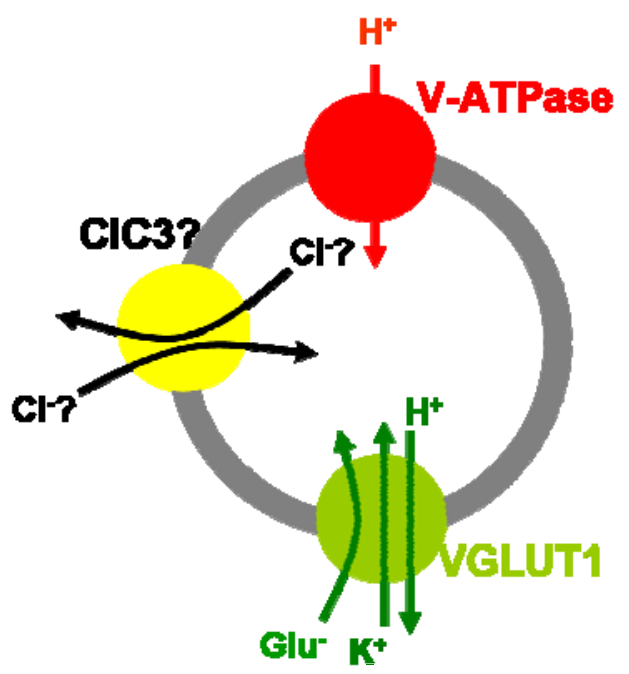

Figure 4.40 Proposed ionic coupling of glutamate transport. VGLUT1 is translocating glutamate and exchanging luminal $\mathrm{H}^{+}$for external $\mathrm{K}^{+}$. Luminal $\mathrm{Cl}^{-}$is supposedly shunted by a $\mathrm{Cl}^{-}$ channel. 
Discussion 


\section{References}

1. Katz, B., Quantal mechanism of neural transmitter release. Science, 1971. 173(3992): p. 123-6.

2. $\quad$ Sudhof, T.C., The synaptic vesicle cycle. Annu Rev Neurosci, 2004. 27: p. 50947.

3. Rosenmund, C. and C.F. Stevens, Definition of the readily releasable pool of vesicles at hippocampal synapses. Neuron, 1996. 16(6): p. 1197-207.

4. Sudhof, T.C. and J.E. Rothman, Membrane fusion: grappling with SNARE and SM proteins. Science, 2009. 323(5913): p. 474-7.

5. Nagy, A., et al., The preparation and characterization of synaptic vesicles of high purity. Brain Res, 1976. 109(2): p. 285-309.

6. Huttner, W.B., et al., Synapsin I (protein I), a nerve terminal-specific phosphoprotein. III. Its association with synaptic vesicles studied in a highly purified synaptic vesicle preparation. J Cell Biol, 1983. 96(5): p. 1374-88.

7. Takamori, S., et al., Molecular anatomy of a trafficking organelle. Cell, 2006. 127(4): p. 831-46.

8. Ishikawa, T., Y. Sahara, and T. Takahashi, A single packet of transmitter does not saturate postsynaptic glutamate receptors. Neuron, 2002. 34(4): p. 613-21.

9. Sargent, P.B., et al., Rapid vesicular release, quantal variability, and spillover contribute to the precision and reliability of transmission at a glomerular synapse. J Neurosci, 2005. 25(36): p. 8173-87.

10. Conti, R. and J. Lisman, The high variance of AMPA receptor- and NMDA receptor-mediated responses at single hippocampal synapses: evidence for multiquantal release. Proc Natl Acad Sci U S A, 2003. 100(8): p. 4885-90.

11. Edwards, R.H., The neurotransmitter cycle and quantal size. Neuron, 2007. 55(6): p. 835-58.

12. Wilson, N.R., et al., Presynaptic regulation of quantal size by the vesicular glutamate transporter VGLUT1. J Neurosci, 2005. 25(26): p. 6221-34.

13. Wojcik, S.M., et al., An essential role for vesicular glutamate transporter 1 (VGLUT1) in postnatal development and control of quantal size. Proc Natl Acad Sci U S A, 2004. 101(18): p. 7158-63.

14. Prado, V.F., et al., Mice deficient for the vesicular acetylcholine transporter are myasthenic and have deficits in object and social recognition. Neuron, 2006. 51(5): p. 601-12.

15. Daniels, R.W., et al., A single vesicular glutamate transporter is sufficient to fill a synaptic vesicle. Neuron, 2006. 49(1): p. 11-6.

16. Chaudhry, F.A., et al., Pharmacology of neurotransmitter transport into secretory vesicles. Handb Exp Pharmacol, 2008(184): p. 77-106.

17. Jentsch, T.J., Chloride and the endosomal-lysosomal pathway: emerging roles of CLC chloride transporters. J Physiol, 2007. 578(Pt 3): p. 633-40. 
18. Scheel, O., et al., Voltage-dependent electrogenic chloride/proton exchange by endosomal CLC proteins. Nature, 2005. 436(7049): p. 424-7.

19. Graves, A.R., et al., The $\mathrm{Cl}-\mathrm{H}+\mathrm{H}$ antiporter $\mathrm{ClC}-7$ is the primary chloride permeation pathway in lysosomes. Nature, 2008. 453(7196): p. 788-92.

20. Juge, N., et al., Vesicular inhibitory amino acid transporter is a Cl-/gammaaminobutyrate Co-transporter. J Biol Chem, 2009. 284(50): p. 35073-8.

21. Schenck, S., et al., A chloride conductance in VGLUT1 underlies maximal glutamate loading into synaptic vesicles. Nat Neurosci, 2009. 12(2): p. 156-62.

22. El Mestikawy, S., et al., From glutamate co-release to vesicular synergy: vesicular glutamate transporters. Nat Rev Neurosci, 2011. 12(4): p. 204-16.

23. Erickson, J.D., L.E. Eiden, and B.J. Hoffman, Expression cloning of a reserpinesensitive vesicular monoamine transporter. Proc Natl Acad Sci U S A, 1992. 89(22): p. 10993-7.

24. Erickson, J.D., et al., Distinct pharmacological properties and distribution in neurons and endocrine cells of two isoforms of the human vesicular monoamine transporter. Proc Natl Acad Sci U S A, 1996. 93(10): p. 5166-71.

25. Liu, Y., et al., A cDNA that suppresses $M P P+$ toxicity encodes a vesicular amine transporter. Cell, 1992. 70(4): p. 539-51.

26. Schutz, B., et al., Vesicular amine transporter expression and isoform selection in developing brain, peripheral nervous system and gut. Brain Res Dev Brain Res, 1998. 106(1-2): p. 181-204.

27. Peter, D., et al., The chromaffin granule and synaptic vesicle amine transporters differ in substrate recognition and sensitivity to inhibitors. J Biol Chem, 1994. 269(10): p. 7231-7.

28. Johnson, R.G., Jr., Accumulation of biological amines into chromaffin granules: a model for hormone and neurotransmitter transport. Physiol Rev, 1988. 68(1): p. 232-307.

29. Erickson, J.D., et al., Functional identification of a vesicular acetylcholine transporter and its expression from a "cholinergic" gene locus. J Biol Chem, 1994. 269(35): p. 21929-32.

30. Varoqui, H., et al., Cloning and expression of the vesamicol binding protein from the marine ray Torpedo. Homology with the putative vesicular acetylcholine transporter UNC-17 from Caenorhabditis elegans. FEBS Lett, 1994. 342(1): p. 97-102.

31. Varoqui, H. and J.D. Erickson, Active transport of acetylcholine by the human vesicular acetylcholine transporter. J Biol Chem, 1996. 271(44): p. 27229-32.

32. Nguyen, M.L., G.D. Cox, and S.M. Parsons, Kinetic parameters for the vesicular acetylcholine transporter: two protons are exchanged for one acetylcholine. Biochemistry, 1998. 37(38): p. 13400-10.

33. McIntire, S.L., et al., Identification and characterization of the vesicular GABA transporter. Nature, 1997. 389(6653): p. 870-6.

34. Sagne, C., et al., Cloning of a functional vesicular GABA and glycine transporter by screening of genome databases. FEBS Lett, 1997. 417(2): p. 17783.

35. Riazanski, V., et al., Presynaptic CLC-3 determines quantal size of inhibitory transmission in the hippocampus. Nat Neurosci, 2011. 14(4): p. 487-94. 
36. Ahnert-Hilger, G. and R. Jahn, CLC-3 spices up GABAergic synaptic vesicles. Nat Neurosci, 2011. 14(4): p. 405-7.

37. Takamori, S., et al., Identification of a vesicular glutamate transporter that defines a glutamatergic phenotype in neurons. Nature, 2000. 407(6801): p. 18994.

38. Bellocchio, E.E., et al., Uptake of glutamate into synaptic vesicles by an inorganic phosphate transporter. Science, 2000. 289(5481): p. 957-60.

39. Hayashi, M., et al., Differentiation-associated Na+-dependent inorganic phosphate cotransporter (DNPI) is a vesicular glutamate transporter in endocrine glutamatergic systems. J Biol Chem, 2001. 276(46): p. 43400-6.

40. Fremeau, R.T., Jr., et al., The expression of vesicular glutamate transporters defines two classes of excitatory synapse. Neuron, 2001. 31(2): p. 247-60.

41. Takamori, S., et al., Identification of differentiation-associated brain-specific phosphate transporter as a second vesicular glutamate transporter (VGLUT2). J Neurosci, 2001. 21(22): p. RC182.

42. Bai, L., et al., Molecular and functional analysis of a novel neuronal vesicular glutamate transporter. J Biol Chem, 2001. 276(39): p. 36764-9.

43. Takamori, S., et al., Molecular cloning and functional characterization of human vesicular glutamate transporter 3. EMBO Rep, 2002. 3(8): p. 798-803.

44. Schafer, M.K., et al., Molecular cloning and functional identification of mouse vesicular glutamate transporter 3 and its expression in subsets of novel excitatory neurons. J Biol Chem, 2002. 277(52): p. 50734-48.

45. Gras, C., et al., A third vesicular glutamate transporter expressed by cholinergic and serotoninergic neurons. J Neurosci, 2002. 22(13): p. 5442-51.

46. Fremeau, R.T., Jr., et al., The identification of vesicular glutamate transporter 3 suggests novel modes of signaling by glutamate. Proc Natl Acad Sci U S A, 2002. 99(22): p. 14488-93.

47. $\mathrm{Ni}$, B., et al., Cloning and expression of a cDNA encoding a brain-specific $\mathrm{Na}(+)$-dependent inorganic phosphate cotransporter. Proc Natl Acad Sci U S A, 1994. 91(12): p. 5607-11.

48. Hisano, S., et al., Regional expression of a gene encoding a neuron-specific $\mathrm{Na}(+)$-dependent inorganic phosphate cotransporter (DNPI) in the rat forebrain. Brain Res Mol Brain Res, 2000. 83(1-2): p. 34-43.

49. Danbolt, N.C., Glutamate uptake. Prog Neurobiol, 2001. 65(1): p. 1-105.

50. Bezzi, P., et al., Astrocytes contain a vesicular compartment that is competent for regulated exocytosis of glutamate. Nat Neurosci, 2004. 7(6): p. 613-20.

51. Montana, V., et al., Vesicular glutamate transporter-dependent glutamate release from astrocytes. J Neurosci, 2004. 24(11): p. 2633-42.

52. Seal, R.P., et al., Sensorineural deafness and seizures in mice lacking vesicular glutamate transporter 3. Neuron, 2008. 57(2): p. 263-75.

53. Seal, R.P., et al., Injury-induced mechanical hypersensitivity requires C-low threshold mechanoreceptors. Nature, 2009. 462(7273): p. 651-5.

54. Hnasko, T.S. and R.H. Edwards, Neurotransmitter corelease: mechanism and physiological role. Annu Rev Physiol, 2012. 74: p. 225-43.

55. Tecuapetla, F., et al., Glutamatergic signaling by mesolimbic dopamine neurons in the nucleus accumbens. J Neurosci, 2010. 30(20): p. 7105-10. 
56. Hnasko, T.S., et al., Vesicular glutamate transport promotes dopamine storage and glutamate corelease in vivo. Neuron, 2010. 65(5): p. 643-56.

57. Weston, M.C., et al., Interplay between VGLUT isoforms and endophilin A1 regulates neurotransmitter release and short-term plasticity. Neuron, 2011. 69(6): p. 1147-59.

58. Gras, C., et al., The vesicular glutamate transporter VGLUT3 synergizes striatal acetylcholine tone. Nat Neurosci, 2008. 11(3): p. 292-300.

59. Fremeau, R.T., Jr., et al., Vesicular glutamate transporters 1 and 2 target to functionally distinct synaptic release sites. Science, 2004. 304(5678): p. 1815-9.

60. Moechars, D., et al., Vesicular glutamate transporter VGLUT2 expression levels control quantal size and neuropathic pain. J Neurosci, 2006. 26(46): p. 1205566.

61. Wallen-Mackenzie, A., et al., Vesicular glutamate transporter 2 is required for central respiratory rhythm generation but not for locomotor central pattern generation. J Neurosci, 2006. 26(47): p. 12294-307.

62. Juge, N., et al., Vesicular glutamate transporter contains two independent transport machineries. J Biol Chem, 2006. 281(51): p. 39499-506.

63. Almqvist, J., et al., Docking and homology modeling explain inhibition of the human vesicular glutamate transporters. Protein Sci, 2007. 16(9): p. 1819-29.

64. Liu, G., Presynaptic control of quantal size: kinetic mechanisms and implications for synaptic transmission and plasticity. Curr Opin Neurobiol, 2003. 13(3): p. 324-31.

65. De Gois, S., et al., Identification of endophilins 1 and 3 as selective binding partners for VGLUT1 and their co-localization in neocortical glutamatergic synapses: implications for vesicular glutamate transporter trafficking and excitatory vesicle formation. Cell Mol Neurobiol, 2006. 26(4-6): p. 679-93.

66. Voglmaier, S.M., et al., Distinct endocytic pathways control the rate and extent of synaptic vesicle protein recycling. Neuron, 2006. 51(1): p. 71-84.

67. Vinatier, J., et al., Interaction between the vesicular glutamate transporter type 1 and endophilin A1, a protein essential for endocytosis. J Neurochem, 2006. 97(4): p. 1111-25.

68. Maycox, P.R., et al., Glutamate uptake by brain synaptic vesicles. Energy dependence of transport and functional reconstitution in proteoliposomes. J Biol Chem, 1988. 263(30): p. 15423-8.

69. Naito, S. and T. Ueda, Characterization of glutamate uptake into synaptic vesicles. J Neurochem, 1985. 44(1): p. 99-109.

70. Wolosker, H., D.O. de Souza, and L. de Meis, Regulation of glutamate transport into synaptic vesicles by chloride and proton gradient. J Biol Chem, 1996. 271(20): p. 11726-31.

71. Hartinger, J. and R. Jahn, An anion binding site that regulates the glutamate transporter of synaptic vesicles. J Biol Chem, 1993. 268(31): p. 23122-7.

72. Tabb, J.S., et al., Glutamate transport into synaptic vesicles. Roles of membrane potential, pH gradient, and intravesicular pH. J Biol Chem, 1992. 267(22): p. 15412-8. 
73. Hell, J.W., P.R. Maycox, and R. Jahn, Energy dependence and functional reconstitution of the gamma-aminobutyric acid carrier from synaptic vesicles. $\mathrm{J}$ Biol Chem, 1990. 265(4): p. 2111-7.

74. Juge, N., et al., Metabolic control of vesicular glutamate transport and release. Neuron, 2010. 68(1): p. 99-112.

75. Maycox, P.R., J.W. Hell, and R. Jahn, Amino acid neurotransmission: spotlight on synaptic vesicles. Trends Neurosci, 1990. 13(3): p. 83-7.

76. Goh, G.Y., et al., Presynaptic regulation of quantal size: $\mathrm{K}+\mathrm{H}+$ exchange stimulates vesicular glutamate transport. Nat Neurosci, 2011. 14(10): p. 128592.

77. Omote, H., et al., Vesicular neurotransmitter transporter: bioenergetics and regulation of glutamate transport. Biochemistry, 2011. 50(25): p. 5558-65.

78. Whittaker, V.P., Biophysical and biochemical studies of isolated cholinergic vesicles from Torpedo marmorata. Fed Proc, 1982. 41(11): p. 2759-64.

79. Hell, J.W., et al., Uptake of GABA by rat brain synaptic vesicles isolated by a new procedure. EMBO J, 1988. 7(10): p. 3023-9.

80. Suzuki, T., et al., F(0) of ATP synthase is a rotary proton channel. Obligatory coupling of proton translocation with rotation of c-subunit ring. $\mathrm{J}$ Biol Chem, 2002. 277(15): p. 13281-5.

81. Li, Y., E. Wang, and Y. Wang, A modified procedure for fast purification of T7 RNA polymerase. Protein Expr Purif, 1999. 16(2): p. 355-8.

82. Schwarz, D., et al., Preparative scale expression of membrane proteins in Escherichia coli-based continuous exchange cell-free systems. Nat Protoc, 2007. 2(11): p. 2945-57.

83. Bieniossek, C., T.J. Richmond, and I. Berger, MultiBac: multigene baculovirusbased eukaryotic protein complex production. Curr Protoc Protein Sci, 2008. Chapter 5: p. Unit 520.

84. Keefe, A.D., et al., One-step purification of recombinant proteins using a nanomolar-affinity streptavidin-binding peptide, the SBP-Tag. Protein Expr Purif, 2001. 23(3): p. 440-6.

85. Chen, C. and H. Okayama, High-efficiency transformation of mammalian cells by plasmid DNA. Mol Cell Biol, 1987. 7(8): p. 2745-52.

86. Rigaud, J.L. and D. Levy, Reconstitution of membrane proteins into liposomes. Methods Enzymol, 2003. 372: p. 65-86.

87. Degrip, W.J., J. Vanoostrum, and P.H. Bovee-Geurts, Selective detergentextraction from mixed detergent/lipid/protein micelles, using cyclodextrin inclusion compounds: a novel generic approach for the preparation of proteoliposomes. Biochem J, 1998. 330 ( Pt 2): p. 667-74.

88. Rigaud, J.L., A. Bluzat, and S. Buschlen, Incorporation of bacteriorhodopsin into large unilamellar liposomes by reverse phase evaporation. Biochem Biophys Res Commun, 1983. 111(2): p. 373-82.

89. Palmgren, M.G., Acridine orange as a probe for measuring $\mathrm{pH}$ gradients across membranes: mechanism and limitations. Anal Biochem, 1991. 192(2): p. 31621. 
90. Russell, J.T., Delta $\mathrm{pH}, \mathrm{H}+$ diffusion potentials, and $\mathrm{Mg} 2+$ ATPase in neurosecretory vesicles isolated from bovine neurohypophyses. J Biol Chem, 1984. 259(15): p. 9496-507.

91. Shioi, J., S. Naito, and T. Ueda, Glutamate uptake into synaptic vesicles of bovine cerebral cortex and electrochemical potential difference of proton across the membrane. Biochem J, 1989. 258(2): p. 499-504.

92. Schagger, H., Tricine-SDS-PAGE. Nat Protoc, 2006. 1(1): p. 16-22.

93. Towbin, H., T. Staehelin, and J. Gordon, Electrophoretic transfer of proteins from polyacrylamide gels to nitrocellulose sheets: procedure and some applications. Proc Natl Acad Sci U S A, 1979. 76(9): p. 4350-4.

94. Stein, A., et al., Synaptotagmin activates membrane fusion through a Ca2+dependent trans interaction with phospholipids. Nat Struct Mol Biol, 2007. 14(10): p. 904-11.

95. Castorph, S., et al., Synaptic vesicles studied by dynamic light scattering. Eur Phys J E Soft Matter, 2011. 34(6): p. 1-11.

96. Schurr, J.M., Dynamic light scattering of biopolymers and biocolloids. CRC Crit Rev Biochem, 1977. 4(4): p. 371-431.

97. Pobbati, A.V., A. Stein, and D. Fasshauer, $N$ - to C-terminal SNARE complex assembly promotes rapid membrane fusion. Science, 2006. 313(5787): p. 673-6.

98. Gibson, G.A. and L.M. Loew, Phospholipid vesicle fusion monitored by fluorescence energy transfer. Biochem Biophys Res Commun, 1979. 88(1): p. 135-40.

99. Hoekstra, D. and N. Duzgunes, Lipid mixing assays to determine fusion in liposome systems. Methods Enzymol, 1993. 220: p. 15-32.

100. Grisshammer, R. and C.G. Tate, Overexpression of integral membrane proteins for structural studies. Q Rev Biophys, 1995. 28(3): p. 315-422.

101. Wagner, S., et al., Rationalizing membrane protein overexpression. Trends Biotechnol, 2006. 24(8): p. 364-71.

102. Midgett, C.R. and D.R. Madden, Breaking the bottleneck: eukaryotic membrane protein expression for high-resolution structural studies. J Struct Biol, 2007. 160(3): p. 265-74.

103. Klammt, C., et al., Cell-free production of $G$ protein-coupled receptors for functional and structural studies. J Struct Biol, 2007. 158(3): p. 482-93.

104. Klammt, C., et al., Functional analysis of cell-free-produced human endothelin $B$ receptor reveals transmembrane segment 1 as an essential area for ET-1 binding and homodimer formation. FEBS J, 2007. 274(13): p. 3257-69.

105. Schwarz, D., V. Dotsch, and F. Bernhard, Production of membrane proteins using cell-free expression systems. Proteomics, 2008. 8(19): p. 3933-46.

106. Reckel, S., et al., Strategies for the cell-free expression of membrane proteins. Methods Mol Biol, 2010. 607: p. 187-212.

107. Tate, C.G., E. Whiteley, and M.J. Betenbaugh, Molecular chaperones stimulate the functional expression of the cocaine-sensitive serotonin transporter. J Biol Chem, 1999. 274(25): p. 17551-8.

108. Higgins, M.K., M. Demir, and C.G. Tate, Calnexin co-expression and the use of weaker promoters increase the expression of correctly assembled Shaker 
potassium channel in insect cells. Biochim Biophys Acta, 2003. 1610(1): p. 12432.

109. Ailor, E. and M.J. Betenbaugh, Modifying secretion and post-translational processing in insect cells. Curr Opin Biotechnol, 1999. 10(2): p. 142-5.

110. Seddon, A.M., P. Curnow, and P.J. Booth, Membrane proteins, lipids and detergents: not just a soap opera. Biochim Biophys Acta, 2004. 1666(1-2): p. 105-17.

111. Sonoda, Y., et al., Tricks of the trade used to accelerate high-resolution structure determination of membrane proteins. FEBS Lett, 2010. 584(12): p. 2539-47.

112. Hell, J.W., et al., Functional reconstitution of the gamma-aminobutyric acid transporter from synaptic vesicles using artificial ion gradients. Biochemistry, 1991. 30(51): p. 11795-800.

113. Maycox, P.R., T. Deckwerth, and R. Jahn, Bacteriorhodopsin drives the glutamate transporter of synaptic vesicles after co-reconstitution. EMBO J, 1990. 9(5): p. 1465-9.

114. Fischer, S., et al., ATP synthesis catalyzed by the ATP synthase of Escherichia coli reconstituted into liposomes. Eur J Biochem, 1994. 225(1): p. 167-72.

115. Phillips, R., et al., Emerging roles for lipids in shaping membrane-protein function. Nature, 2009. 459(7245): p. 379-85.

116. Stobrawa, S.M., et al., Disruption of ClC-3, a chloride channel expressed on synaptic vesicles, leads to a loss of the hippocampus. Neuron, 2001. 29(1): p. 185-96.

117. Attwell, D., B. Barbour, and M. Szatkowski, Nonvesicular release of neurotransmitter. Neuron, 1993. 11(3): p. 401-7.

118. Orlowski, J. and S. Grinstein, Diversity of the mammalian sodium/proton exchanger SLC9 gene family. Pflugers Arch, 2004. 447(5): p. 549-65.

119. Ni, B., et al., Molecular cloning, expression, and chromosomal localization of a human brain-specific $\mathrm{Na}(+)$-dependent inorganic phosphate cotransporter. J Neurochem, 1996. 66(6): p. 2227-38.

120. Gronborg, M., et al., Quantitative comparison of glutamatergic and GABAergic synaptic vesicles unveils selectivity for few proteins including MAL2, a novel synaptic vesicle protein. J Neurosci, 2010. 30(1): p. 2-12.

121. Morrow, E.M., et al., Identifying autism loci and genes by tracing recent shared ancestry. Science, 2008. 321(5886): p. 218-23.

122. Franke, B., B.M. Neale, and S.V. Faraone, Genome-wide association studies in ADHD. Hum Genet, 2009. 126(1): p. 13-50.

123. Holt, M., et al., Synaptic vesicles are constitutively active fusion machines that function independently of Ca2+. Curr Biol, 2008. 18(10): p. 715-22.

124. Moriyama, Y. and A. Yamamoto, Vesicular L-glutamate transporter in microvesicles from bovine pineal glands. Driving force, mechanism of chloride anion activation, and substrate specificity. J Biol Chem, 1995. 270(38): p. 22314-20.

125. Reimer, R.J., et al., The essence of excitation. Curr Opin Cell Biol, 2001. 13(4): p. 417-21. 
References

126. Burger, P.M., et al., Synaptic vesicles immunoisolated from rat cerebral cortex contain high levels of glutamate. Neuron, 1989. 3(6): p. 715-20.

127. Miesenbock, G., D.A. De Angelis, and J.E. Rothman, Visualizing secretion and synaptic transmission with $\mathrm{pH}$-sensitive green fluorescent proteins. Nature, 1998. 394(6689): p. 192-5. 


\section{Summary}

In neuronal signal transmission, vesicular neurotransmitter transporters play a key role in quantal size modification. They are filling synaptic vesicles (SVs) with neurotransmitter, fuelled by an electrochemical gradient $\left(\Delta \mu \mathrm{H}^{+}\right)$across the membrane which is generated by the vacuolar ATPase (V-ATPase). Understanding the regulation of SV filling will resolve fundamental questions regarding synaptic function. In particular, questions addressing the vesicular glutamate transporter (VGLUT), which is filling SVs with the excitatory neurotransmitter L-glutamate, such as the mechanism and ionic coupling, remain unanswered. For instance, it is not fully understood which mechanism underlies the biphasic dependence of glutamate uptake on $\mathrm{Cl}^{-}$. Furthermore, there are inconsistent reports on a $\mathrm{Cl}^{-}$conductance by VGLUT1. Recently, a regulatory mode exchanging luminal $\mathrm{H}^{+}$for cytosolic $\mathrm{K}^{+}$which is affecting glutamate uptake by changing $\Delta \mu \mathrm{H}^{+}$has been proposed.

In this study, particularly the transport of $\mathrm{Cl}^{-}$by VGLUT1 and a putative $\mathrm{K}^{+} / \mathrm{H}^{+}$ exchange mechanism involved in the regulation of VGLUT1 were investigated in order to unravel the ionic coupling of glutamate transport. These questions were addressed in a minimal system with recombinant mouse VGLUT1 and a proton pump from bacillus thermophilus $\left(\mathrm{TF}_{0} \mathrm{~F}_{1}\right)$ in artificial membranes, which was established in this work. In reconstituted liposomes containing VGLUT1 and $\mathrm{TF}_{0} \mathrm{~F}_{1}$, VGLUT1 did not exhibit any $\mathrm{Cl}^{-}$conductance in contrast to previous reports. Additionally, high luminal $\mathrm{Cl}^{-}$ concentrations did not enhance glutamate uptake, conflicting with recent studies. This finding further supported a lack of $\mathrm{Cl}^{-}$conductance in VGLUT1. By studying SVs, a $\mathrm{K}^{+} / \mathrm{H}^{+}$exchange mechanism was observed supporting previous studies. Remarkably, preliminary observations in the present work suggest that VGLUT is mediating $\mathrm{K}^{+} / \mathrm{H}^{+}$ exchange in SVs. Furthermore, a "hybrid" system of SVs fused with proteoliposomes containing $\mathrm{TF}_{0} \mathrm{~F}_{1}$ and a fusion mediating machinery was established. The unique benefit of "fused SVs" is that SV contents can be efficiently manipulated, which hitherto has been a challenging task. Preliminary measurements indicate that $\mathrm{SVs}$ and $\mathrm{TF}_{0} \mathrm{~F}_{1}$ 
maintain their activity after fusion. Fused SVs provide a unique opportunity to study the putative stimulatory effect of high luminal $\mathrm{Cl}^{-}$on glutamate uptake. 


\section{Acknowledgements}

I want to thank Prof. Reinhard Jahn for the opportunity to work in his group. I am truly grateful for his mentoring, advice and support throughout these sometimes quite tough years.

I would like to thank my thesis committee, Prof. Claudia Steinem and Prof. Marina Bennati, for advice and feedback.

I also would like to thank the staff of the department of Neurobiology, particularly Dr. Gottfried Mieskes for constant support throughout my thesis and Ursel Ries.

Many thanks go to my collaborators, Prof. Gudrun Ahnert Hilger, Dr. Irene Brunk, Dr. Johnannes-Friedrich Zander, Karine Dos Santos, Prof. Peter Gräber, Dr. Frank Bernhard, Prof. Masasuke Yoshida, Dr. Dietmar Riedel for their experimental support and discussions.

I would like to say many thanks to my colleagues from the department for scientific support and discussions Matias Hernandez, Nathan Pavlos, Saheeb Ahmed, Stephan Schenck, Geert van den Boogart, Ricarda Busse, Janina Boyken, John Chua, Alexander Stein, Nickias Kienle and Andreea Scacioc.

Many thanks go to the animal facility, especially to Sascha.

I also want to thank my colleagues and friends from the lab, making the hours in the lab and the lunches so enjoyable and fun. Hale, Momchil, Esra, Dominika, Matias, Janina, Ricarda, Saskia, Caro, Partho, Andreea, Yongsoo, Seiichi and Geert.

I would like to say a special thank you to my cousin Sofina. Sofinchik, thanks for being there for me.

I am deeply grateful for my family, their endless love and support. Мама, папа, и лёха, я очень благдарна за вашу любовь, подкрепление и терпение. 
